\title{
Diagnosis and Management of Tickborne Rickettsial Diseases: Rocky Mountain Spotted Fever and Other Spotted Fever Group Rickettsioses, Ehrlichioses, and Anaplasmosis - United States
}

\section{A Practical Guide for Health Care and Public Health Professionals}
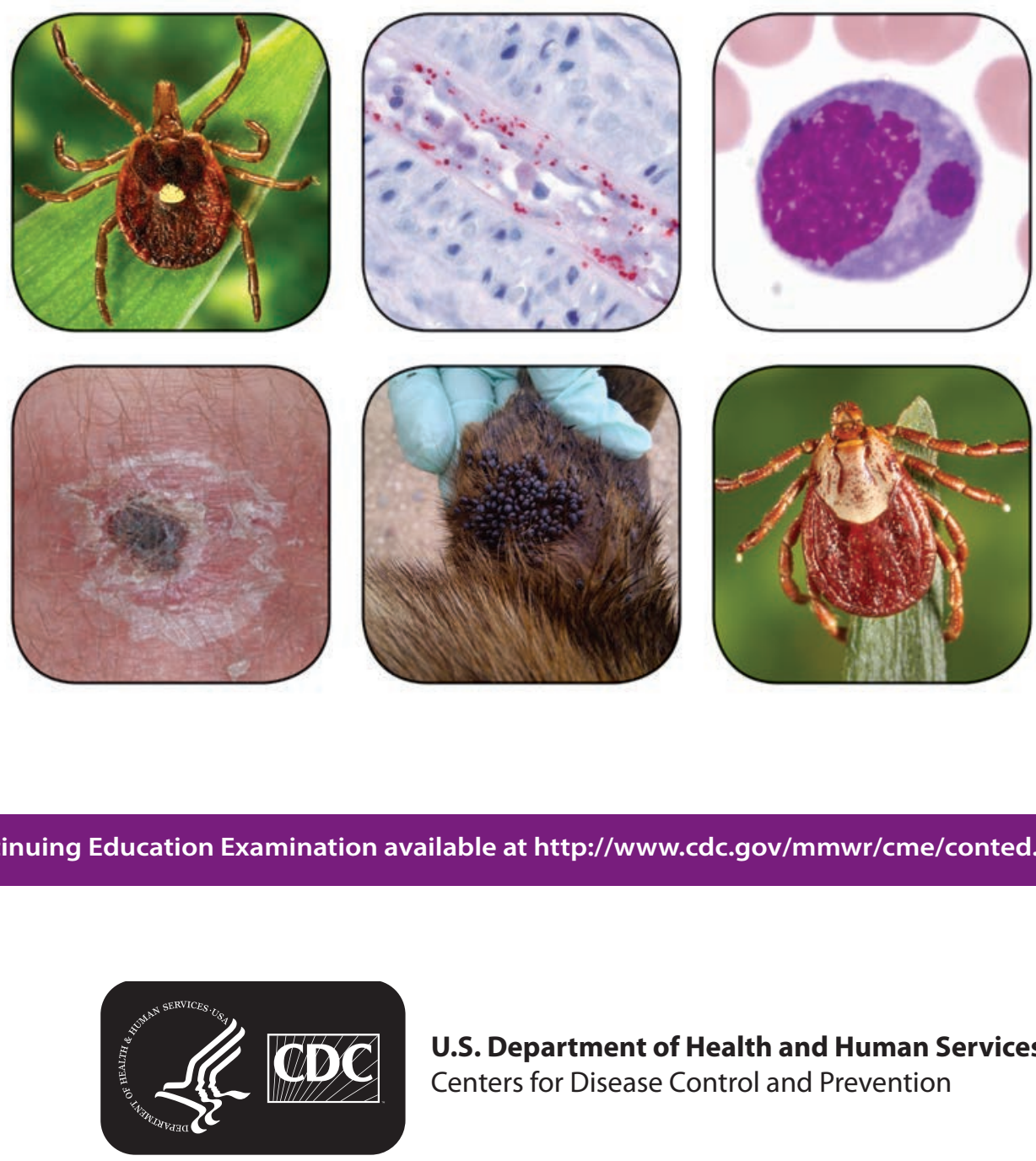


\section{CONTENTS}

Introduction ..... 1

Methods .. .2

Epidemiology ....3

Clinical Signs and Symptoms and Pathophysiology of Disease........ 13

Treatment and Management............................................................................... 21

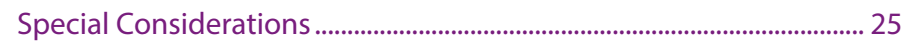

Confirmatory Diagnostic Tests..................................................................... 26

Prevention of Tickborne Rickettsial Diseases ............................................. 30

Surveillance and Reporting ..................................................................... 32

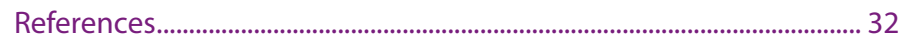

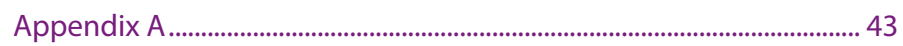

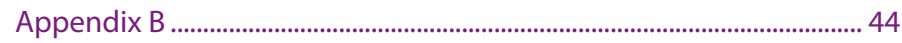

\section{Disclosure of Relationship}

CDC, our planners, and our presenters wish to disclose that they have no financial interests or other relationships with the manufacturers of commercial products, suppliers of commercial services, or commercial supporters with the following exceptions:

J. Stephen Dumler, MD, receives a royalty from the University of Maryland School of Medicine for license of patent on in vitro growth of Anaplasma phagocytophilum for diagnostic antigen production. Bobbi S. Pritt, MD, is employed by Mayo Clinic, which performs reference laboratory testing for physicians throughout the United States. Planning committee reviewed content to ensure there is no bias.

Content will not include any discussion of the unlabeled use of a product or a product under investigational use.

Front cover photos: Top row, left to right: adult female Amblyomma americanum (lone star tick), immunohistochemical stain demonstrating Rickettsia rickettsii (red) in blood vessel endothelial cells, Wright stain of peripheral blood smear showing an intramonocytic morula associated with Ehrlichia chaffeensis infection. Bottom row, left to right: eschar associated with Rickettsia parkeri rickettsiosis, dog infested with Rhipicephalus sanguineus ticks, adult female Dermacentor andersoni (Rocky Mountain wood tick).

The MMWR series of publications is published by the Center for Surveillance, Epidemiology, and Laboratory Services, Centers for Disease Control and Prevention (CDC), U.S. Department of Health and Human Services, Atlanta, GA 30329-4027.

Suggested citation: [Author names; first three, then et al., if more than six.] [Title]. MMWR Recomm Rep 2016;65(No. RR-\#):[inclusive page numbers].

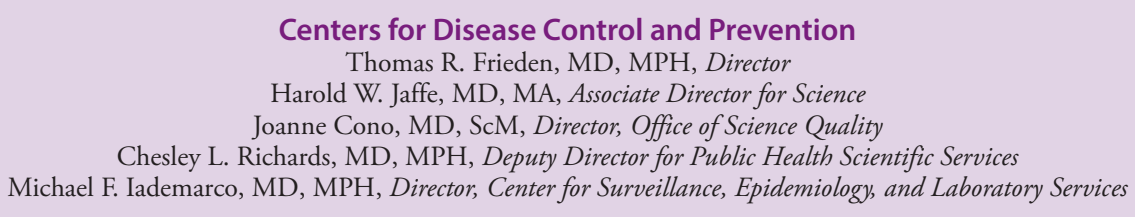

MMWR Editorial and Production Staff (Serials)

Sonja A. Rasmussen, MD, MS, Editor-in-Chief

Charlotte K. Kent, $\mathrm{PhD}, \mathrm{MPH}$, Executive Editor Christine G. Casey, MD, Editor

Teresa F. Rutledge, Managing Editor

David C. Johnson, Lead Technical Writer-Editor Kristina B. Clark, Project Editor
Martha F. Boyd, Lead Visual Information Specialist

Maureen A. Leahy, Julia C. Martinroe, Stephen R. Spriggs, Moua Yang, Tong Yang, Visual Information Specialists Quang M. Doan, MBA, Phyllis H. King, Terraye M. Starr, Information Technology Specialists

\section{MMWR Editorial Board}

Timothy F. Jones, MD, Chairman Matthew L. Boulton, MD, MPH Virginia A. Caine, MD

Katherine Lyon Daniel, PhD

Jonathan E. Fielding, MD, MPH, MBA David W. Fleming, MD
William E. Halperin, MD, DrPH, MPH

King K. Holmes, MD, PhD

Robin Ikeda, MD, MPH

Rima F. Khabbaz, MD

Phyllis Meadows, PhD, MSN, RN

Jewel Mullen, MD, MPH, MPA
Jeff Niederdeppe, PhD

Patricia Quinlisk, MD, MPH

Patrick L. Remington, MD, MPH Carlos Roig, MS, MA

William L. Roper, MD, MPH

William Schaffner, MD 


\title{
Diagnosis and Management of Tickborne Rickettsial Diseases: Rocky Mountain Spotted Fever and Other Spotted Fever Group Rickettsioses, Ehrlichioses, and Anaplasmosis - United States
}

\author{
A Practical Guide for Health Care and \\ Public Health Professionals
}

\author{
Holly M. Biggs, $\mathrm{MD}^{1}$; Casey Barton Behravesh, DVM, DrPH ${ }^{1}$; Kristy K. Bradley, DVM ${ }^{2}$; F. Scott Dahlgren, MSPH ${ }^{1}$; Naomi A. Drexler, MPH ${ }^{1}$; \\ J. Stephen Dumler, MD ${ }^{3}$; Scott M. Folk, MD ${ }^{4}$; Cecilia Y. Kato, $\mathrm{PhD}^{1}$; R. Ryan Lash, MA ${ }^{1}$; Michael L. Levin, PhD ${ }^{1}$; Robert F. Massung, PhD ${ }^{1}$; \\ Robert B. Nadelman, MD5; William L. Nicholson, $\mathrm{PhD}^{1}$; Christopher D. Paddock, MD ${ }^{1}$; Bobbi S. Pritt, MD ${ }^{6}$; Marc S. Traeger, MD \\ ${ }^{1}$ National Center for Emerging and Zoonotic Infectious Diseases, CDC, Atlanta, Georgia \\ ${ }^{2}$ Oklahoma State Department of Health, Oklahoma City, Oklahoma \\ 3 University of Maryland School of Medicine, Baltimore, Maryland \\ ${ }^{4}$ Mosaic Life Care, St. Joseph, Missouri \\ ${ }^{5}$ New York Medical College, Valhalla, New York \\ ${ }^{6}$ Mayo Clinic, Rochester, Minnesota \\ 7 Indian Health Service, Whiteriver, Arizona
}

\begin{abstract}
Summary
Tickborne rickettsial diseases continue to cause severe illness and death in otherwise healthy adults and children, despite the availability of low-cost, effective antibacterial therapy. Recognition early in the clinical course is critical because this is the period when antibacterial therapy is most effective. Early signs and symptoms of these illnesses are nonspecific or mimic other illnesses, which can make diagnosis challenging. Previously undescribed tickborne rickettsial diseases continue to be recognized, and since 2004, three additional agents have been described as causes of human disease in the United States: Rickettsia parkeri, Ehrlichia muris-like agent, and Rickettsia species 364D. This report updates the 2006 CDC recommendations on the diagnosis and management of tickborne rickettsial diseases in the United States and includes information on the practical aspects of epidemiology, clinical assessment, treatment, laboratory diagnosis, and prevention of tickborne rickettsial diseases. The CDC Rickettsial Zoonoses Branch, in consultation with external clinical and academic specialists and public health professionals, developed this report to assist health care providers and public health professionals to 1) recognize key epidemiologic features and clinical manifestations of tickborne rickettsial diseases, 2) recognize that doxycycline is the treatment of choice for suspected tickborne rickettsial diseases in adults and children, 3) understand that early empiric antibacterial therapy can prevent severe disease and death, 4) request the appropriate confirmatory diagnostic tests and understand their usefulness and limitations, and 5) report probable and confirmed cases of tickborne rickettsial diseases to public health authorities.
\end{abstract}

\section{Introduction}

Ticks (Acari: Ixodidae and Argasidae) transmit multiple and diverse pathogens (including bacteria, protozoa, and viruses), which cause a wide range of human and animal diseases, including rickettsial diseases, caused by bacteria in the order Rickettsiales. Vertebrate animals play an integral role in the life cycle of tick species, whereas humans are incidental hosts. Awareness, diagnosis, and control of tickborne rickettsial diseases are most effectively addressed by considering the intersecting components of human, animal, and environmental health that collectively form the foundation of One Health (1),

Corresponding author: Holly M. Biggs, National Center for Emerging and Zoonotic Infectious Diseases, CDC. Telephone: 404-639-1075; E-mail: Rzbepidiag@cdc.gov. an approach that integrates expertise from multiple disciplines and facilitates understanding of these complex zoonoses.

Tickborne rickettsial diseases in humans often share similar clinical features yet are epidemiologically and etiologically distinct. In the United States, these diseases include 1) Rocky Mountain spotted fever (RMSF) caused by Rickettsia rickettsii; 2) other spotted fever group (SFG) rickettsioses, caused by Rickettsia parkeri and Rickettsia species 364D; 3) Ehrlichia chaffeensis ehrlichiosis, also called human monocytic ehrlichiosis; 4) other ehrlichioses, caused by Ehrlichia ewingii and Ehrlichia murislike (EML) agent; and 5) anaplasmosis, caused by Anaplasma phagocytophilum (2), also called human granulocytic anaplasmosis. Rickettsial pathogens transmitted by arthropods other than ticks, including fleas (Rickettsia typhi), lice (Rickettsia prowazekii), and mites (Rickettsia akari) are not included in this report. Imported tickborne rickettsial infections that might be diagnosed in returning 
international travelers are summarized; however, tickborne and nontickborne rickettsial illnesses typically encountered outside the United States are not addressed in detail in this report.

The reported incidence of tickborne rickettsial diseases in the United States has increased during the past decade (3-5). Tickborne rickettsial diseases continue to cause severe illness and death in otherwise healthy adults and children, despite the availability of effective antibacterial therapy. Early signs and symptoms of tickborne rickettsial illnesses are nonspecific, and most cases of RMSF are misdiagnosed at the patient's first visit for medical care, even in areas where awareness of RMSF is high $(6,7)$. To increase the likelihood of an early, accurate diagnosis, health care providers should be familiar with risk factors, signs, and symptoms consistent with tickborne rickettsial diseases.

This report provides practical information to help health care providers and public health professionals to

- recognize the epidemiology and clinical manifestations of tickborne rickettsial diseases;

- obtain an appropriate clinical history for suspected tickborne rickettsial diseases;

- recognize potential severe manifestations of tickborne rickettsial diseases;

- make treatment decisions on the basis of epidemiologic and clinical evidence;

- recognize that early and empiric treatment with doxycycline can prevent severe morbidity or death;

- recognize doxycycline as the treatment of choice for adults and children of all ages with suspected rickettsial disease;

- make treatment decisions for patients with certain conditions, such as a doxycycline allergy or pregnancy;

- recognize when to consider coinfection with other tickborne pathogens;

- determine appropriate confirmatory diagnostic tests for tickborne rickettsial diseases;

- understand the availability, limitations, and usefulness of confirmatory diagnostic tests;

- recognize unusual transmission routes, such as transfusionor transplantation-associated transmission;

- recognize selected rickettsial diseases among returning travelers;

- advise patients regarding how to avoid tick bites; and

- report probable and confirmed cases to appropriate public health authorities to assist with surveillance, control measures, and public health education efforts.

Additional information concerning the tickborne rickettsial diseases described in this report is available from medical and veterinary specialists, various medical and veterinary societies, state and local health authorities, and CDC. The information and recommendations in this report are meant to serve as a source of general guidance for health care providers and public health professionals; however, individual clinical circumstances should always be considered. This report is not intended to be a substitute for professional medical advice for individual patients, and persons should seek advice from their health care providers if they have concerns about tickborne rickettsial diseases.

\section{Methods}

This report updates the 2006 CDC recommendations for the diagnosis and management of tickborne rickettsial diseases in the United States (8). Updated recommendations are needed to address the changing epidemiology of tickborne rickettsial diseases, provide current information about new and emerging tickborne rickettsial pathogens, and highlight advances in recommended diagnostic tests and updated treatment information.

The CDC Rickettsial Zoonoses Branch reviewed the 2006 report and determined which subject-matter areas required updates or revisions. Internal and external subject-matter experts in tickborne rickettsial diseases, representing a range of professional experiences and viewpoints, were identified by the CDC Rickettsial Zoonoses Branch to contribute to the revision. Contributors represented various areas of expertise within the field of tickborne rickettsioses and included practicing physicians specializing in internal medicine, family medicine, infectious diseases, and pathology; veterinarians with expertise in state, national, and international public health; epidemiologists; tick ecologists; microbiologists; and experts in rickettsial laboratory diagnostics. The peer-reviewed literature, published guidelines, and public health data were reviewed, with particular attention to new material available since preparation of the previous report. The scientific literature was searched through February 2016 using the MEDLINE database of the National Library of Medicine. The terms searched were Rickettsia, Rickettsia infections, R. rickettsii, RMSF, Ehrlichia, ehrlichiosis, E. chaffeensis, anaplasmosis, Anaplasma, and A. phagocytophilum. Text word searches were performed on multiple additional terms tailored to specific questions, which included epidemiology, treatment, diagnosis, and prevention. Titles of articles and abstracts extracted by the search were reviewed, and if considered potentially relevant, the full text of the article was retrieved. Reference lists of included articles were reviewed, and additional relevant citations were provided by contributors. In certain instances, textbook references were used to support statements considered general knowledge in the field. Articles selected were in English or had available translations. Peer-reviewed publications and published guidelines were used to support recommendations 
when possible. Abstracts without a corresponding full-length publication, dissertations, or other non-peer-reviewed literature were not used to support recommendations. When possible, data were obtained from studies that determined the presence of tickborne rickettsial infection using confirmatory diagnostic methods. Additional criteria were applied on a perquestion basis. For some questions, an insufficient number of studies was identified to support the development of a recommendation. In these instances, the report indicates that the evidence was insufficient for a recommendation, and when possible, general guidance is provided based on the available evidence and expert opinion of the CDC Rickettsial Zoonoses Branch. All contributors had the opportunity to review and provide input on multiple drafts of the report, including the final version. Future updates to this report will be dictated by new data in the field of tickborne rickettsial diseases.

\section{Epidemiology}

\section{Overview}

Tickborne rickettsial pathogens are maintained in natural cycles involving domestic or wild vertebrates and primarily hard-bodied ticks (Acari: Ixodidae). The epidemiology of each tickborne rickettsial disease reflects the geographic distribution and seasonal activities of the tick vectors and vertebrate hosts involved in the transmission of these pathogens, as well as the human behaviors that place persons at risk for tick exposure, tick attachment, and subsequent infection (Box 1). SFG rickettsiosis, ehrlichiosis, and anaplasmosis are nationally notifiable in the United States. Cases have been reported in each month of the year, although most cases are reported during April-September, coincident with peak levels of tick host-seeking activity (3-5,9-14). The distribution of tickborne rickettsial diseases varies geographically in the United States and approximates the primary tick vector distributions, making it important for health care providers to be familiar with the regions where tickborne rickettsial diseases are common. Travelers within the United States might be exposed to different tick vectors during travel, which can result in illness after they return home. Travelers outside of the United States might also be exposed to different tick vectors and rickettsial pathogens in other countries, which can result in illness after they return to the United States (see Travel Outside of the United States). Health care, public health, and veterinary professionals should be aware of changing vector distributions, emerging and newly identified human tickborne rickettsial pathogens, and increasing travel among persons and pets within and outside of the United States.

\section{Spotted Fever Group Rickettsiae}

SFG rickettsiae are related closely by various genetic and antigenic characteristics and include $R$. rickettsii (the cause of RMSF), R. parkeri, and Rickettsia species 364D, as well as many other Rickettsia species of unknown pathogenicity. RMSF is the rickettsiosis in the United States that is associated with the highest rates of severe and fatal outcomes. During 2008-2012, passive surveillance indicated that the estimated average annual incidence of SFG rickettsiosis was 8.9 cases per million persons in the United States (4). The passive surveillance category in the United States for SFG rickettsiosis might not differentiate between RMSF and other SFG rickettsioses because of the limitations of submitted diagnostic evidence. Reported annual incidence of SFG rickettsiosis has increased substantially during the past 2 decades. The highest incidence occurs in persons aged 60-69 years, and the highest case-fatality rate is among children aged $<10$ years, although illness occurs in all age groups (4). Incidence varies considerably by geographic area (Figure 1). During 2008-2012, 63\% of reported SFG rickettsiosis cases originated from five states: Arkansas, Missouri, North Carolina, Oklahoma, and Tennessee (4). However, SFG rickettsiosis cases have been reported from each of the contiguous 48 states and the District of Columbia $(4,9,12,14)$.

A notable regional increase in the reported incidence of SFG rickettsiosis occurred in Arizona during 2003-2013. Over this period, approximately 300 cases of RMSF and 20 deaths were reported from American Indian reservations in Arizona compared with three RMSF cases reported in the state during the previous decade (15). Since identification of the first case of locally transmitted RMSF in 2003 (16), RMSF has been found to be endemic in several American Indian communities in Arizona. On the three most affected reservations, the average annual incidence rate for 2009-2012 was approximately 1,360 cases per million persons (17). The $7 \%-10 \%$ case-fatality rate in these communities, which is the highest of any region in the United States, has been associated predominantly with delayed recognition and treatment $(4,18)$.

\section{Rickettsia rickettsii}

In the United States, the tick species that is most frequently associated with transmission of $R$. rickettsii is the American dog tick, Dermacentor variabilis (Figure 2). This tick is found primarily in the eastern, central, and Pacific coastal United States (Figure 3). The Rocky Mountain wood tick, Dermacentor andersoni (Figure 4), is associated with transmission in the western United States (Figure 5). More recently, the brown dog tick, Rhipicephalus sanguineus (Figure 6), which is located throughout the United States (Figure 7), has been 


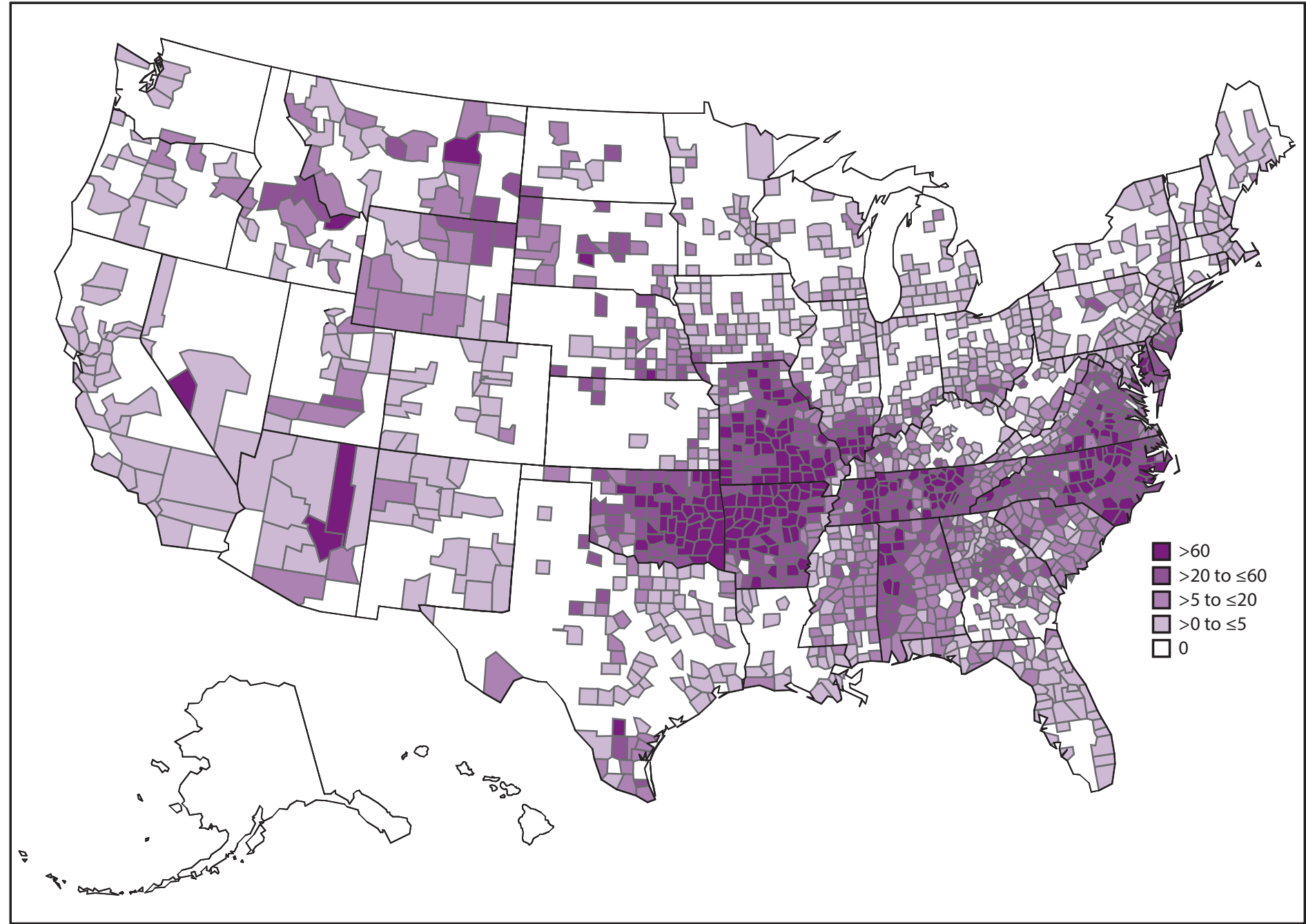

* As reported through national surveillance, per 1,000,000 persons per year. Cases are reported by county of residence, which is not always where the infection was acquired.

${ }^{\dagger}$ Includes Rocky Mountain spotted fever (RMSF) and other spotted fever group rickettsioses. In 2010, the name of the reporting category changed from RMSF to spotted fever rickettsiosis.

recognized as an important vector in parts of Arizona (16) and along the U.S.-Mexico border. Several tick species of the genus Amblyomma are vectors of $R$. rickettsii from Mexico to Argentina, including $A$. cajennense, $A$. aureolatum, $A$. imitator, and $A$. sculptum (19-22). Although the geographic ranges of $A$. imitator and $A$. mixtum (a species closely related to A. cajennense) extend into Texas, the role of Amblyomma ticks in transmission of $R$. rickettsii in the United States has not been established.

D. variabilis ticks often are encountered in wooded, shrubby, and grassy areas and tend to congregate along walkways and trails. These ticks also can be found in residential areas and city parks. Larval and nymphal stages of most Dermacentor spp. ticks in the United States usually do not bite humans. Although adult $D$. variabilis and $D$. andersoni ticks bite humans, the principal hosts tend to be deer, dogs, and livestock. Adult Dermacentor ticks are active from spring through autumn, with maximum activity during late spring through early summer.

The brown dog tick, $R h$. sanguineus, has been a recognized vector of $R$. rickettsii in Mexico since the 1940s (23); however, Rhipicephalus-transmitted $R$. rickettsii in the United States was not identified until 2003, when it was confirmed in a child on tribal lands in Arizona (16). Canids, especially domestic dogs, are the preferred hosts for the brown dog tick at all life stages. Humans are incidental hosts, bitten as a result of contact with tick-infested dogs or tick-infested environments. All active stages (larvae, nymphs, and adults) of $R h$. sanguineus will bite humans and can transmit $R$. rickettsii. Heavily parasitized dogs 
FIGURE 2. Adult female Dermacentor variabilis (American dog tick)

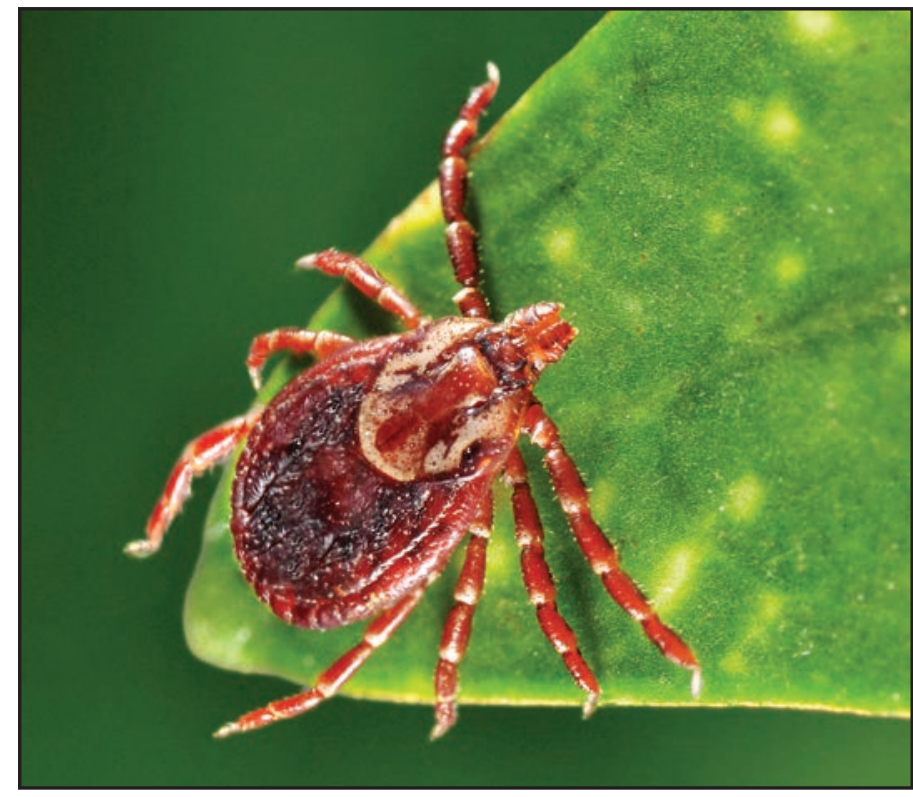

Photo/CDC

FIGURE 3. Approximate U.S. distribution of Dermacentor variabilis (American dog tick)

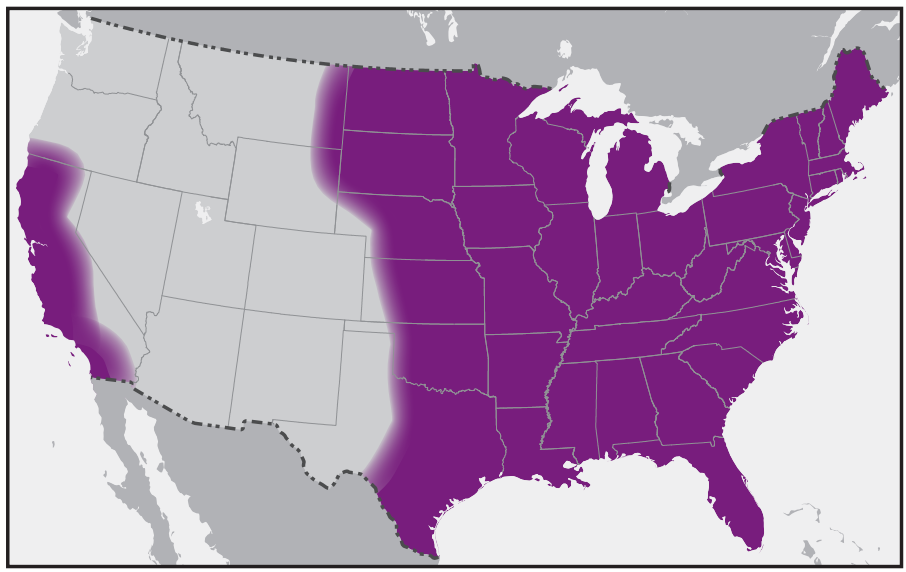

(Figure 8), as well as sizable infestations of brown dog ticks in and around homes, have been found in affected communities in Arizona $(16,17,24)$. Free-roaming dogs can spread infected ticks among households within a neighborhood, resulting in community-level clusters of infection. Children aged $<10$ years represent more than half of reported cases in this region and are theorized to have higher rates of exposure to $R h$. sanguineus ticks because of increased interaction with dogs and their habitats $(16,25)$. On Arizona tribal lands, the warm climate and proximity of ticks to domiciles provide a suitable environment for $R h$. sanguineus to remain active year-round (26). The majority of human cases of RMSF in Arizona occur during July-October after seasonal monsoon rains; however, cases have been reported every month of the year (25).
FIGURE 4. Adult female Dermacentor andersoni (Rocky Mountain wood tick)

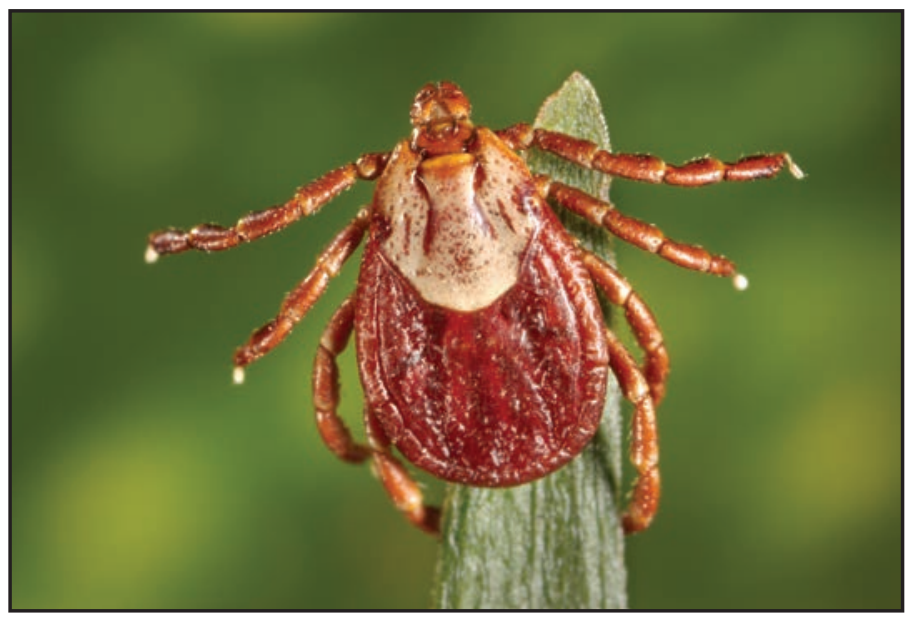

Photo/CDC

FIGURE 5. Approximate U.S. distribution of Dermacentor andersoni (Rocky Mountain wood tick)

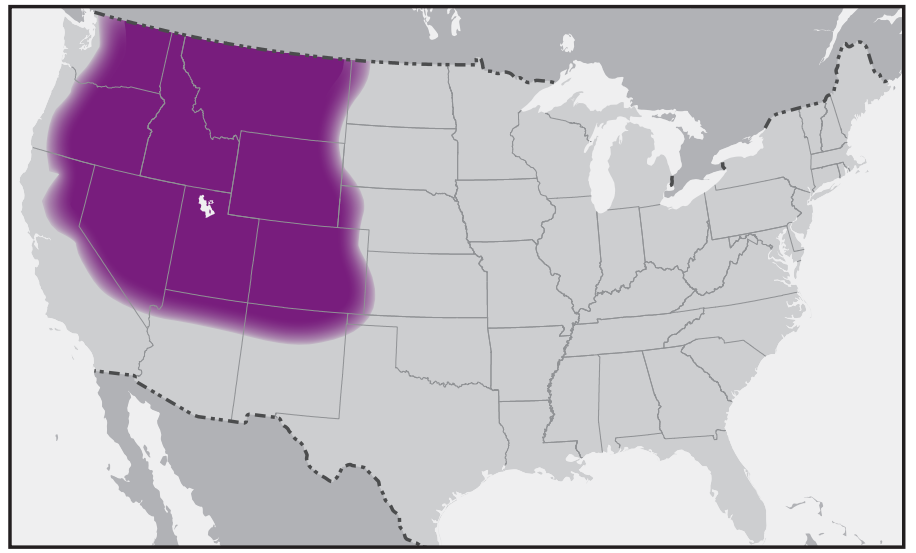

Similar epidemiologic characteristics and transmission dynamics have been reported in parts of Mexico (27-30). A high incidence of RMSF occurs in several northern Mexican states, including Baja California and Sonora, which border the United States. Persons infected with $R$. rickettsii in Mexico have sought health care across the U.S. border; health care providers should be aware of the risk for RMSF in persons traveling from areas where the disease incidence is high. $R h$. sanguineus is found worldwide but is reported to transmit $R$. rickettsii in the southwestern United States, Mexico, and possibly some RMSF-endemic areas of South America (16,29-32). This species might contribute to the enzootic cycle more commonly than has been recognized $(33,34)$.

\section{Rickettsia parkeri}

The first confirmed case of human $R$. parkeri infection was reported in 2004 (35). During 2004-2015, at least 40 patients 
FIGURE 6. Adult female Rhipicephalus sanguineus (brown dog tick)

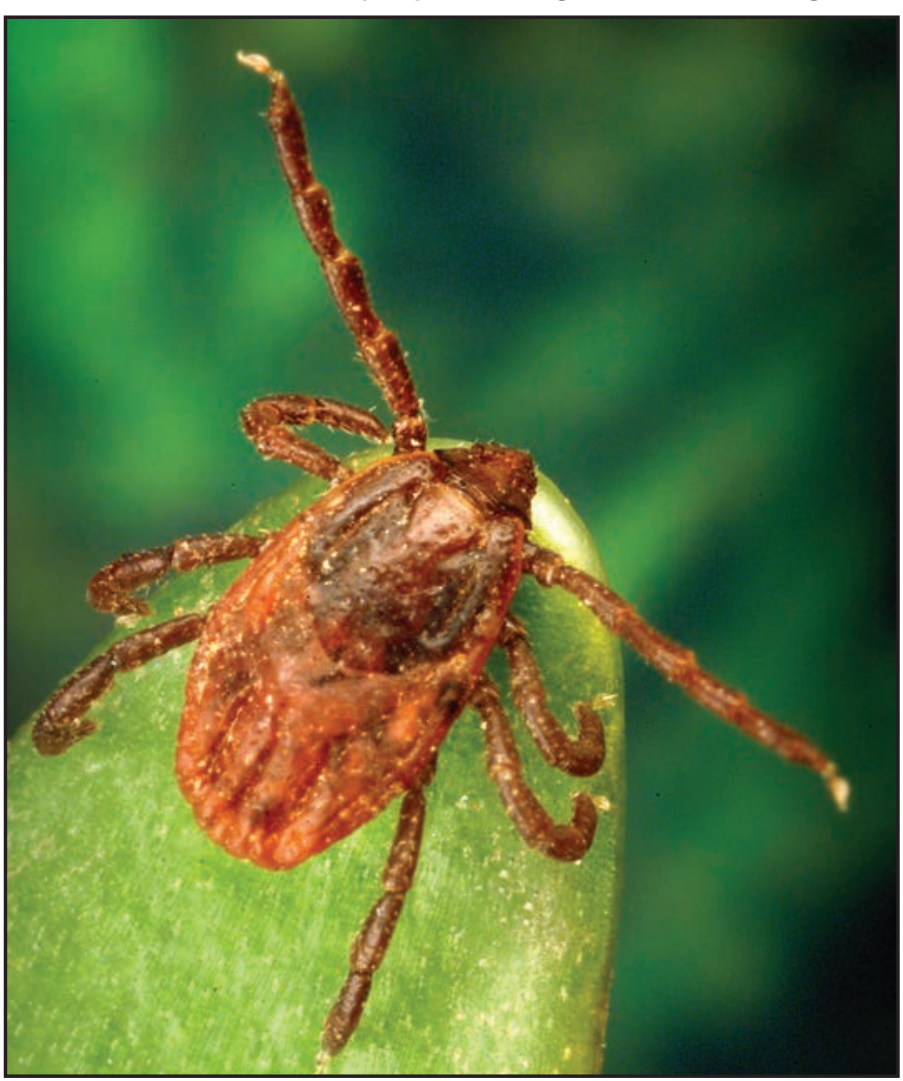

Photo/CDC

FIGURE 7. Approximate U.S. distribution of Rhipicephalus sanguineus (brown dog tick)

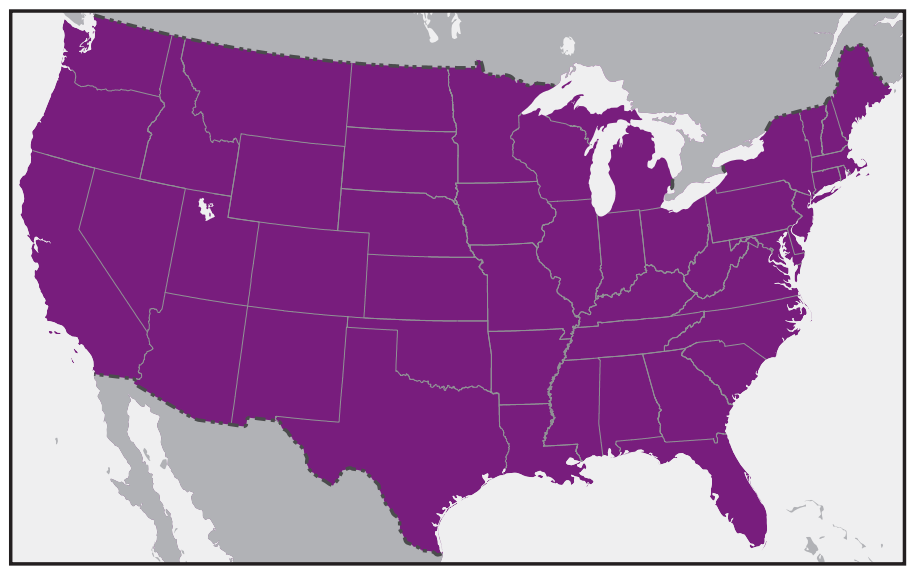

with $R$. parkeri rickettsiosis were identified from 10 states (35-41) (CDC, unpublished data, 2015). The median age of patients from case reports was 53 years (range: 23-83 years) (38); R. parkeri rickettsiosis has not been documented in children, and no fatal cases have been reported. $R$. parkeri is transmitted by the Gulf Coast tick, Amblyomma maculatum (Figure 9). The geographic range of $A$. maculatum extends across the southern United States from Texas to South Carolina
FIGURE 8. Dog infested with Rhipicephalus sanguineus ticks

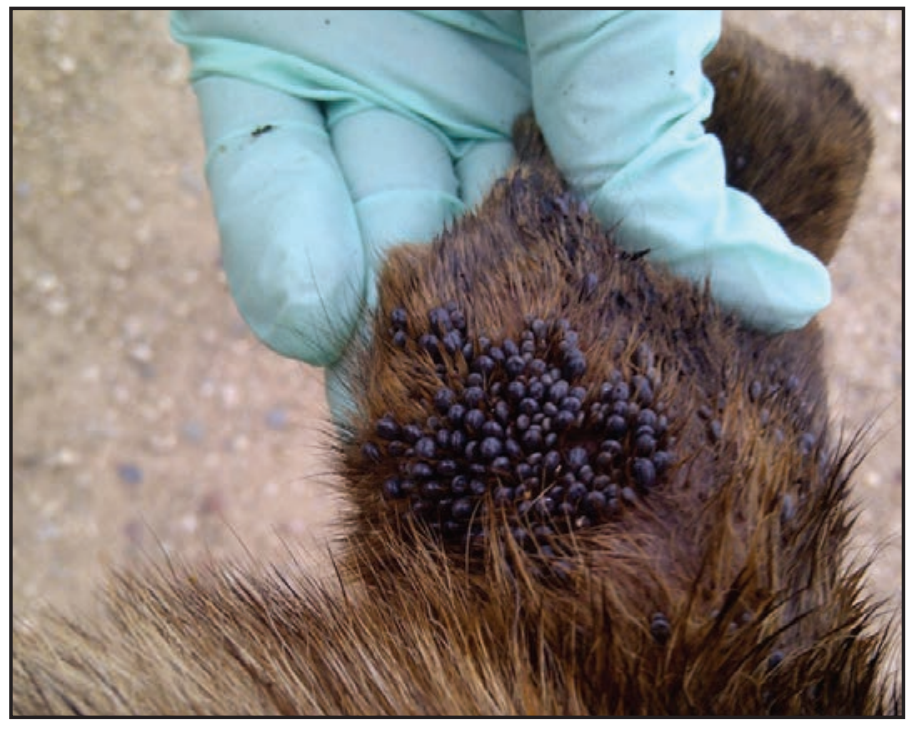

Photo/CDC

and as far north as Kansas, Maryland, Oklahoma, and Virginia (Figure 10). The Gulf Coast tick is typically found in prairie grassland and coastal upland habitats (42). R. parkeri rickettsiosis cases have been documented during AprilOctober, with most cases occurring during July-September.

\section{Rickettsia Species 364D}

The first confirmed case of human disease associated with Rickettsia species 364D was described in 2010 from California and likely was transmitted by the Pacific Coast tick, Dermacentor occidentalis (43). Fewer than 10 cases of Rickettsia species 364D infection, all from California, have been reported in the literature $(43,44)$. Cases have been documented in children and adults (44). The Pacific Coast tick is found in the coastal ranges of Oregon and California and in the states of Baja California and Sinaloa in Mexico. Principal hosts of adult ticks are horses, cattle, and black-tailed deer, whereas immature ticks feed on rodents and rabbits. The prevalence and distribution of Rickettsia species 364D in D. occidentalis ticks suggests that these infections in humans might be more common in California than currently recognized $(45,46)$. Reported cases of Rickettsia species 364D rickettsiosis have occurred during July-September $(43,44)$.

\section{Ehrlichiae}

In the United States, three Ehrlichia species are known to cause symptomatic human infection. E. chaffeensis, the cause of human monocytic ehrlichiosis, was described first in 1987 and is the most common agent of human ehrlichiosis (47). E. ewingii was reported as a human pathogen in 1999 after 
FIGURE 9. Adult female Amblyomma maculatum (Gulf Coast tick)

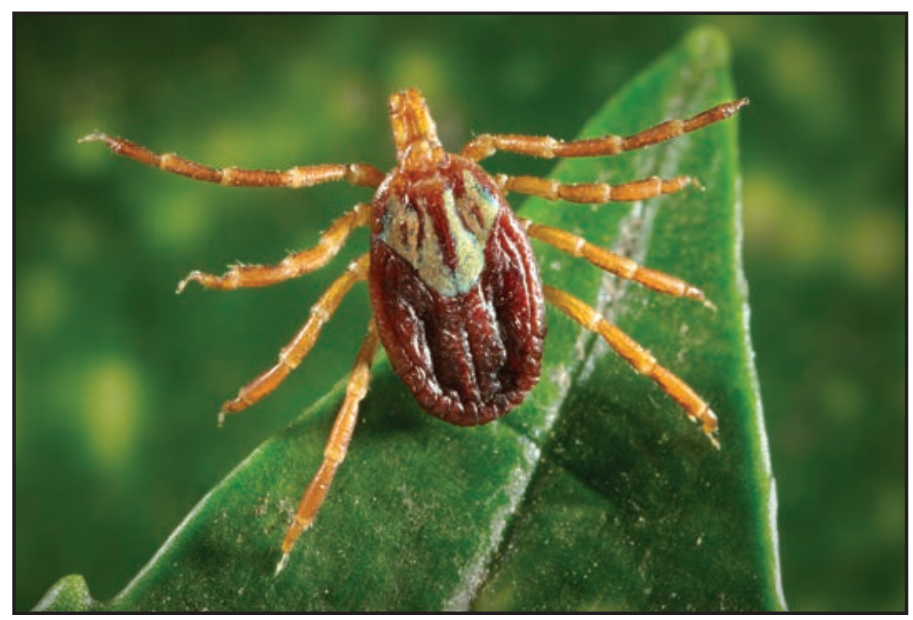

Photo/CDC

FIGURE 10. Approximate U.S. distribution of Amblyomma maculatum (Gulf Coast tick)

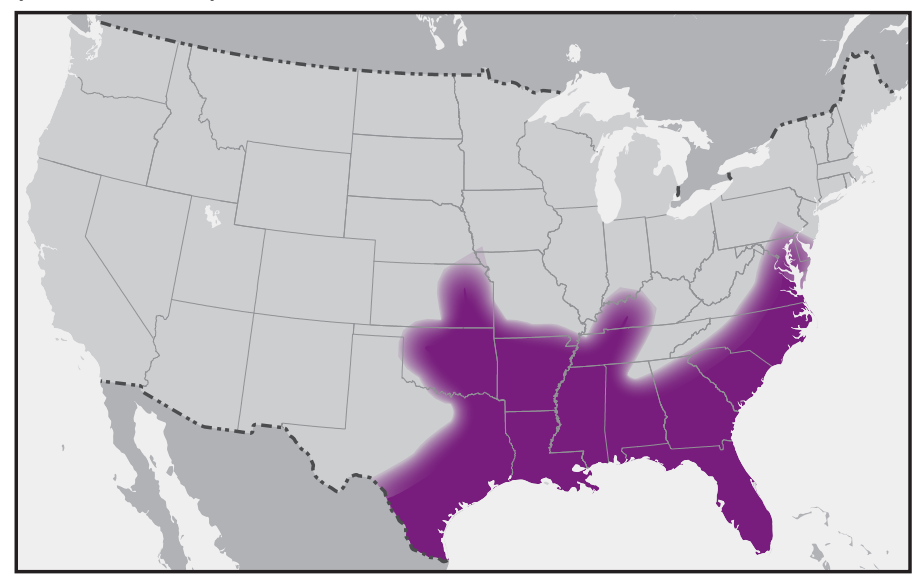

being detected in peripheral blood leukocytes of four patients with illness during 1996-1998 (48). EML agent ehrlichiosis, first described in 2011, is the most recently recognized form of human ehrlichiosis in the United States and was detected originally in the blood of four patients from Minnesota and Wisconsin in 2009 (49).

During 2008-2012, the average annual incidence of ehrlichiosis was 3.2 cases per million persons, which is more than twice the estimated incidence during 2000-2007 (5). Cases have been reported from an increasing number of counties (5) (Figure 11). Incidence generally increases with age, with the highest age-specific incidences occurring among persons aged 60-69 years $(5,13,50)$. Case-fatality rates are highest among children aged $<10$ years and adults aged $\geq 70$ years, and an increased risk for death has been documented among persons who are immunosuppressed $(5,13)$. In areas where ehrlichiosis is endemic, the actual disease incidence is likely underrepresented in estimates that are based on passive surveillance (51-53).

\section{Ehrlichia chaffeensis}

E. chaffeensis is transmitted to humans by the lone star tick, Amblyomma americanum (Figure 12). The lone star tick is among the most commonly encountered ticks in the southeastern United States, with a range that extends into areas of the Midwest and New England states (Figure 13). Ehrlichiosis cases have been reported throughout the range of the lone star tick; states with the highest reported incidence rates include Arkansas, Delaware, Missouri, Oklahoma, Tennessee, and Virginia (5). The whitetailed deer is a major host of all stages of lone star ticks and is thought to be an important natural reservoir for E. chaffeensis (54). Consequently, the lone star tick is found most commonly in woodland habitats that have white-tailed deer populations. The lone star tick feeds on a wide range of hosts, including humans, and has been implicated as the most common tick to bite humans in the southern United States $(55,56)$. Although all stages of this tick feed on humans, only adult and nymphal ticks are known to be responsible for transmission of $E$. chaffeensis to humans. Most cases of $E$. chaffeensis ehrlichiosis occur during May-August.

\section{Ehrlichia ewingii}

E. ewingii ehrlichiosis became a notifiable disease in 2008 . During 2008-2012, cases were primarily reported from Missouri; however, cases also were reported from 10 other states within the distribution of the principal vector, the lone star tick, $A$. americanum $(5,57)$ (Figure 13). Although E. ewingii ehrlichiosis initially was reported predominantly among persons who were immunosuppressed, passive surveillance data from 2008-2012 indicated that the majority of persons (74\%) with reported E. ewingii infection did not report immunosuppression (5). No fatal cases of $E$. ewingii ehrlichiosis have been reported. The ecologic features of E. ewingii are not completely known; however, dogs, goats, and deer have been infected naturally and experimentally (58-60).

\section{Ehrlichia muris-Like Agent}

In 2011, a new species of Ehrlichia referred to as the EML agent was described as a human pathogen after detection in the blood from four patients (three from Wisconsin and one from Minnesota) by using molecular testing techniques (49). The EML agent subsequently was identified in blood specimens from 69 symptomatic patients who lived in or were exposed to ticks in Minnesota or Wisconsin during 2007-2013 (61). The blacklegged tick, Ixodes scapularis (Figure 14), is an efficient vector for the EML agent in experimental studies $(62,63)$, and DNA from the EML agent has been detected from I. scapularis collected in Minnesota and Wisconsin but has not been detected in I. scapularis from other states $(64,65)$. 


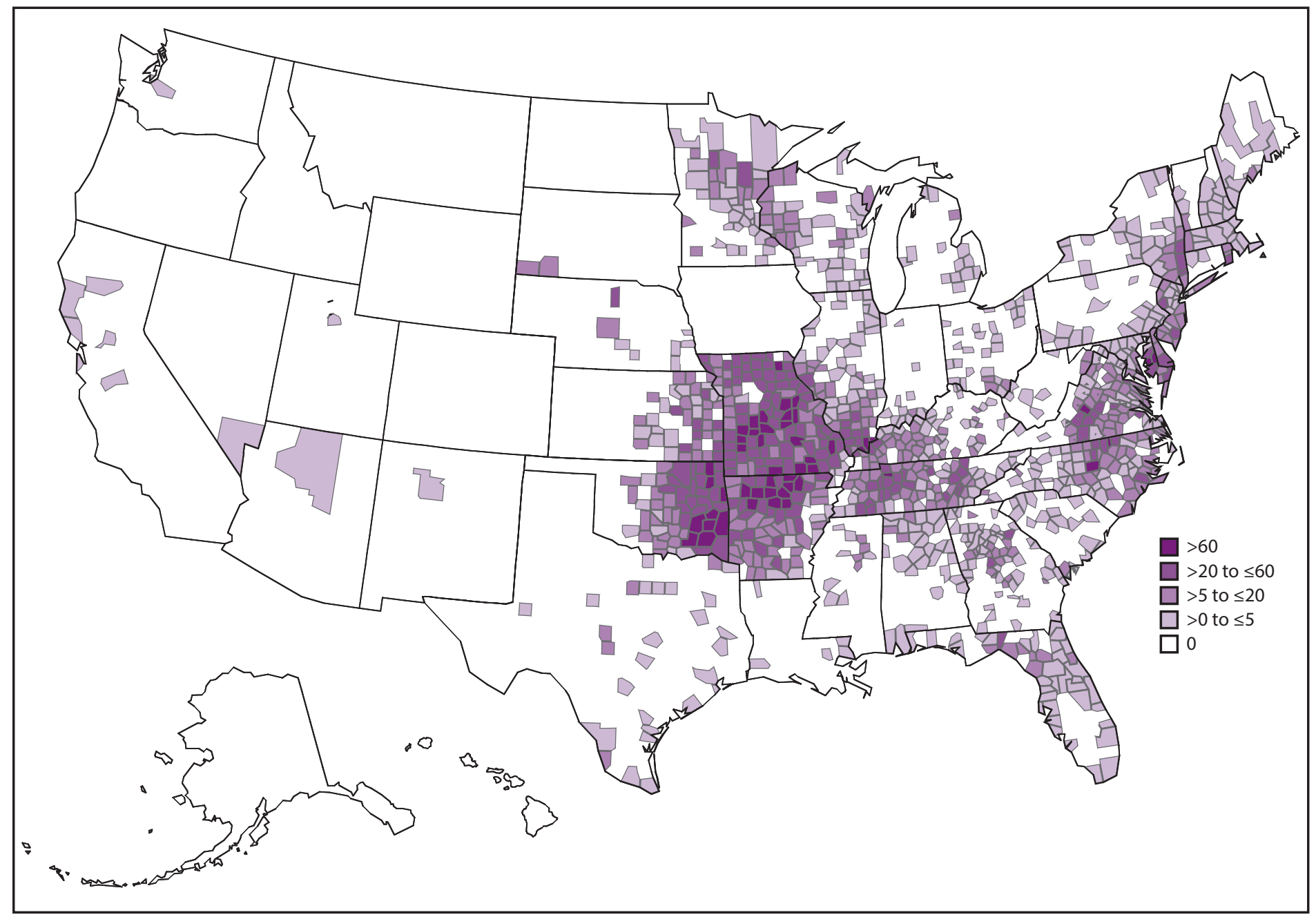

* As reported through national surveillance, per 1,000,000 persons per year. Cases are reported by county of residence, which is not always where the infection was acquired.

\section{Anaplasma phagocytophilum}

A. phagocytophilum causes human anaplasmosis, which is also known as human granulocytic anaplasmosis (formerly known as human granulocytic ehrlichiosis). Passive surveillance from 2008-2012 indicates that the average annual incidence of anaplasmosis was 6.3 cases per million persons (3). Incidence is highest in the northeastern and upper Midwestern states, and the geographic range of anaplasmosis appears to be expanding $(3,66)$ (Figure 15). In Wisconsin, anaplasmosis has been identified as an important cause of nonspecific febrile illness during the tick season (67). Age-specific incidence of anaplasmosis is highest among those aged $\geq 60$ years (3). The reported case-fatality rate during 2008-2012 was $0.3 \%$ and was higher among persons aged $\geq 70$ years and those with immunosuppression (3).

I. scapularis (Figure 14) is the vector for A. phagocytophilum in the northeastern and Midwestern United States (68) (Figure 16), whereas the western blacklegged tick, Ixodes pacificus (Figure 17), is the principal vector along the West Coast (Figure 18). The bites of nymphal and adult ticks can transmit $A$. phagocytophilum to humans. The relative roles of particular animal species as reservoirs of $A$. phagocytophilum strains that cause human illness are not fully understood and likely vary geographically; however, mice, squirrels, woodrats, and other wild rodents are thought to be important in the enzootic cycle. Most anaplasmosis cases occur during June-November. The seasonality of anaplasmosis is bimodal, with the first peak during June-July and a smaller peak during October, which corresponds to the emergence of the adult stage of I. scapularis (13).

The blacklegged tick also transmits nonrickettsial pathogens in certain geographic areas, including Borrelia burgdorferi (the cause of Lyme disease), Babesia microti (the primary cause of human babesiosis in the United States), Borrelia miyamotoi, (a cause of tickborne relapsing fever), and deer tick virus 
FIGURE 12. Adult female Amblyomma americanum (lone star tick)

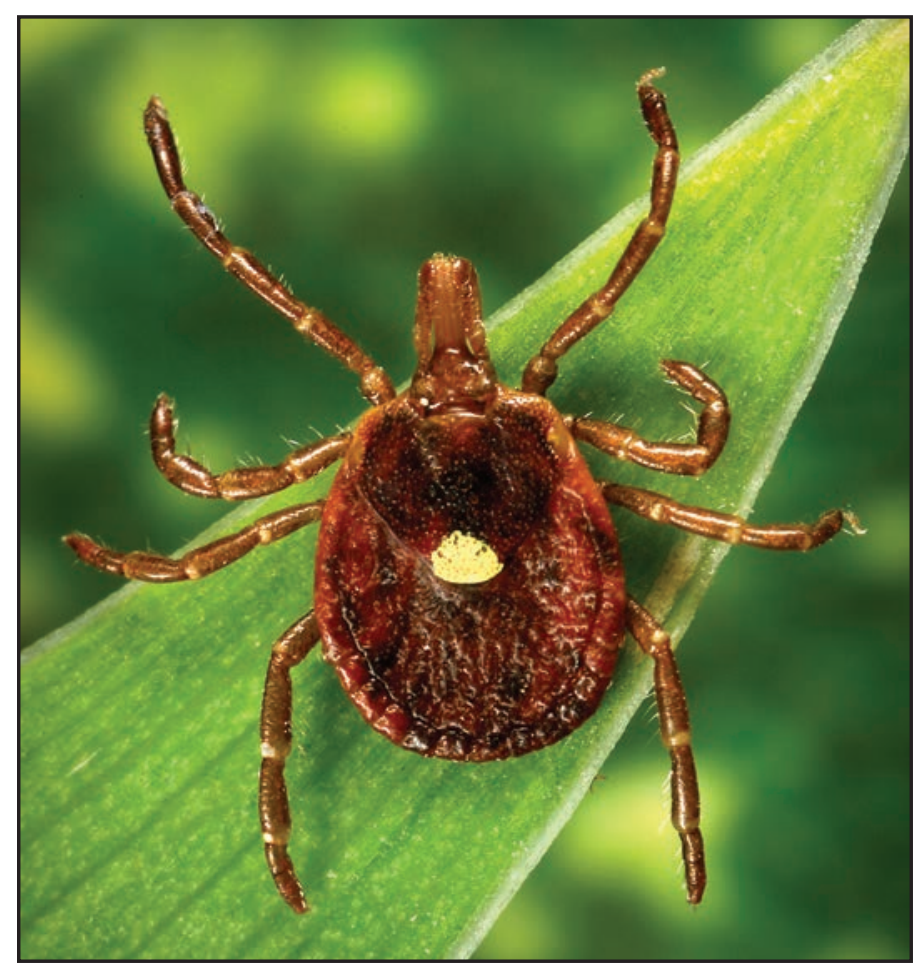

Photo/CDC

FIGURE 13. Approximate U.S. distribution of Amblyomma americanum (lone star tick)

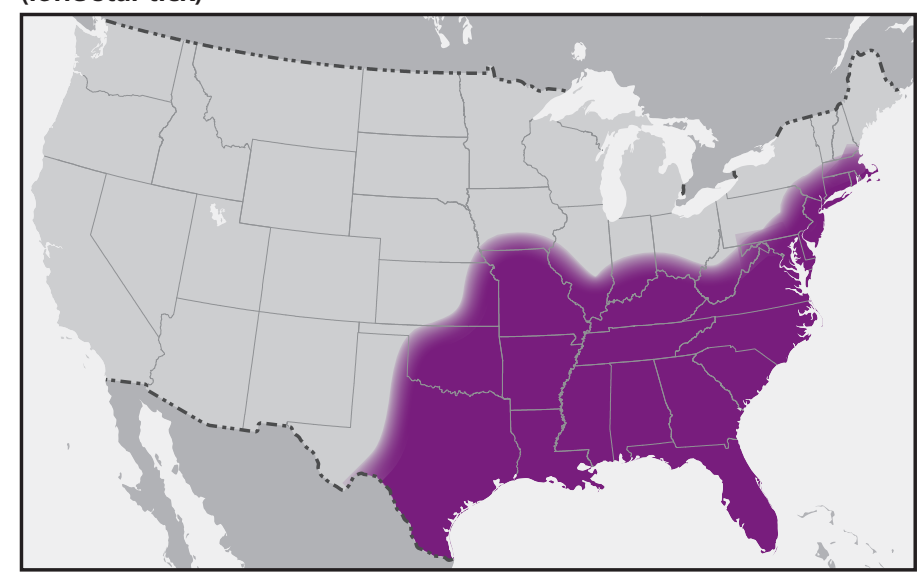

(Powassan virus, lineage II; a cause of tickborne encephalitis). The preponderance of cases of human anaplasmosis occur in the same states that report high incidences of Lyme disease and human babesiosis. Simultaneous infections with A. phagocytophilum and B. burgdorferi or B. microti have been described (69-73), and discerning such a mixed infection is important because it might affect antimicrobial choice (see Coinfections of Anaplasma with Other Tickborne Pathogens).
BOX 1. Summary of epidemiologic features of tickborne rickettsial diseases

- Incidence varies geographically in the United States, thus it is important for health care providers to know the regions in which particular tickborne rickettsial diseases typically occur.

- Occurrence is seasonal and corresponds with the feeding period for the life stage of the primary tick vector; the majority of illness occurs during the spring and summer months but might occur throughout the year, especially in geographic regions with warmer climates.

- In the past decade, Rickettsia parkeri, Rickettsia species 364D, and EML agent were newly recognized as agents of tickborne rickettsial disease in the United States.

- SFG rickettsioses, including RMSF, are reported from all of the contiguous 48 states and the District of Columbia.

- RMSF and Ehrlichia chaffeensis ehrlichiosis most commonly are reported in states from Missouri and Oklahoma east to North Carolina and Virginia.

- RMSF has emerged in parts of Arizona where it is associated with a different tick vector, Rhipicephalus sanguineus. RMSF in this area is characterized by unusually high incidence and case-fatality rates (particularly among children) and associated with prolonged periods of seasonal tick exposure and increased domestic and peridomestic exposures.

- Cases of RMSF have been reported in persons who acquire infection in areas of Mexico where disease incidence is high and subsequently seek health care across the U.S.-Mexico border.

- $R$. parkeri rickettsiosis first was described in 2004, and cases most commonly are reported along the Gulf Coast and the eastern seaboard.

- Rickettsia species 364D rickettsiosis first was described in 2010, and all reported cases are from California.

- Although recognized human cases of Ehrlichia ewingii ehrlichiosis are uncommon, cases increasingly are recognized and reported over a wider geographic range.

- EML agent ehrlichiosis first was described in 2011, and cases have been identified in persons exposed to ticks in Minnesota and Wisconsin.

- Anaplasmosis is reported predominantly from the northeastern United States, Minnesota, and Wisconsin.

Abbreviations: $\mathrm{EML}=$ Ehrlichia muris-like; RMSF = Rocky Mountain spotted fever; SFG = spotted fever group. 


\section{Epidemiologic Clues from the Clinical History}

Obtaining a thorough clinical history that includes questions about recent 1) tick exposure, 2) recreational or occupational exposure to tick-infested habitats, 3) travel to areas where tickborne rickettsial diseases are endemic, and 4) occurrence of similar illness in family members, coworkers, or pet dogs can provide critical information to make a presumptive diagnosis of tickborne rickettsial disease. However, the absence of one or more of these factors does not exclude a diagnosis of tickborne rickettsial disease. Health care providers should be familiar with the epidemiologic clues that support the diagnosis of tickborne rickettsial disease but recognize that classic epidemiologic features are not reported in many instances (Box 2).

\section{History of Tick Bite or Exposure}

A detailed history should be taken to elicit information about known tick bites or activities that might be associated with exposure to ticks. Although the recognition of a tick bite is helpful, unrecognized tick bites are common in patients who are later confirmed to have a tickborne rickettsial disease. A history of a tick bite within 14 days of illness onset is reported in only $55 \%-60 \%$ of RMSF cases $(9,12,25)$ and $68 \%$ of ehrlichiosis cases (10). Therefore, absence of a recognized tick bite should never dissuade health care providers from considering tickborne rickettsial disease in the appropriate clinical context. In fact, the absence of classic features, such as a reported tick bite, has been associated with delays in RMSF diagnosis and increased risk for death $(9,18,74,75)$. The location of the tick bite might be obscure, and the bite is typically painless. Bites from immature stages of ticks (e.g., nymphs, which are 1-2 mm, or the size of a pinhead) (Figure 19) might be even less apparent. Some patients who do not report tick exposure might describe other pruritic, erythematous, or ulcerated cutaneous lesions that they refer to as mosquito, spider, chigger, or bug bites, all of which might be indistinguishable from a recent tick bite.

A thorough recreational and occupational history can help reveal potential exposures to tick habitats. In areas endemic for ticks, activities as commonplace as playing in a backyard, visiting a neighborhood park, gardening, or walking dogs are potential sources of tick exposure. Many types of environments serve as tick habitats, depending on the specific tick vector species. Areas with high uncut grass, weeds, and low brush might pose a high risk for certain vector species; however, these tick species also seek hosts in well-maintained grass lawns around suburban homes (76). Moreover, certain species can withstand drier conditions and might be found in vegetationfree areas or forest floors covered with only leaf litter or pine needles. Additional areas that might be inhabited by ticks
FIGURE 14. Adult female Ixodes scapularis (blacklegged tick)

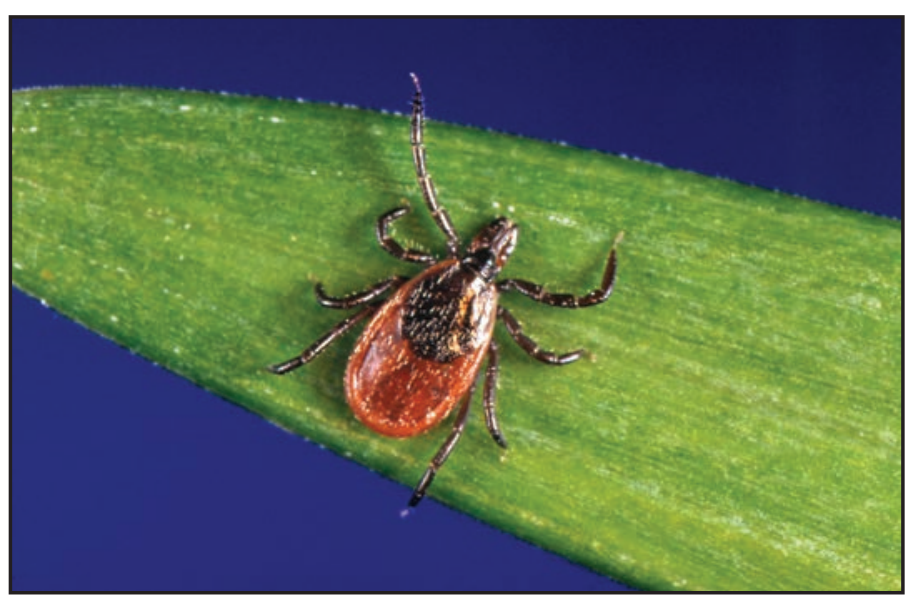

Photo/CDC

include vegetation bordering roads, trails, yards, or fields; urban and suburban recreational parks; golf courses; and debris piles or refuse around homes (24,77-80). Activities that commonly result in contact with potential tick habitats include recreational pursuits (e.g., camping, hiking, fishing, hunting, gardening, and golfing) and occupational activities (e.g., forestry work, farming, landscaping, and military exercises). Although peak tick season is an important consideration, health care providers should remain aware that tickborne rickettsial illnesses have been reported in every month of the year, including winter (3-5,25,81). Climate differences and seasonal weather patterns can influence the duration and peak of tick season in a given geographic region and a given year.

Queries about contact with pets, especially dogs, and a history of tick attachment or recent tick removal from pets might be useful in assessing potential human tick exposure. Pet dogs with attached ticks can serve as useful indicators of peridomestic tick infestation $(17,82,83)$. Tick-infested dogs can transfer ticks directly to humans during interactions and serve as transport hosts, carrying ticks in and around dwellings where the ticks can then transfer to the human occupants (84) (see Similar Illness in Household Members, Coworkers, or Pets).

\section{Recent Travel to Areas Known To Be Endemic for Tickborne Rickettsial Diseases}

Health care providers practicing in areas where the incidence of tickborne rickettsial disease is historically low might be less likely to distinguish these diseases from other clinically similar and more commonly encountered infectious and noninfectious syndromes. Tickborne rickettsial diseases typically are sporadic, and identifying these infections requires a high index of clinical suspicion, especially in environments in which the infections 


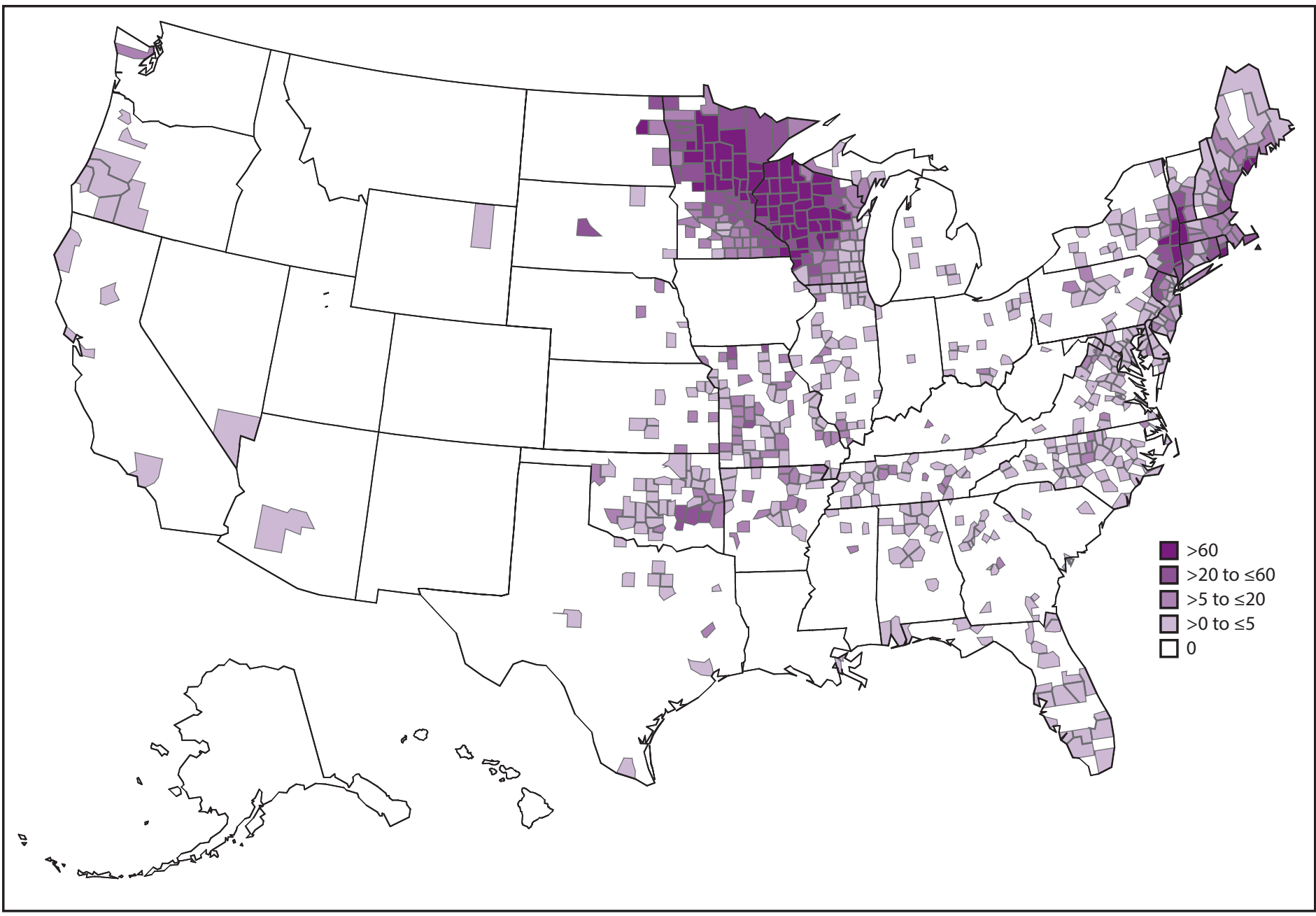

* As reported through national surveillance, per 1,000,000 persons per year. Cases are reported by county of residence, which is not always where the infection was acquired.

have not been recognized previously as occurring frequently. Knowledge of the epidemiology of tickborne rickettsial diseases, including the regions of the United States with a high incidence, is important. The distribution of tickborne rickettsial diseases is influenced by the geographic range of the tick vector, which can change over time. Distribution maps of tick vectors and disease incidence can serve as guides; however, the distribution borders are not fixed in space or over time, and the ranges for many tick species might be expanding.

Travel history within and outside of the United States can provide an important clue in considering the diagnosis of a tickborne rickettsial disease. Travel from an area where tickborne rickettsial diseases are endemic within 2 weeks of the onset of a clinically compatible illness could support a presumptive diagnosis of tickborne illness, especially if travel activities that might result in tick exposure are reported. Tickborne rickettsial diseases occur worldwide, and the
FIGURE 16. Approximate U.S. distribution of Ixodes scapularis (blacklegged tick)

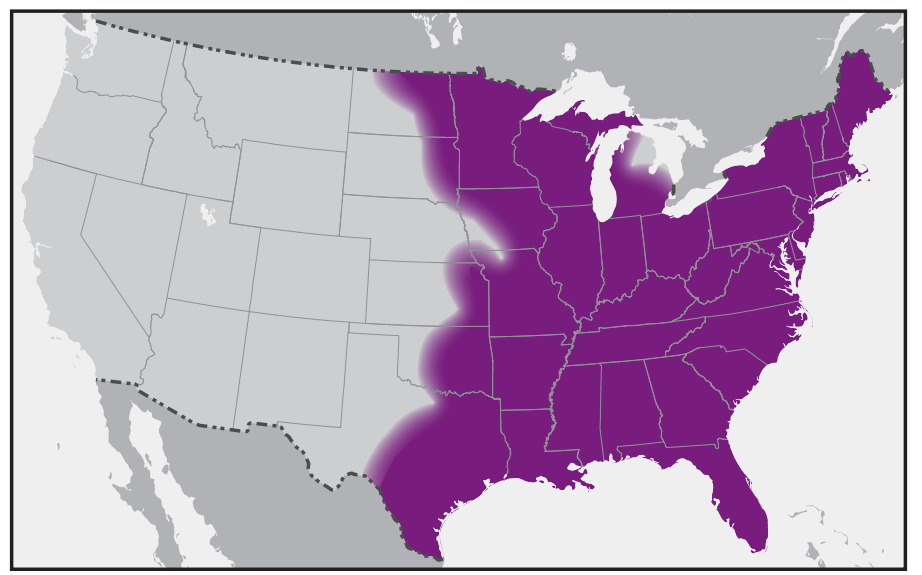


FIGURE 17. Adult female Ixodes pacificus (western blacklegged tick)

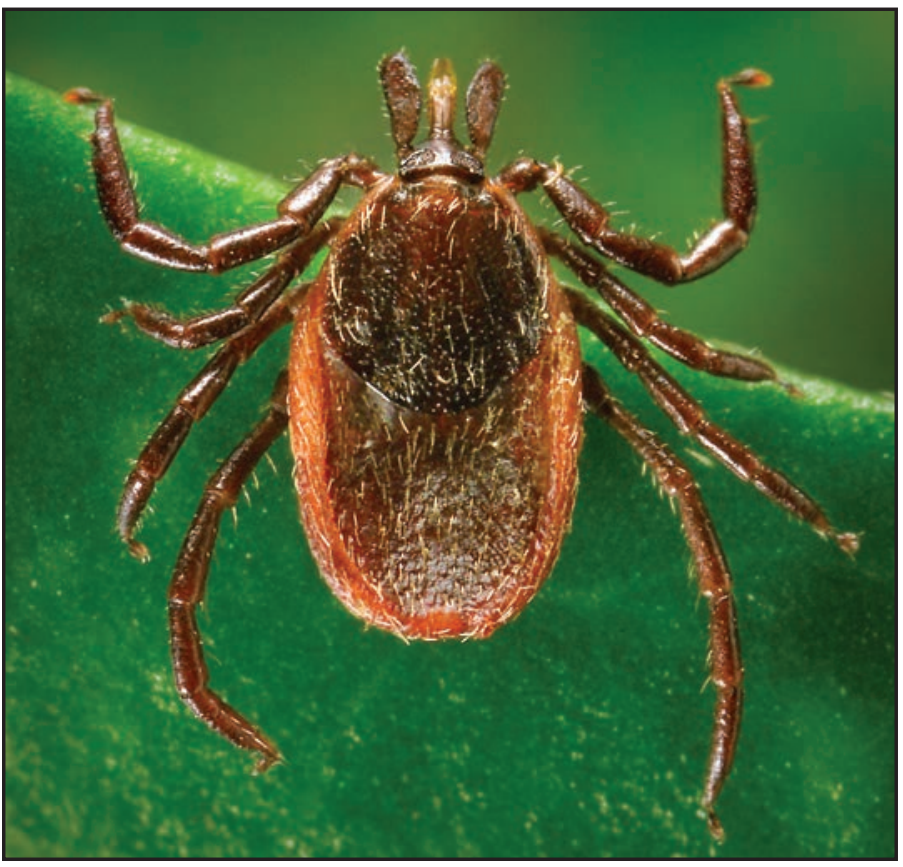

Photo/CDC

FIGURE 18. Approximate U.S. distribution of Ixodes pacificus (western blacklegged tick)

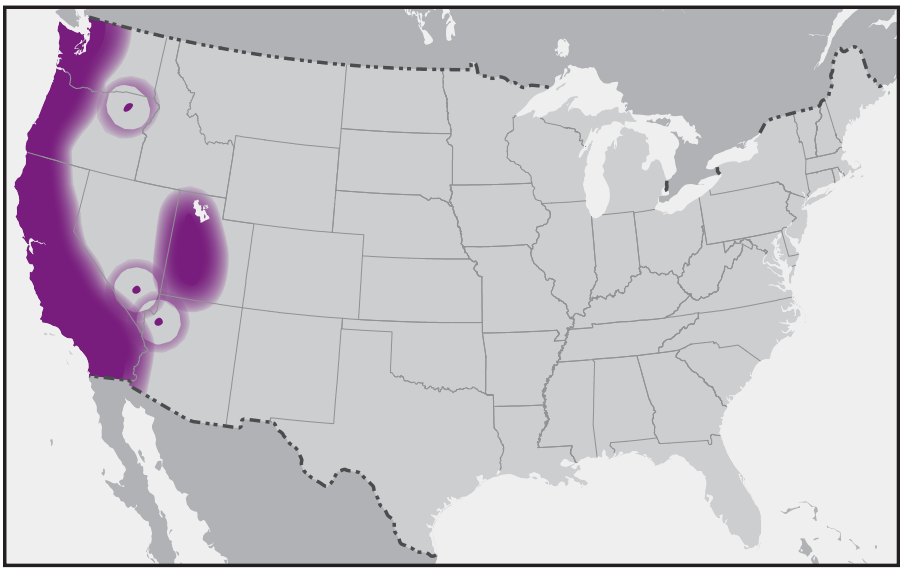

imported diseases might have epidemiologic, seasonal, and clinical features that differ from those in the United States. Selected additional tickborne rickettsial diseases that might be considered in returning international travelers are presented (see Travel Outside of the United States and Appendix A).

\section{Similar Illness in Household Members, Coworkers, or Pets}

Clustering of certain tickborne rickettsial diseases is a well-recognized epidemiologic occurrence, particularly after common exposures to natural foci of infected ticks. Temporally and geographically related clusters of illness have occurred among family members (including their pet dogs), coworkers,
FIGURE 19. Sizes of the larva, nymph, and adult stages of Rhipicephalus sanguineus (brown dog tick) compared with a human finger

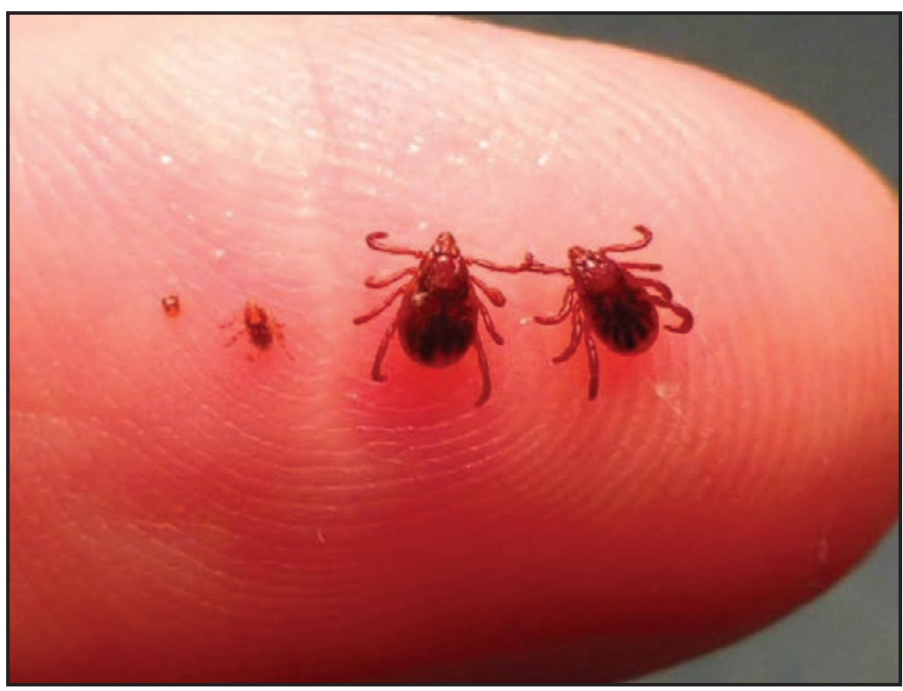

Photo/CDC

or persons frequenting a particular common area. Described clusters include ehrlichiosis among residents of a golfing community (80), ehrlichiosis and RMSF among soldiers on field maneuvers $(85,86)$, and RMSF among family members (87-89). Infections with $R$. rickettsii and Ehrlichia species have been observed concurrently in humans and their pet dogs $(48,83,90)$. Recognition of a dog's death from RMSF has even prompted recognition and appropriate treatment of RMSF in the sick owner (90). Health care providers should ask ill patients about similar illnesses among family members, coworkers, community residents, and pet dogs.

Dogs are frequently exposed to ticks and are susceptible to infections with many of the same tickborne rickettsial pathogens as humans, including $R$. rickettsii, E. chaffeensis, E. ewingii, and A. phagocytophilum (82). Evidence of current or past rickettsial infection in dogs might be useful in determining the presence of human risk for tickborne rickettsial diseases in a given geographic area (82). Tickborne rickettsial infection in dogs can range from inapparent to severe. RMSF in dogs manifests with fever, lethargy, decreased appetite, tremors, scleral injection, maculopapular rash on ears and exposed skin, and petechial lesions on mucous membranes (91-93). A veterinarian should be consulted when tickborne rickettsial disease is suspected in dogs or other animals (see Protecting Pets from Tick Bites). Documentation of a tickborne rickettsial disease in a dog should prompt veterinary professionals to warn pet owners about the risk for acquiring human tickborne disease. Cases of RMSF in dogs preceding illness in their owners (83) illustrate the value of communication between veterinarians and human health care providers when zoonotic diseases are suspected and emphasize the importance of a One Health approach to address zoonotic diseases. 
BOX 2. Summary of epidemiologic clues from the clinical history

- The absence of known tick attachment should never dissuade a health care provider from considering the diagnosis of tickborne rickettsial disease.

- A detailed history of recent recreational and occupational activities and travel might reveal potential exposure to ticks or tick habitats.

- Familiarity with tickborne rickettsial disease epidemiology is helpful when asking patients about recent travel to areas (domestic and international) where these diseases are endemic.

- Clustering of certain tickborne rickettsial diseases is well recognized and has been reported among family members, pet dogs, coworkers, military personnel, and other groups.

- Dogs and humans are susceptible to infection with many of the same tickborne rickettsial pathogens, including Rickettsia rickettsii, Ehrlichia chaffeensis, Ehrlichia ewingii, and Anaplasma phagocytophilum; in some instances, pet dogs might serve as sentinels for tickborne rickettsial disease in humans.

\section{Clinical Signs and Symptoms and Pathophysiology of Disease}

Tickborne rickettsial diseases commonly have nonspecific clinical signs and symptoms early in the course of disease. Although the clinical presentations of tickborne rickettsial disease overlap, the frequency of certain associated signs and symptoms (e.g., rash and other cutaneous findings), typical laboratory findings, and case-fatality rates differ by pathogen (Table 1). Familiarity with the clinical signs and symptoms and pathophysiology of tickborne rickettsial diseases, including RMSF and other SFG rickettsioses (Box 3), ehrlichioses (Box 4), and anaplasmosis (Box 5) will assist health care providers in developing a differential diagnosis, prescribing appropriate antibacterial treatment, and ordering appropriate confirmatory diagnostic tests.

\section{Rocky Mountain Spotted Fever and Other Spotted Fever Group Rickettsioses}

\section{Rocky Mountain Spotted Fever}

\section{Pathophysiology}

$R$. rickettsii is an obligate intracellular pathogen that primarily infects vascular endothelial cells, and, less commonly, underlying smooth muscle cells of small and medium vessels (Figure 20). Infection with $R$. rickettsii leads to systemic vasculitis that manifests externally as characteristic petechial skin lesions. If disease progresses untreated, it can result in end-organ damage associated with severe morbidity and death. Pathogen-mediated injury to the vascular endothelium results in increased capillary permeability, microhemorrhage, and platelet consumption (94). Late-stage manifestations, such as noncardiogenic pulmonary edema (acute respiratory distress syndrome $[\mathrm{ARDS}]$ ) and cerebral edema, are consequences of microvascular leakage. Hyponatremia occurs as a result of appropriate secretion of antidiuretic hormone in response to hypovolemia (95).

\section{Signs and Symptoms}

Symptoms of RMSF typically appear 3-12 days after the bite of an infected tick or between the fourth and eighth day after discovery of an attached tick (96). The incubation period is generally shorter (5 days or less) in patients who develop severe disease (97). Initial symptoms include sudden onset of fever, headache, chills, malaise, and myalgia. Other early symptoms might include nausea or vomiting, abdominal pain, anorexia, and photophobia. A rash typically appears $2-4$ days after the onset of fever; however, most patients initially seek health care before appearance of a rash $(25,74,98)$. The classic triad of fever, rash, and reported tick bite is present in only a minority of patients during initial presentation to health care $(6,25)$; therefore, health care providers should not wait for development of this triad before considering a diagnosis of RMSF.

The RMSF rash classically begins as small $(1-5 \mathrm{~mm}$ in diameter), blanching, pink macules on the ankles, wrists, or forearms that subsequently spread to the palms, soles, arms, legs, and trunk, usually sparing the face. Over the next several days of illness, the rash typically becomes maculopapular, sometimes with central petechiae (Figures 21 and 22). The classic spotted or generalized petechial rash, including involvement of the palms and soles, usually appears by day 5 or 6 and is indicative of advanced disease. Absence of rash should not preclude consideration of RMSF; $<50 \%$ of patients have a rash in the first 3 days of illness, and a smaller percentage of patients never develop a rash $(6,25)$. The rash might be atypical, localized, faint, or evanescent (99). In some persons, skin pigmentation might make the rash difficult to recognize. The rash might resemble those of other infectious and noninfectious etiologies (see Differential Diagnosis of Fever and Rash). Children aged $<15$ years more frequently have a rash than older patients and develop the rash earlier in the course of illness (6-8). Lack of rash or late-onset rash in RMSF has been associated with delays in diagnosis and increased mortality $(6,18,74)$. Unlike some SFG rickettsioses, an inoculation eschar is rarely present with RMSF $(100,101)$. Other clinical 


\begin{tabular}{|c|c|c|c|c|c|}
\hline Disease & $\begin{array}{l}\text { Incubation } \\
\text { period }\end{array}$ & $\begin{array}{l}\text { Common initial signs and } \\
\text { symptoms }\end{array}$ & Cutaneous signs & Common laboratory findings & $\begin{array}{l}\text { Estimated } \\
\text { case-fatality } \\
\text { rate }\end{array}$ \\
\hline $\begin{array}{l}\text { Rocky Mountain spotted } \\
\text { fever }\end{array}$ & 3-12 days & $\begin{array}{l}\text { Fever, headache, chills, } \\
\text { malaise, myalgia, nausea, } \\
\text { vomiting, abdominal pain, } \\
\text { photophobia, anorexia }\end{array}$ & $\begin{array}{l}\text { Maculopapular rash } \\
\text { approximately } 2-4 \text { days after } \\
\text { fever onset in most, might } \\
\text { become petechial and involve } \\
\text { palms and soles }\end{array}$ & $\begin{array}{l}\text { Thrombocytopenia, slightly } \\
\text { increased hepatic transaminase } \\
\text { levels, normal or slightly } \\
\text { increased white blood cell count } \\
\text { with increased immature } \\
\text { neutrophils, hyponatremia }\end{array}$ & $5 \%-10 \%$ \\
\hline $\begin{array}{l}\text { Rickettsia parkeri } \\
\text { rickettsiosis }\end{array}$ & 2-10 days & Fever, myalgia, headache & $\begin{array}{l}\text { Eschar, sparse maculopapular or } \\
\text { vesiculopapular rash that } \\
\text { might involve palms and soles }\end{array}$ & $\begin{array}{l}\text { Mild thrombocytopenia, mild } \\
\text { leukopenia, increased hepatic } \\
\text { transaminase levels }\end{array}$ & - \\
\hline $\begin{array}{l}\text { Rickettsia species 364D } \\
\text { rickettsiosis }\end{array}$ & $-^{\dagger}$ & $\begin{array}{l}\text { Fever, headache, myalgia, } \\
\text { fatigue }\end{array}$ & $\begin{array}{l}\text { Eschar or ulcerative lesion with } \\
\text { regional lymphadenopathy }\end{array}$ & $-^{\dagger}$ & - $^{*}$ \\
\hline $\begin{array}{l}\text { Ehrlichia chaffeensis } \\
\text { ehrlichiosis (human } \\
\text { monocytic ehrlichiosis) }\end{array}$ & 5-14 days & $\begin{array}{l}\text { Fever, headache, malaise, } \\
\text { myalgia, nausea, diarrhea, } \\
\text { vomiting }\end{array}$ & $\begin{array}{l}\text { Rash in approximately } 30 \% \text { of } \\
\text { adults and } 60 \% \text { of children, } \\
\text { variable rash pattern that } \\
\text { might involve palms and soles, } \\
\text { appears a median of } 5 \text { days } \\
\text { after illness onset }\end{array}$ & $\begin{array}{l}\text { Leukopenia, thrombocytopenia, } \\
\text { increased hepatic transaminase } \\
\text { levels, hyponatremia, anemia }\end{array}$ & $3 \%$ \\
\hline $\begin{array}{l}\text { Ehrlichia ewingii } \\
\text { ehrlichiosis }\end{array}$ & $-\epsilon^{\dagger}$ & $\begin{array}{l}\text { Fever, headache, malaise, } \\
\text { myalgia }\end{array}$ & Rash rare & $\begin{array}{l}\text { Leukopenia, thrombocytopenia, } \\
\text { increased hepatic transaminase } \\
\text { levels }\end{array}$ & -* \\
\hline $\begin{array}{l}\text { Ehrlichia muris-like agent } \\
\text { ehrlichiosis }\end{array}$ & $-^{\dagger}$ & $\begin{array}{l}\text { Fever, headache, malaise, } \\
\text { myalgia }\end{array}$ & Rash in approximately $12 \%$ & $\begin{array}{l}\text { Thrombocytopenia, lymphopenia, } \\
\text { leukopenia, increased hepatic } \\
\text { transaminase levels, anemia }\end{array}$ & - $^{*}$ \\
\hline $\begin{array}{l}\text { Human anaplasmosis } \\
\text { (human granulocytic } \\
\text { anaplasmosis) }\end{array}$ & 5-14 days & $\begin{array}{l}\text { Fever, headache, malaise, } \\
\text { myalgia, chills }\end{array}$ & Rash rare, in $<10 \%$ & $\begin{array}{l}\text { Thrombocytopenia, leukopenia, } \\
\text { mild anemia, increased hepatic } \\
\text { transaminase levels, increased } \\
\text { numbers of immature } \\
\text { neutrophils }\end{array}$ & $<1 \%$ \\
\hline
\end{tabular}

* No known deaths.

${ }^{\dagger}$ Not documented.

FIGURE 20. Immunohistochemical stain demonstrating Rickettsia rickettsii (red) in blood vessel endothelial cells

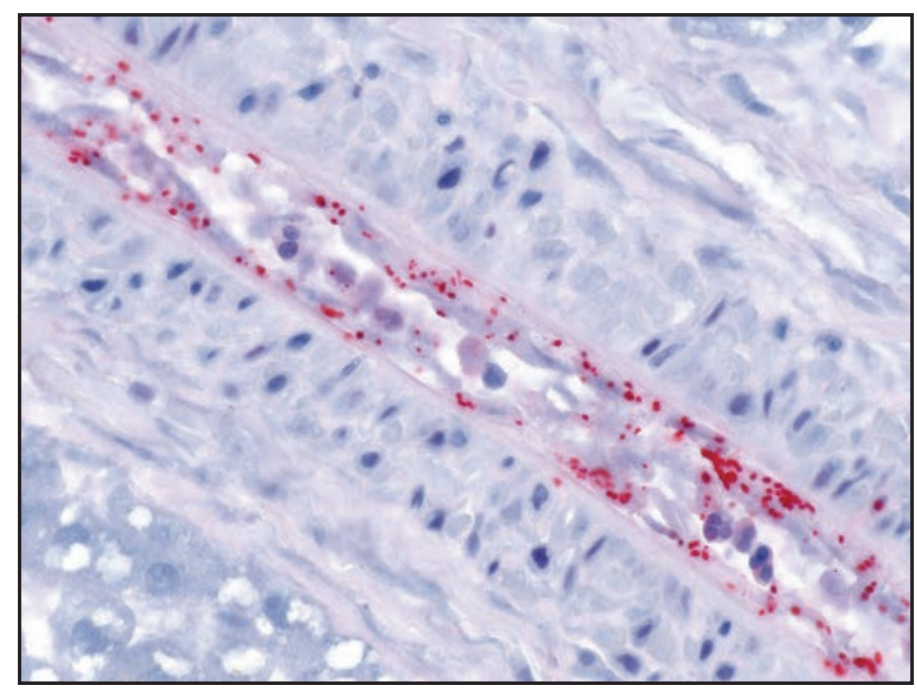

Photo/CDC features that have been observed in association with RMSF include abdominal pain that mimics acute appendicitis (102), cholecystitis (103), or gastroenteritis; diarrhea; conjunctival suffusion; periorbital and peripheral edema (more common in children); calf pain; acute transient hearing loss; hepatomegaly; and splenomegaly $(6,104)$.

Severe, late-stage manifestations of RMSF include meningoencephalitis, acute renal failure, ARDS, cutaneous necrosis, shock, arrhythmia, and seizure. Features of late illness might be confused with other diseases or syndromes. For example, RMSF-associated cutaneous necrosis and gangrene might be difficult to distinguish clinically from purpura fulminans associated with meningococcemia (105). RMSF-associated neurologic manifestations, renal failure, and thrombocytopenia have led to confusion with the diagnosis of thrombotic thrombocytopenic purpura (TTP) (106-108). RMSF-associated vasculitis has been confused with idiopathic, acute vasculitides, such as Kawasaki disease in pediatric patients. RMSF might also mimic bacterial or viral meningoencephalitis (109). Focal neurologic deficits, including cranial or peripheral motor nerve paralysis, or sudden transient hearing loss can occur (110-112). 
FIGURE 21. Maculopapular rash with central petechiae associated with Rocky Mountain spotted fever

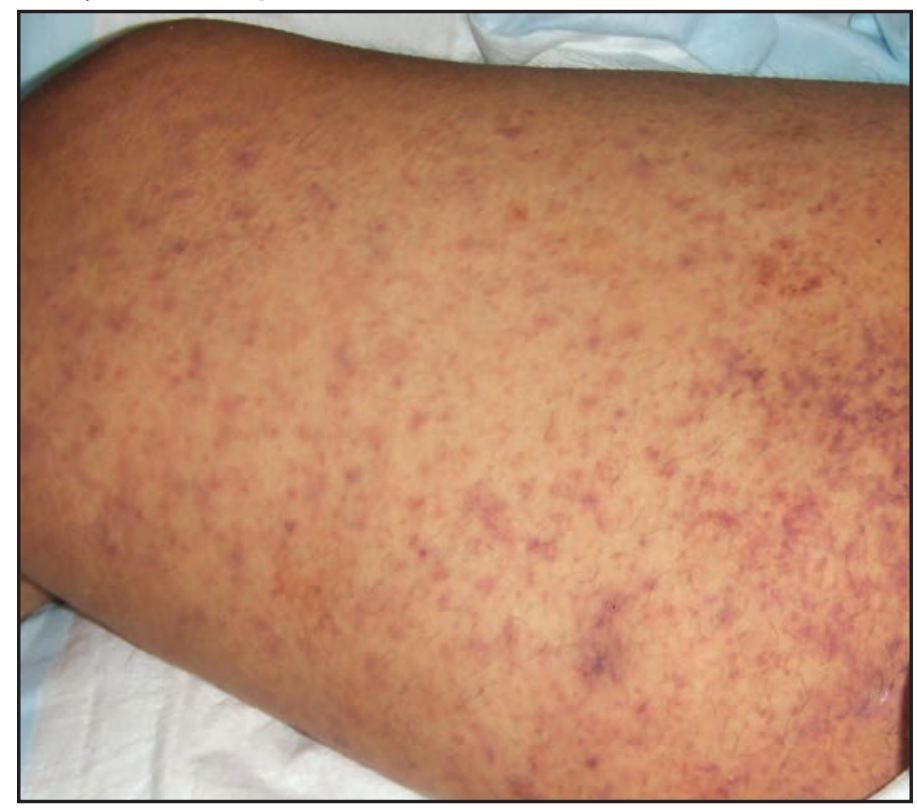

Photo/CDC

\section{Clinical Course}

Clinical suspicion for RMSF should be maintained in cases of nonspecific febrile illness and sepsis of unclear etiology, particularly during spring and summer months. Delay in diagnosis and treatment is the most important factor associated with increased likelihood of death, and early empiric therapy is the best way to prevent RMSF progression. Without treatment, RMSF progresses rapidly. Patients treated after the fifth day of illness are more likely to die than those treated earlier in the course of illness $(9,18,74,75)$. The frequency of hospital admission, intensive care unit admission, and death increases with time from symptom onset to initiation of appropriate antibacterial treatment (18) (Table 2). Delays in diagnosis and initiation of antirickettsial therapy have been associated with seeking health care early in the course of the illness $(7,74)$, late-onset or absence of rash $(6,18)$, and nonspecific or atypical early manifestations, such as gastrointestinal symptoms $(18,98)$ or absence of headache $(75)$. Epidemiologic factors associated with increased risk for death include disease that occurs early or late in the typical tick season (74) and the lack of a report of a tick bite $(9,75,98)$. Although knowledge of the epidemiology might help guide diagnosis, the absence of epidemiologic clues can be misleading.

RMSF is the most frequently fatal rickettsial illness in the United States; the case-fatality rate in the preantibiotic era was approximately $25 \%$ (113-115). Present-day case-fatality rates, estimated at 5\%-10\% overall, depend in part on the timing of initiation of appropriate treatment; case-fatality rates of $40 \%-50 \%$ among patients treated on days 8 or 9 of illness
FIGURE 22. Late-stage petechial purpuric rash involving the sole of the foot in a patient with Rocky Mountain spotted fever

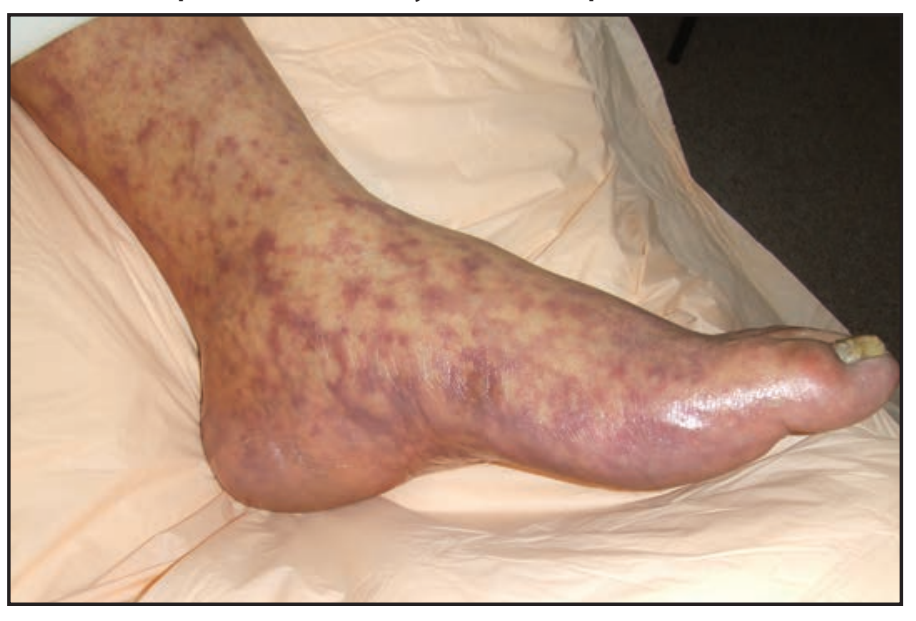

Photo/CDC

have been described recently (18) (Table 2). Additional risk factors for fatal RMSF include age $\geq 40$ years, age $<10$ years, and alcohol abuse $(18,75,116,117)$. Glucose-6-phosphate dehydrogenase deficiency is a risk factor for fulminant RMSF, with death occurring in $\leq 5$ days (118). Experimental and accumulated anecdotal clinical data suggest that treatment of patients with RMSF using a sulfonamide antimicrobial can result in increased disease severity and death $(119,120)$.

Long-term neurologic sequelae of RMSF include cognitive impairment; paraparesis; hearing loss; blindness; peripheral neuropathy; bowel and bladder incontinence; cerebellar, vestibular, and motor dysfunction; and speech disorders $(7,110,121-124)$. These complications are observed most frequently in persons recovering from severe, life-threatening disease, often after lengthy hospitalizations, and are most likely the result of $R$. rickettsii-induced vasculopathy. Cutaneous necrosis and gangrene (Figure 23) might result in amputation of digits or limbs (105). Long-term or persistent disease caused by $R$. rickettsii has not been observed.

\section{Laboratory Findings}

The total white blood cell count is typically normal or slightly increased in patients with RMSF, and increased numbers of immature neutrophils often are observed. Thrombocytopenia, slight elevations in hepatic transaminases (aspartate transaminase and alanine transaminase), and hyponatremia might be present, particularly as the disease advances $(25,77)$; however, laboratory values cannot be relied on to guide early treatment decisions because they are often within or slightly deviated from the reference range early in the course of illness (25). Indicators of diffuse tissue injury, such as elevated levels of creatine kinase or serum lactate dehydrogenase, might be present later in the course 
TABLE 2. Outcome for confirmed cases of Rocky Mountain spotted fever, by day of illness that treatment with doxycycline was started - two tribal communities in eastern Arizona, 2002-2011

\begin{tabular}{|c|c|c|c|c|}
\hline Day (no. of patients)* & $\begin{array}{l}\text { Outpatient } \\
\text { No. (\%) }\end{array}$ & $\begin{array}{c}\text { Hospitalized } \\
\text { No. (\%) }\end{array}$ & $\begin{array}{c}\text { ICU patients among } \\
\text { those hospitalized } \\
\text { No. (\%) }\end{array}$ & $\begin{array}{c}\text { Deaths among hospitalized } \\
\text { and ICU patients } \\
\text { No. (\%) }\end{array}$ \\
\hline Day 1 (6) & $5(83)$ & $1(17)$ & $0(0)$ & $0(0)$ \\
\hline Day 2 (11) & $8(73)$ & $3(27)$ & $0(0)$ & $0(0)$ \\
\hline Day 3 (9) & $4(44)$ & $5(56)$ & $1(11)$ & $0(0)$ \\
\hline Day 4 (7) & $3(43)$ & $4(57)$ & $1(14)$ & $0(0)$ \\
\hline Day 5 (8) & $2(25)$ & $6(75)$ & $4(50)$ & $0(0)$ \\
\hline Day 6 (9) & $0(0)$ & $9(100)$ & $5(55)$ & $3(33)$ \\
\hline Day 7 (11) & $0(0)$ & $11(100)$ & $4(36)$ & $3(27)$ \\
\hline Day 8 (5) & $1(20)$ & $4(80)$ & $2(40)$ & $2(40)$ \\
\hline Day 9 (4) & $0(0)$ & $4(100)$ & $4(100)$ & $2(50)$ \\
\hline
\end{tabular}

Source: Adapted from Regan JJ, Traeger MS, Humpherys D, et al. Risk factors for fatal outcome from Rocky Mountain spotted fever in a highly endemic area-Arizona, 2002-2011. Clin Infect Dis 2015;60:1659-66.

Abbreviation: ICU = intensive care unit.

* Day of illness that treatment was started and the total number of confirmed patients treated on that day.

FIGURE 23. Gangrene of the digits in a patient with late-stage Rocky Mountain spotted fever

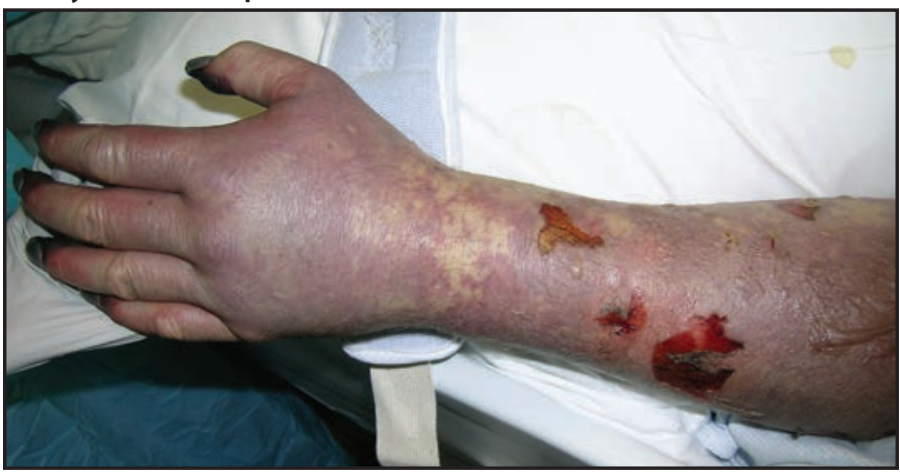

Photo/CDC

of illness. Disseminated intravascular coagulation (DIC) is rare $(125,126)$. When cerebrospinal fluid (CSF) is evaluated, a lymphocytic (or less commonly, neutrophilic) pleocytosis (usually $<100$ cells $/ \mu \mathrm{L}$ ) can be observed (122). CSF protein might be moderately elevated $(100-200 \mathrm{mg} / \mathrm{dL})$, and the glucose level is typically within normal range $(111,127)$.

\section{Rickettsia parkeri Rickettsiosis}

Compared with RMSF, $R$. parkeri rickettsiosis is less severe. Symptoms develop a median of 5 days (range: 2-10 days) after the bite of an infected tick (39). The first manifestation in nearly all patients is an inoculation eschar (a dark, scabbed plaque overlying a shallow ulcer, typically $0.5-2 \mathrm{~cm}$ in diameter), which generally is nonpruritic, nontender or mildly tender, and surrounded by an indurated, erythematous halo and occasionally a few petechiae (Figure 24). The presence of more than one eschar has been described (39). Fever typically develops within a few days of the eschar. Shortly after the onset of fever (approximately 0.5-4 days later), a nonpruritic maculopapular or vesiculopapular rash commonly develops (90\%) (Figure 25). The rash primarily involves the trunk and extremities and might involve the palms and soles in approximately half of patients and the face in $<20 \%$ of patients (39). Other common symptoms include myalgia $(76 \%)$ and headache (86\%). Regional lymphadenopathy is detected in approximately $25 \%$ of patients. Gastrointestinal manifestations, such as nausea or vomiting, are rare $(38,39)$. Mild thrombocytopenia has been observed in $40 \%$, mild leukopenia in $50 \%$, and modest elevation of hepatic transaminase levels in $78 \%$ of cases (39). Hospitalization from $R$. parkeri rickettsiosis occurs in less than one third of patients; no severe manifestations or deaths have been reported. Because the clinical description of $R$. parkeri infection is based on observations from a limited number of cases, the full clinical spectrum of illness is likely incomplete.

\section{Rickettsia Species 364D Rickettsiosis}

The first clinical description of a confirmed case of Rickettsia species 364D infection was published in 2010 (43). Although the full spectrum of illness has yet to be described, 364D infection appears to be characterized by an eschar (Figure 26) or ulcerative skin lesion with regional lymphadenopathy $(43,44)$. Fever, headache, myalgia, and fatigue have occurred among persons with confirmed infection. Rash has not been a notable feature of this illness. Illnesses among the few described patients have been relatively mild and have readily responded to appropriate antimicrobial therapy. 
BOX 3. Summary of clinical features of Rocky Mountain spotted fever and other spotted fever group rickettsioses

- RMSF is the most severe rickettsial illness in the United States.

- Delay in recognition and treatment is the most important factor associated with risk for death from RMSF.

- Early empiric therapy is the best way to prevent RMSF progression and resultant morbidity and mortality.

- The classic triad of fever, rash, and reported tick bite is rarely present when patients with RMSF first seek care.

- Rash is present in most patients during the course of RMSF, although it can appear late or be atypical, localized, faint, evanescent, and difficult to recognize in persons with darker pigmented skin.

- Thrombocytopenia, increased immature neutrophils, elevations in hepatic transaminase levels, and hyponatremia might be present in patients with RMSF; however, laboratory findings are often within or slightly deviated from the reference ranges early in the course of illness.

- Rickettsia parkeri rickettsiosis is typically milder than RMSF, and the first manifestation in nearly all patients is an inoculation eschar.

- The few described cases of Rickettsia species 364D rickettsiosis have involved a relatively mild illness characterized by eschar and regional lymphadenopathy.

$\overline{\text { Abbreviation: } \mathrm{RMSF}}=$ Rocky Mountain spotted fever.

\section{Ehrlichioses}

\section{Ehrlichia chaffeensis Ehrlichiosis (Human Monocytic Ehrlichiosis)}

\section{Pathophysiology}

Ehrlichiae are obligate intracellular bacteria that infect peripheral blood leukocytes. E. chaffeensis, the pathogen that causes human monocytic ehrlichiosis, predominantly infects monocytes and tissue macrophages (Figure 27). The organisms multiply in cytoplasmic membrane-bound vacuoles, forming tightly packed clusters of bacteria called morulae. In patients with fatal E. chaffeensis ehrlichiosis, systemic, multiorgan involvement has been described with the greatest distribution of bacteria in the spleen, lymph nodes, and bone marrow (128). Unlike in RMSF, direct vasculitis and endothelial injury are rare in ehrlichiosis. The host systemic inflammatory response, rather than direct effects of the pathogen, is likely to be largely responsible for many of the clinical manifestations of ehrlichiosis (129).
FIGURE 24. Various appearances of eschars associated with Rickettsia parkeri rickettsiosis

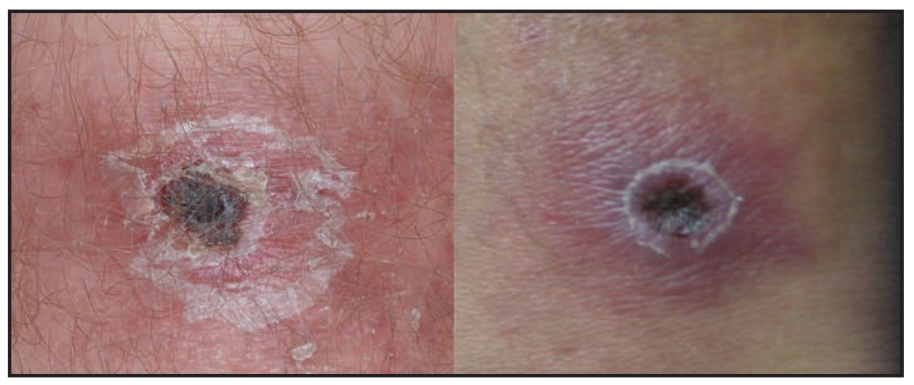

Photos/CDC

FIGURE 25. Vesiculopapular rash associated with Rickettsia parkeri rickettsiosis

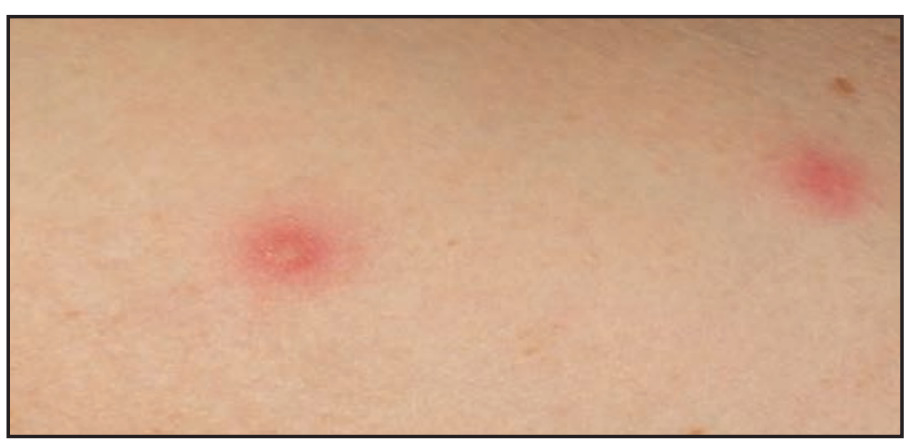

Photo/CDC

\section{Signs and Symptoms}

Symptoms of E. chaffeensis ehrlichiosis typically appear a median of 9 days (range: 5-14 days) after the bite of an infected tick (128). Fever (96\%), headache (72\%), malaise (77\%), and myalgia (68\%) are common signs and symptoms. Gastrointestinal manifestations can be prominent, including nausea (57\%), vomiting (47\%), and diarrhea (25\%) (129131). Abdominal pain, vomiting, and diarrhea might be more common among children (132). Approximately one-third of patients develop a skin rash during the course of illness; rash occurs more frequently in children than in adults. Rash patterns vary in character from petechial or maculopapular $(128,132)$ to diffuse erythema $(133)$ and typically occur a median of 5 days after illness onset (10). The rash typically involves the extremities and trunk but can affect the palms, soles, or face (134). Cough or respiratory symptoms are reported in approximately $28 \%$ of patients and are more common among adults $(10,51,129)$. Central nervous system involvement, such as meningitis or meningoencephalitis, is present in approximately $20 \%$ of patients (135).

Other severe manifestations include ARDS, toxic shocklike or septic shock-like syndromes, renal failure, hepatic failure, coagulopathies, and occasionally, hemorrhagic 
FIGURE 26. Eschar on a patient with Rickettsia species 364D rickettsiosis

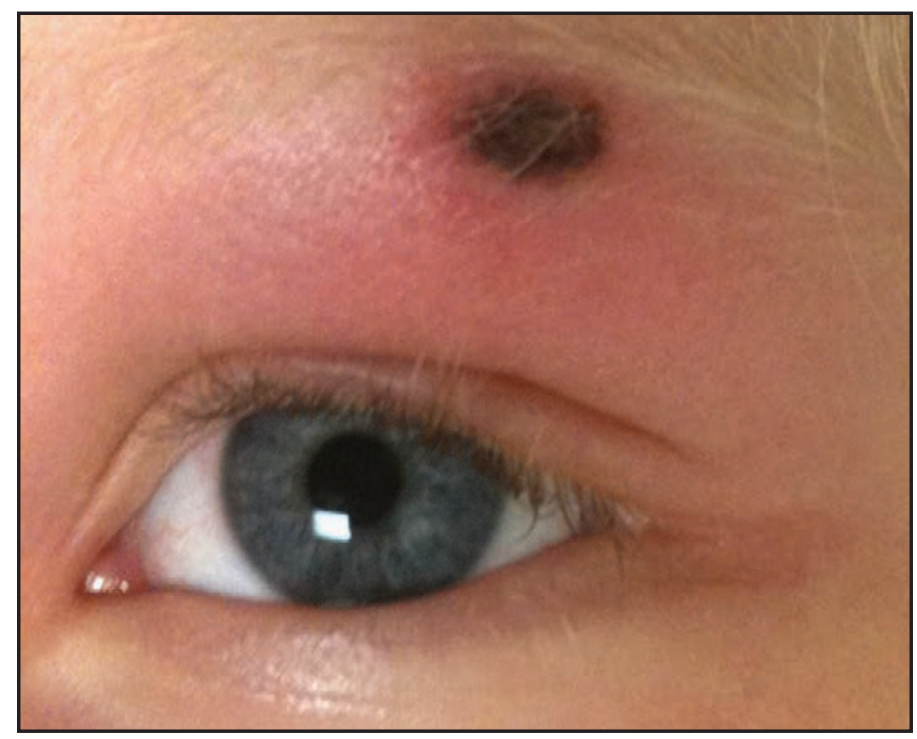

Photo/Samantha H. Johnston, Children's Hospital \& Research Center Oakland

manifestations (133). E. chaffeensis infection might rarely trigger hemophagocytic lymphohistiocytosis (136-140). Severe cases have been mistaken for TTP (141), appendicitis (142), or fulminant viral hepatitis (143). Heartland virus disease, a recently identified tickborne viral infection transmitted by the lone star tick, can closely resemble ehrlichiosis (144).

\section{Clinical Course}

E. chaffeensis ehrlichiosis can cause severe disease or death, although at lower rates than have been observed for RMSF. Approximately $3 \%$ of patients with symptoms severe enough to seek medical attention die from the infection $(51,128)$. The severity of ehrlichiosis could be related, in part, to host factors such as age and the immune status of the patient. Persons who have compromised immune systems as a result of immunosuppressive therapies, human immunodeficiency virus (HIV) infection $(145,146)$, organ transplantation $(147,148)$, or splenectomy more frequently have severe symptoms of ehrlichiosis and are hospitalized more often (13). Case-fatality rates among persons who are immunosuppressed are higher than those among the general population, on the basis of U.S. passive surveillance and some case series $(5,13,145)$; delays in recognition and initiation of appropriate antibacterial treatment in this population might contribute to increased mortality (149). Although older age ( $\geq 60$ years) and immunosuppression are risk factors for severe ehrlichiosis $(5,10,13)$, many cases of severe or fatal ehrlichiosis have been described in previously healthy children and young adults (128). Pediatric patients frequently have an asymptomatic or a mild infection $(51,128,132)$; however, children aged $<10$ years
FIGURE 27. Immunohistochemical stain demonstrating Ehrlichia chaffeensis morulae (red) within monocytes in the kidney of a patient with ehrlichiosis

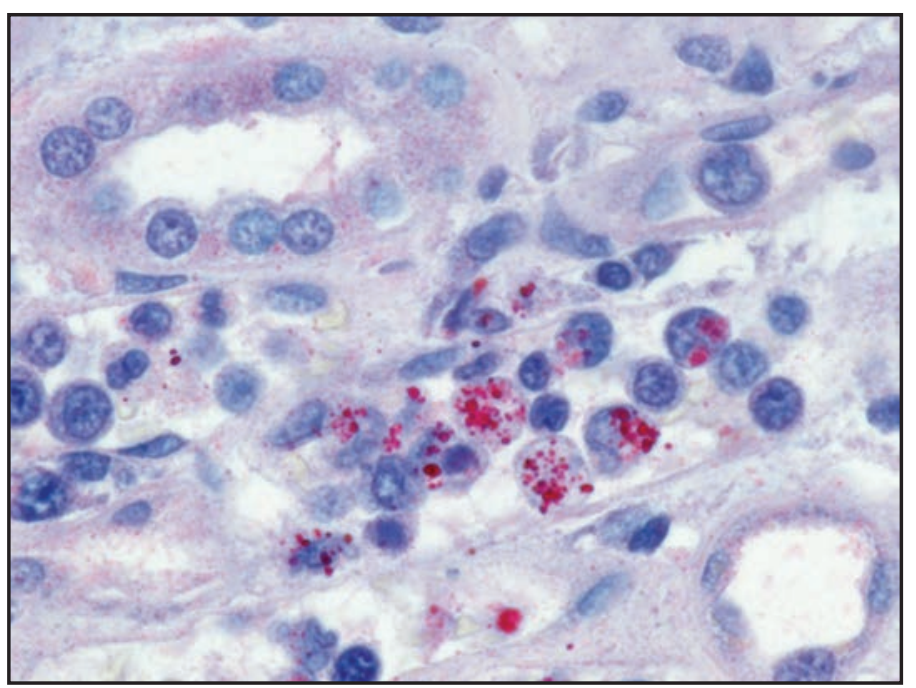

Photo/CDC

have the highest case-fatality rate among passively reported cases $(5,13)$. Receiving a sulfonamide antimicrobial agent might also predispose to severe ehrlichial illness (150-153). Confirmed reinfection with $E$. chaffeensis has been described in an immunosuppressed patient; however, the frequency of reinfection in immunocompetent persons is unknown (154).

\section{Laboratory Findings}

Characteristic laboratory findings in the first week of E. chaffeensis ehrlichiosis include leukopenia (nadir usually 1,300-4,000 cells/ $\mu \mathrm{L}$ ) (129), thrombocytopenia (nadir usually $50,000-140,000$ platelets/ $\mu \mathrm{L}$, although occasionally $<20,000$ platelets $\mu \mathrm{L}$ ), and mildly or moderately elevated levels of hepatic transaminases. Anemia occurs later in clinical illness and is reported in 50\% of patients (129). Mild-to-moderate hyponatremia might also be present (128). During the recovery period, a relative and absolute lymphocytosis is seen in most patients (155). In some cases, pancytopenia due to ehrlichiosis has prompted bone marrow aspirate and biopsy, which typically reveals normocellular or hypercellular marrow $(128,156)$. In some patients, morulae might be observed in monocytes in peripheral blood (157) (Figure 28) and occasionally in CSF $(158,159)$ or bone marrow. In this context, a routine blood smear can provide a presumptive clue for early diagnosis; however, the visualization of morulae still requires confirmatory diagnostic testing (see Confirmatory Diagnostic Tests). When CSF is evaluated, a lymphocytic pleocytosis is most commonly observed, although neutrophilic pleocytosis also can occur $(128,135)$. CSF white blood cell counts are typically 
FIGURE 28. Wright stain of peripheral blood smears showing an intramonocytic morula associated with Ehrlichia chaffeensis infection (left) and an intragranulocytic morula (right), such as associated with Ehrlichia ewingii or Anaplasma phagocytophilum infection

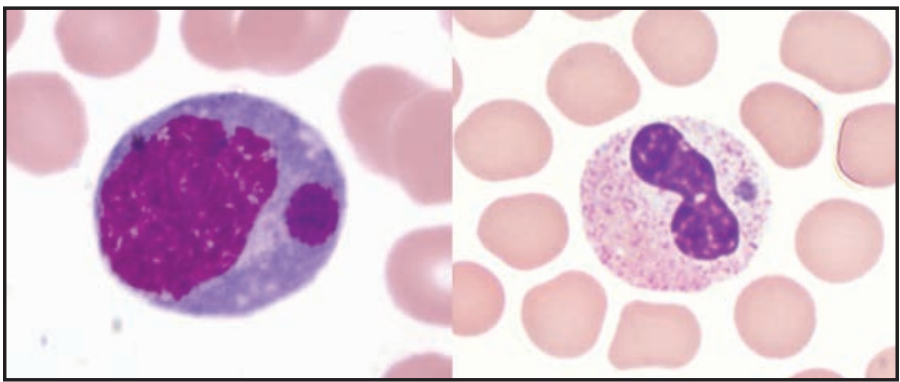

Photos/J. Stephen Dumler, University of Maryland (left); Bobbi S. Pritt, Mayo Clinic (right)

$<250$ cells $/ \mu \mathrm{L}$ but can be higher in children $(128,135,158)$. Elevated CSF protein levels are common (135).

\section{Ehrlichia ewingii Ehrlichiosis}

Clinical manifestations of E. ewingii ehrlichiosis are similar to $E$. chaffeensis ehrlichiosis and include fever, headache, malaise, and myalgia. Gastrointestinal symptoms have been described less commonly in E. ewingii ehrlichiosis, and rash is rare. Fewer severe manifestations have been reported with E. ewingii than with E. chaffeensis ehrlichiosis (145), and no deaths have been described. Although E. ewingii infection has been considered more common in persons who are immunosuppressed (149), recent passive surveillance data indicated that most $(74 \%)$ reported cases were not in persons with documented immunosuppression (5). Similar to E. chaffeensis ehrlichiosis, patients with E. ewingii ehrlichiosis commonly have leukopenia, thrombocytopenia, and elevated hepatic transaminase levels. E. ewingii has a predilection for granulocytes, and morulae might be observed in granulocytes during examination of a blood smear, bone marrow, or CSF $(48,160)$ (Figure 28).

\section{Ehrlichia muris-Like Agent Ehrlichiosis}

EML agent ehrlichiosis is associated with fever (87\%), malaise (76\%), headache (67\%), and myalgia (60\%) $(49,61)$. Rash is reported in $12 \%$ of described cases (61). Symptomatic EML agent ehrlichiosis might be more common among persons who are immunosuppressed. No fatal cases have been reported to date. Thrombocytopenia (67\%), lymphopenia (53\%), leukopenia $(39 \%)$, elevated levels of hepatic transaminases (78\%), and anemia (36\%) are described (61). Morulae have not been observed yet in peripheral blood cells of patients infected with the EML agent.
BOX 4. Summary of clinical features of ehrlichioses

- Symptoms of Ehrlichia chaffeensis ehrlichiosis typically include fever, headache, malaise, myalgia, and gastrointestinal symptoms.

- With E. chaffeensis ehrlichiosis, rash is present in approximately one third of patients but is more common among children than among adults.

- Neurologic manifestations are reported for approximately $20 \%$ of patients with $E$. chaffeensis ehrlichiosis.

- Increased severity of $E$. chaffeensis ehrlichiosis has been associated with increased age ( $\geq 60$ years) and immunosuppression.

- Leukopenia, thrombocytopenia, and elevated hepatic transaminase levels are characteristic laboratory findings in the first week of $E$. chaffeensis ehrlichiosis.

- E. chaffeensis has a predilection for mononuclear phagocytic cells, and morulae might be observed in monocytes of the blood, CSF, or bone marrow phagocytes.

- Ehrlichia ewingii ehrlichiosis has similar clinical features as E. chaffeensis ehrlichiosis; however, rash and gastrointestinal symptoms are less common.

- E. ewingii has a predilection for granulocytes, and morulae might be observed in granulocytes of the blood, CSF, or bone marrow.

- Signs and symptoms of EML agent ehrlichiosis are similar to those of E. ewingii ehrlichiosis.

- EML agent ehrlichiosis has recently been described, and the target cell type is not known.

- The case-fatality rate for $E$. chaffeensis ehrlichiosis is approximately 3\%; no deaths from E. ewingii or EML agent ehrlichiosis have been reported.

$\overline{\text { Abbreviations: } \mathrm{CSF}}=$ cerebrospinal fluid; $\mathrm{EML}=$ Ehrlichia muris-like.

\section{Anaplasmosis}

\section{Anaplasma phagocytophilum (Human Granulocytic Anaplasmosis)}

\section{Pathophysiology}

A. phagocytophilum is an obligate, intracellular bacterium that is found predominantly within granulocytes. Similar to ehrlichiae, anaplasmae multiply in cytoplasmic membrane-bound vacuoles as microcolonies called morulae. Infection with $A$. phagocytophilum induces a systemic inflammatory response, which is thought to be the mechanism for tissue damage in anaplasmosis (161). Altered host neutrophil function occurs with $A$. phagocytophilum infection 
and could result in host neutrophils being ineffective at regulating inflammation or microbicidal activity (161).

\section{Signs and Symptoms}

Symptoms of anaplasmosis typically appear 5-14 days after the bite of an infected tick and usually include fever (92\%-100\%), headache (82\%), malaise (97\%), myalgia (77\%), and shaking chills (129). Rash is present in $<10 \%$ of patients, and compared with E. chaffeensis ehrlichiosis and RMSF, gastrointestinal symptoms are less frequent and central nervous system involvement is rare $(129,162)$. Patients with anaplasmosis typically seek medical care later in the course of illness (4-8 days after onset) than patients with other tickborne rickettsial diseases $(2-4$ days after onset) $(8,163)$.

\section{Clinical Course}

In most cases, anaplasmosis is a self-limiting illness. Severe or life-threatening manifestations are less frequent with anaplasmosis than with RMSF or E. chaffeensis ehrlichiosis; however, ARDS, peripheral neuropathies, DIC-like coagulopathies, hemorrhagic manifestations, rhabdomyolysis, pancreatitis, and acute renal failure have been reported. Severe anaplasmosis can also resemble toxic shock syndrome, TTP (164), or hemophagocytic syndromes (165). Serious and fatal opportunistic viral and fungal infections during the course of anaplasmosis infection have been described $(166,167)$. Although the case-fatality rate among patients who seek health care for anaplasmosis is $<1 \%$, approximately $7 \%$ of hospitalized patients require admission to the intensive care unit $(13,166,168)$. Predictors of a more severe course of anaplasmosis include advanced patient age, immunosuppression, comorbid medical conditions such as diabetes, and delay in diagnosis and treatment $(13,168)$.

\section{Laboratory Findings}

Characteristic laboratory findings in anaplasmosis include thrombocytopenia, leukopenia, elevated hepatic transaminase levels, increased numbers of immature neutrophils, and mild anemia (169). Similar to ehrlichiosis, lymphocytosis can be present during the recovery period (170). CSF evaluation typically does not reveal any abnormalities (168). Blood smear examination might reveal morulae within granulocytes (Figure 28) (see Confirmatory Diagnostic Tests). Bone marrow is usually normocellular or hypercellular in acute anaplasmosis, and morulae might be observed $(161,166,171)$.

\section{Coinfections of Anaplasma with Other Tickborne Pathogens}

The tick vector responsible for $A$. phagocytophilum transmission in the eastern United States, I. scapularis, also transmits nonrickettsial pathogens in certain geographic areas, including
Borrelia burgdorferi, Babesia microti, Borrelia miyamotoi, and deer tick virus (Powassan virus, lineage II). Simultaneous infections with $A$. phagocytophilum and B. burgdorferi or B. microti have occurred $(69-71,172)$. Confirmed Anaplasma coinfection has been reported in $<10 \%$ of patients with Lyme disease $(69,70,172)$.

Response to treatment can provide clues to possible coinfection. For example, anaplasmosis should respond readily to treatment with doxycycline. If the clinical response is delayed, coinfection or an alternative infection might be considered in the appropriate epidemiologic setting (173-175). Conversely, if Lyme disease is treated with a beta-lactam antibacterial drug in a patient with unrecognized A. phagocytophilum coinfection, symptoms of anaplasmosis could persist $(70,173)$. Leukopenia or thrombocytopenia in a patient with Lyme disease should raise clinical suspicion for possible coinfection with $A$. phagocytophilum (173).

\section{BOX 5. Summary of clinical features of anaplasmosis}

- Patients with anaplasmosis typically have fever, headache, and myalgia; rash is rare.

- The case-fatality rate for anaplasmosis is $<1 \%$.

- Serious and fatal opportunistic viral and fungal infections have occurred during the course of anaplasmosis.

- Leukopenia, thrombocytopenia, elevated hepatic transaminase levels, and mild anemia are characteristic laboratory findings in anaplasmosis.

- Anaplasma phagocytophilum has a predilection for granulocytes, and blood smear or bone marrow examination might reveal morulae within these cells.

- The tick vector that transmits $A$. phagocytophilum also transmits other pathogens, and coinfections with Borrelia burgdorferi or Babesia microti have been described.

\section{Differential Diagnosis of Fever and Rash}

The differential diagnosis of fever and rash is broad $(176,177)$ (Box 6), and during the early stages of illness, tickborne rickettsial diseases can be clinically indistinguishable from many viral exanthemas and other illnesses, particularly in children. Tickborne rickettsial diseases can be mistaken for viral gastroenteritis, upper respiratory tract infection, pneumonia, urinary tract infection, nonrickettsial bacterial sepsis, TTP, idiopathic vasculitides, or viral or bacterial meningoencephalitides $(104,129)$. Despite nonspecific initial symptoms of tickborne rickettsial diseases (e.g., fever, malaise, and headache), early consideration in the differential diagnosis and empiric treatment is critical in preventing poor outcomes, especially for RMSF, which progresses rapidly without treatment. The dermatologic classification of the rash, 
its distribution, pattern of progression, and timing relative to onset of fever, and other systemic signs provide clues to help guide the differential diagnosis. A complete blood count, peripheral blood smear, and routine chemistry and hepatic function panels also can be helpful in guiding the differential diagnosis. Epidemiologic clues (e.g., season, tick bite history, travel, outdoor activities, exposure to pets or other animals, and exposures or risk factors relevant to diagnoses other than tickborne rickettsial diseases) might prove useful. Other lifethreatening illnesses that can have signs and symptoms that are similar to those of tickborne rickettsial diseases, such as meningococcemia, are important to recognize, consider in the initial differential diagnosis, and treat empirically pending further diagnostic evaluation.

\section{Treatment and Management}

Doxycycline is the drug of choice for treatment of all tickborne rickettsial diseases in patients of all ages, including children aged $<8$ years, and should be initiated immediately in persons with signs and symptoms suggestive of rickettsial disease $(8,178-180)$ (Box 7). Diagnostic tests for rickettsial diseases, particularly for RMSF, are usually not helpful in making a timely diagnosis during the initial stages of illness. Treatment decisions for rickettsial pathogens should never be delayed while awaiting laboratory confirmation. Delay in treatment can lead to severe disease and long-term sequelae or death $(74,116,181)$.

A thorough clinical history, physical examination, and laboratory results (e.g., complete blood count with differential leukocyte count, hepatic transaminase levels, and serum sodium level) collectively guide clinicians in developing a differential diagnosis and treatment plan. Because of the nonspecific signs and symptoms of tickborne rickettsial diseases, early empiric treatment for rickettsial diseases often needs to be administered concomitantly with empiric treatment for other conditions in the differential diagnosis. For example, for a patient in whom meningococcal disease and tickborne rickettsial disease are being considered, administering antibacterial therapy to treat potential Neisseria meningitidis infection in addition to administering doxycycline to treat rickettsial agents is appropriate while awaiting additional diagnostic information.

The recommended dose of doxycycline for the treatment of tickborne rickettsial diseases is $100 \mathrm{mg}$ twice daily (orally or intravenously) for adults and $2.2 \mathrm{mg} / \mathrm{kg}$ body weight twice daily (orally or intravenously) for children weighing $<100 \mathrm{lbs}$ (45 kg) (8) (Table 3). Oral therapy is appropriate for patients with early stage disease who can be treated as outpatients. Intravenous therapy might be indicated for more severely ill patients who require hospitalization, particularly in patients who are vomiting or obtunded. The recommended duration of therapy for RMSF and ehrlichiosis is at least 3 days after subsidence of fever and until evidence of clinical improvement

BOX 6. Selected conditions other than tickborne rickettsial diseases that can result in acute illness with fever and rash

\begin{tabular}{|c|c|c|}
\hline Bacterial infections & Viral infections & Other conditions \\
\hline Meningococcemia* & Hand, foot, and mouth disease* & Drug eruptions* \\
\hline Secondary syphilis* & Roseola & Kawasaki disease* \\
\hline Disseminated gonococcal infection* & Measles & Thrombotic thrombocytopenic purpura \\
\hline Bacterial endocarditis* & Rubella & Immune thrombocytopenic purpura \\
\hline Scarlet fever & Mononucleosis & Immune complex vasculitis \\
\hline Rat bite fever* & Acute (primary) HIV infection & Toxic shock syndrome* \\
\hline Lyme disease & Cytomegalovirus infection & Erythema multiforme* \\
\hline Relapsing fever & Human parvovirus B19 infection & Stevens-Johnson syndrome* \\
\hline Leptospirosis & Chickenpox & \\
\hline Murine typhus & Colorado tick fever & \\
\hline Rickettsialpox & West Nile virus disease & \\
\hline Sylvatic and epidemic typhus & Chikungunya virus disease & \\
\hline Scrub typhus & Dengue fever & \\
\hline Capnocytophaga canimorsus infection & Zika virus disease & \\
\hline Mycoplasma pneumoniae infection & Viral hemorrhagic fevers & \\
\hline \multicolumn{3}{|l|}{ Typhoid and paratyphoid fevers } \\
\hline
\end{tabular}


Recommendations and Reports

TABLE 3. Recommended treatment for tickborne rickettsial diseases

\begin{tabular}{|c|c|c|c|c|}
\hline Age category & Drug & Dosage & Maximum & Duration \\
\hline Adults* & Doxycycline & $100 \mathrm{mg}$ twice per day, orally or IV & $100 \mathrm{mg}$ per dose & \multirow{2}{*}{$\begin{array}{l}\text { At least } 3 \text { days after fever } \\
\text { subsides and until evidence } \\
\text { of clinical improvement is } \\
\text { noted; minimum treatment } \\
\text { course of 5-7 days }{ }^{\dagger}\end{array}$} \\
\hline Children weighing $<100 \mathrm{lbs}$ ( $45 \mathrm{~kg}$ ) & Doxycycline & $\begin{array}{l}2.2 \mathrm{mg} / \mathrm{kg} \text { of body weight per dose } \\
\text { twice per day, orally or IV }\end{array}$ & $100 \mathrm{mg}$ per dose & \\
\hline
\end{tabular}

Source: CDC, Division of Vector-Borne Diseases. Tickborne diseases of the United States, a reference manual for health care providers. 3rd ed. Atlanta, GA: US Department of Health and Human Services, CDC; 2015. http://www.cdc.gov/lyme/resources/tickbornediseases.pdf

Abbreviation: IV = intravenously.

* Guidance is available for the treatment of suspected tickborne rickettsial disease during pregnancy (see Pregnancy and Lactation).

${ }^{\dagger}$ Treatment for patients with anaplasmosis should be extended to 10 days if concurrent Lyme disease is suspected, or alternatively, another antimicrobial with efficacy against Borrelia burgdorferi should be included.

is noted $(8,180,182,183)$; typically the minimum total course of treatment is 5-7 days. Severe or complicated disease could require longer treatment courses. Patients with anaplasmosis should be treated with doxycycline for 10 days to provide appropriate length of therapy for possible coinfection with B. burgdorferi (173). Children aged $<8$ years with anaplasmosis in whom concurrent Lyme disease is not suspected can be treated for a duration similar to that for other tickborne rickettsial diseases $(173,183)$.

Fever typically subsides within 24-48 hours after treatment when the patient receives doxycycline in the first 4-5 days of illness. Lack of a clinical response within 48 hours of early treatment with doxycycline could be an indication that the condition is not a tickborne rickettsial disease, and alternative diagnoses or coinfection should be considered. Severely ill patients might require $>48$ hours of treatment before clinical improvement is noted, especially if they have multiple organ dysfunction.

Patients with evidence of organ dysfunction, severe thrombocytopenia, mental status changes, or the need for supportive therapy should be hospitalized. Other important considerations for hospitalization include social factors, the likelihood that the patient can and will take oral medications, and existing comorbid conditions, including the patient's immune status. Certain patients with tickborne rickettsial disease can be treated on an outpatient basis with oral medication, particularly if a reliable caregiver is available in the home and the patient adheres to follow-up medical care. A critical step is for clinicians to keep in close contact with patients who are treated as outpatients to ensure that they are responding to therapy as expected. Similarly, if a 24-hour watch-and-wait approach is taken with a febrile patient who otherwise appears well and has no obvious history of tick bite or exposure, a normal physical examination, and laboratory findings within reference ranges, ensuring close patient follow-up is essential. Patients should be monitored closely because of the potential for rapid decline in untreated patients with tickborne rickettsial diseases, especially among those with RMSF.

Management of severely ill patients with tickborne rickettsial disease should include assessment of fluid and electrolyte balance. Vasopressors and careful fluid management might be needed when the illness is complicated by hypotension or renal failure. Patients with RMSF can develop ARDS or pulmonary infiltrates related to microvascular leakage that might be erroneously attributed to cardiac failure or pneumonia (184). Consultation with an intensive care or infectious disease specialist could be helpful in managing these complications.

\section{Doxycycline in Children}

The American Academy of Pediatrics and CDC recommend doxycycline as the treatment of choice for children of all ages with suspected tickborne rickettsial disease $(8,178)$. Previous concerns about tooth staining in children aged $<8$ years stem from experience with older tetracycline-class drugs that bind more readily to calcium than newer members of the drug class, such as doxycycline (185). Doxycycline used at the dose and duration recommended for treatment of RMSF in children aged $<8$ years, even after multiple courses, did not result in tooth staining or enamel hypoplasia in a 2013 retrospective cohort study of 58 children who received doxycycline before the age of 8 years, compared with 213 children who had not received doxycycline (186). These results support the findings of a study published in 2007 reporting no evidence of tooth staining among 31 children with asthma exacerbation who were treated with doxycycline (187). Combined data from these two studies indicate a tooth staining prevalence rate of $0 \%$ (none of the 89 patients; 95\% confidence interval [CI]: 0\%-3\%) among those treated with short courses of doxycycline before age 8 (186).

The use of doxycycline to treat children with suspected tickborne rickettsial disease should no longer be a subject of controversy (186-188). Nonetheless, recent surveys of health care providers revealed that most $(61 \%-65 \%)$ practicing 
primary care providers did not recognize doxycycline as the appropriate treatment for suspected RMSF in children aged $<8$ years (189-191). During 1999-2012, children aged $<10$ years were five times more likely than older children and adults to die from RMSF (4,116). A similar finding also has been observed among children aged $<5$ years with ehrlichiosis (5). These data suggest that inappropriate or delayed RMSF treatment decisions might be contributing to disproportionately high RMSF case-fatality rates among young children.

\section{Alternative Antibacterial Agents to Doxycycline}

Tetracyclines, including doxycycline, are the only antibacterial agents recommended for treatment of all tickborne rickettsial diseases. Chloramphenicol is the only alternative drug that has been used to treat RMSF; however, epidemiologic studies using CDC case report data suggest that patients with RMSF treated with chloramphenicol are at higher risk for death than persons who received a tetracycline $(9,75)$. Chloramphenicol is no longer available in the oral form in the United States, and the intravenous form is not readily available at all institutions. Chloramphenicol is associated with adverse hematologic effects, which have resulted in its limited use in the United States, and monitoring of blood indices is required if this drug is used $(192,193)$. In vitro evidence indicates that chloramphenicol is not effective in the treatment of ehrlichiosis or anaplasmosis (194,195). Therefore, if chloramphenicol is substituted for doxycycline in the empiric treatment of tickborne rickettsial diseases, ehrlichiosis and anaplasmosis will not be covered and RMSF treatment might be suboptimal.

Rifamycins demonstrate in vitro activity against $E$. chaffeensis and A. phagocytophilum $(194,195)$. Case reports document favorable maternal and pregnancy outcomes in small numbers of pregnant women treated with rifampin for anaplasmosis (196-198). Small numbers of children also have been treated successfully for anaplasmosis using rifampin (199); however, no clinical trials demonstrating in vivo efficacy of rifampin in the treatment of anaplasmosis or ehrlichiosis have been conducted. Rifampin could be an alternative for the treatment of mild illness due to anaplasmosis in the case of pregnancy or documented allergy to tetracycline-class drugs (173). The dose of rifampin is $300 \mathrm{mg}$ orally twice daily for adults or $10 \mathrm{mg} / \mathrm{kg}$ of body weight for children (not to exceed $300 \mathrm{mg} / \mathrm{dose}$ ) (162,173). Before considering treatment with rifampin, clinicians should use caution and ensure that RMSF can be ruled out because the early signs and symptoms of RMSF and anaplasmosis are similar, and rifampin is not considered an acceptable treatment for RMSF. In addition, rifampin does not effectively treat potential coinfection of $A$. phagocytophilum with B. burgdorferi (173).

Many classes of broad-spectrum antibacterial agents that are used empirically to treat febrile patients, such as betalactams, macrolides, aminoglycosides, and sulfonamides, are not effective against tickborne rickettsial diseases $(18,77)$. Although some fluoroquinolones have in vitro activity against rickettsiae (200), their use for treatment of certain rickettsial infections has been associated with delayed subsidence of fever, increased disease severity, and longer hospital stay $(201,202)$. No human efficacy data on fluoroquinolone use in RMSF exist, and fluoroquinolones are not recommended for treatment of RMSF (77). E. chaffeensis exhibits in vitro resistance to fluoroquinolones. Although A. phagocytophilum is susceptible to levofloxacin in vitro $(195,203)$, relapse of infection after treatment with levofloxacin has been reported (204), and, as with the other tickborne rickettsial diseases, fluoroquinolones are not recommended for treatment of anaplasmosis (173).

Sulfonamide antimicrobials are associated with increased severity of tickborne rickettsial diseases. Experimental and accumulated anecdotal clinical data suggest that treatment of patients with RMSF with a sulfonamide drug can result in increased disease severity and death $(119,120)$. Cases of severe ehrlichiosis also have been associated with the use of trimethoprim-sulfamethoxazole (150-153). In some patients treated with sulfonamide or beta-lactam drugs, diagnosis and appropriate treatment of tickborne rickettsial illness was delayed because the development of a rash was mistaken for a drug eruption rather than recognized as a manifestation of rickettsial illness (205).

\section{Doxycycline Allergy}

Severe doxycycline or tetracycline allergy in a patient with a suspected tickborne rickettsial disease poses a challenge because of the lack of equally effective alternative antimicrobial agents. In a patient reporting an allergy to a tetracycline-class drug, determining the type of adverse drug reaction and whether it is potentially life threatening (e.g., anaphylaxis or StevensJohnson syndrome) by history or medical documentation is important. Consultation with an allergy and immunology specialist could be helpful in making this determination. In patients with non-life-threatening tetracycline-class drug reactions, administering doxycycline in an observed setting is an option; however, the risks and benefits should be evaluated on a case-by-case basis. In patients with a life-threatening tetracycline allergy, options include use of alternative antibacterial agents discussed in the preceding section or, possibly for immediate hypersensitivity reactions, rapid doxycycline desensitization in consultation with an 
allergy and immunology specialist. Anaphylactic reactions to tetracycline-class drugs, although rare, have been reported $(206,207)$. Rapid doxycycline desensitization accomplished within several hours in an inpatient intensive care setting in patients with a history of immediate hypersensitivity reactions (including anaphylaxis) has been described (206,208); however, data are limited to individual case reports.

\section{Pregnancy and Lactation}

Use of tetracycline-class drugs has generally been contraindicated during pregnancy because of concerns about potential risk to the musculoskeletal development of the fetus, cosmetic staining of primary dentition in fetuses exposed during the second or third trimester, and development of acute fatty liver of pregnancy in the mother (209-213). Although these adverse effects were observed in association with the use of tetracycline and older tetracycline derivatives, the contraindication for use during pregnancy has been applied across the class of tetracyclines, which includes newer derivatives, such as doxycycline. Controlled studies to assess the safety of doxycycline use in pregnant women have not been conducted, and available data are primarily observational. An expert review on doxycycline use during pregnancy concluded that therapeutic doses were unlikely to pose a substantial teratogenic risk; however, the data were insufficient to conclude that no risk exists $(214,215)$. The risk for cosmetic staining of the primary teeth by doxycycline could not be determined because of limited data (214). A recent systematic review reported no evidence of teratogenicity associated with doxycycline use during pregnancy; however, limited data and a lack of controlled studies were limitations (216). No reports of maternal hepatic toxicity associated with doxycycline use have been published (215-217). Rarely, fatty liver of pregnancy has occurred in patients who received high-dose intravenous tetracycline $(215,218)$; however, the dosages administered in these cases exceeded what is recommended for the treatment of tickborne rickettsial disease.

Only limited clinical data exist that support the use of antibacterial agents other than doxycycline in the treatment of tickborne rickettsial disease during pregnancy. Doxycycline has been used successfully to treat tickborne rickettsial diseases in several pregnant women without adverse effects to the mother; however, follow-up to address adverse effects to the fetus was limited $(142,197)$. Chloramphenicol is a potential alternative treatment for RMSF during pregnancy; however, care must be used when administering the drug late during the third trimester of pregnancy because of the theoretical risk for gray baby syndrome $(193,217)$.
Chloramphenicol is not an alternative for the treatment of ehrlichiosis or anaplasmosis $(194,195)$. Limited case report data suggest that rifampin could be considered an alternative to doxycycline for the treatment of mild anaplasmosis during pregnancy $(173,196,197)$. Patient counseling and discussion of potential risks versus benefits with the pregnant woman by the health care provider are important components in treatment decision-making during pregnancy; nonetheless, for potentially life-threatening illnesses, such as RMSF and E. chaffeensis ehrlichiosis, consideration of disease-related risks for the mother and fetus is of paramount importance.

Doxycycline is excreted into breast milk at low levels; however, the extent of absorption by nursing infants is unknown. Short-term use of doxycycline as recommended for the treatment of tickborne rickettsial disease is considered probably safe during lactation on the basis of available literature and expert opinion (219). Although doxycycline is not specifically addressed, tetracycline is listed by the American Academy of Pediatrics Committee on Drugs as "usually compatible with breastfeeding" (220).

\section{Preventive Therapy After Tick Bite}

Studies of preventive antibacterial therapy for rickettsial infection in humans are limited. Available data (221) do not support prophylactic treatment for rickettsial diseases in persons who have had recent tick bites and are not ill.

\section{Treatment of Asymptomatic Persons Seropositive for Tickborne Rickettsial Diseases}

Treatment of asymptomatic persons seropositive for tickborne rickettsial diseases is not recommended regardless of past treatment status. Antirickettsial antibodies can persist in the absence of clinical disease for months to years after primary infection; therefore, serologic tests cannot be used to monitor response to treatment for tickborne rickettsial diseases $(222-224)$. 
BOX 7. Summary of the treatment and management of tickborne rickettsial diseases

- Doxycycline is the drug of choice for treatment of all tickborne rickettsial diseases in children and adults; empiric therapy should be initiated promptly in patients with a clinical presentation suggestive of a rickettsial disease.

- Tickborne rickettsial diseases respond rapidly to doxycycline, and fever persisting for $>48$ hours after initiation of therapy should prompt consideration of an alternative or additional diagnosis, including the possibility of coinfection.

- Doxycycline is recommended by the American Academy of Pediatrics and CDC as the treatment of choice for patients of all ages, including children aged $<8$ years, with a suspected tickborne rickettsial disease.

- Delay in treatment of tickborne rickettsial diseases can lead to severe disease and death.

- In persons with severe doxycycline allergy or who are pregnant, chloramphenicol may be an alternative treatment for Rocky Mountain spotted fever; however, persons treated with chloramphenicol have a greater risk for death compared with those treated with doxycycline.

- Chloramphenicol is not an acceptable alternative for the treatment of ehrlichiosis or anaplasmosis.

- For mild cases of anaplasmosis, rifampin might be an alternative to doxycycline for patients with a severe drug allergy or who are pregnant.

- Data on the risks of doxycycline use during pregnancy suggest that treatment at the recommended dose and duration for tickborne rickettsial diseases is unlikely to pose a substantial teratogenic risk; however, data are insufficient to state that no risk exists.

- Prophylactic use of doxycycline after a tick bite is not recommended for the prevention of tickborne rickettsial diseases.

- Treatment of asymptomatic persons seropositive for tickborne rickettsial disease is not recommended, regardless of past treatment status, because antibodies can persist for months to years after infection.

\section{Special Considerations}

\section{Transfusion- and Transplant-Associated Transmission}

\section{Blood Product Transfusion}

Transmission of $R$. rickettsii, $A$. phagocytophilum, and E. ewingii via transfusion of infected blood products has been reported infrequently. E. chaffeensis, EML agent, $R$. parkeri, and Rickettsia species $364 \mathrm{D}$ transmission via infected blood products has not been documented in the United States. Infected donors who are asymptomatic or in the presymptomatic period, defined as the period of rickettsemia before the onset of symptoms, pose the greatest risk to the blood supply (225). For example, in the single documented transfusion-acquired case of $R$. rickettsii, the blood donation occurred 3 days before the onset of symptoms in the donor (226). Potential donors with symptomatic rickettsial disease pose less risk because they are likely to be identified by the routine screening for symptomatic infections that is already in place as part of the blood donation process.

Among tickborne rickettsial diseases, anaplasmosis is the most frequently associated with transfusion-acquired infection, with eight published reports from the United States (198,227-232). Transmission of A. phagocytophilum despite leukoreduction of red blood cells and platelets has occurred $(227,228,231,232)$. Transmission of $E$. ewingii infection via leukoreduced, irradiated platelet transfusion also has been reported (233). Although the risk for transmission of certain rickettsial pathogens might be reduced by leukoreduction of blood products (234), the risk for transfusion-acquired infection is not eliminated $(227,228,231,233,235)$. In vitro studies demonstrate that $A$. phagocytophilum and E. chaffeensis survive in refrigerated packed erythrocytes for up to 18 and 11 days, respectively (236,237). Transfusion-acquired $R$. rickettsii infection, reported in 1978, was transmitted in whole blood stored for 9 days (226).

Transfusion-associated transmission is of special concern for persons who are immune suppressed, such as those undergoing chemotherapy, solid organ transplantation, or stem cell transplantation; these persons are at greater risk for severe or fatal outcomes from tickborne rickettsial diseases. No practical screening method has been identified to prevent asymptomatic donors infected with tickborne rickettsiae from donating blood products. Suspected transfusion-associated transmission of a rickettsial disease should be reported as early as possible to the blood product supplier and public health authorities. Early reporting is essential in facilitating timely tracking and quarantining of potentially infectious co-components and notification of the infected donor and blood product recipients. In addition, if a recent blood donor develops symptoms of a tickborne rickettsial disease, the blood bank should be notified so that donated blood can be appropriately quarantined or recalled.

\section{Solid Organ Transplantation}

Two cases of transplant-acquired ehrlichiosis associated with a common deceased donor have been reported (238). Both renal allograft recipients, 20-22 days after transplantation, 
developed an acute febrile illness with rapid clinical deterioration characterized by delirium, new or progressive cytopenias, and renal failure. An extensive infectious disease workup in one recipient led to detection by polymerase chain reaction (PCR) amplification of E. chaffeensis DNA in peripheral blood. Ehrlichiosis was suspected in the second renal allograft recipient after communication with the care team of the other recipient. Transmission of tickborne rickettsial infections through solid organ transplantation is possible (238) and is important to consider during the assessment of early transplant recipients with undifferentiated febrile illness or sepsis syndromes characterized by thrombocytopenia or leukopenia. In this context, a donor from a region highly endemic for tickborne rickettsial diseases with an appropriate epidemiologic history could support clinical suspicion for a donor-transmitted tickborne rickettsial disease.

\section{Travel Outside of the United States}

International travel can pose a risk for infection with rickettsial pathogens not encountered in the United States (Appendix A). SFG rickettsioses are the most commonly diagnosed tickborne rickettsial diseases among returning travelers (239). The most frequently occurring among these are African tick bite fever, caused by Rickettsia africae, and Mediterranean spotted fever (also known as boutonneuse fever), caused by Rickettsia conorii $(240,241)$. Approximately 90\% of imported SFG rickettsioses occur among travelers returning from sub-Saharan Africa $(239,242)$, and nearly all of these represent African tick bite fever $(241,243)$.

Patients with African tick bite fever typically have fever, headache, myalgia, one or more inoculation eschars, regional lymphadenopathy, and sometimes maculopapular or vesicular rash $(241,244)$. The incubation period is typically 5-7 days but can be up to 10 days after the bite of an infected Amblyomma hebraeum or Amblyomma variegatum tick $(241,244)$. The course of illness usually is mild. African tick bite fever can occur in clusters among game hunters, safari tourists, deployed troops, and humanitarian workers $(243,245,246)$. Travel for tourism has been identified as a risk factor $(239,241)$, and African tick bite fever is the second most common cause of febrile illness after malaria among travelers returning from sub-Saharan Africa $(247,248)$.

Mediterranean spotted fever is endemic in the Mediterranean basin, Middle East, parts of Africa, and the Indian subcontinent (240). This infection can be severe or fatal; in Portugal, a case-fatality rate of $21 \%$ among hospitalized adults has been described (249). Onset of Mediterranean spotted fever typically occurs abruptly with fever, myalgia, headache, eschar (usually singular), and maculopapular or petechial rash that can involve the palms and soles. Severe manifestations including neurologic, cardiac, and renal complications have been described. The mean incubation period is 6 days (range: 1-16 days) after being bitten by an infected tick (250). $R h$. sanguineus is the principal tick vector in Europe, Israel, and North Africa. Dogs can serve as reservoir hosts for $R$. conorii (251), and infected $R h$. sanguineus ticks can transfer from dogs to humans during interactions. Other tick vectors might play a role in transmission in sub-Saharan Africa $(250,252)$. Like other tickborne rickettsial diseases, Mediterranean spotted fever and African tick bite fever respond readily to antibacterial treatment with doxycycline.

Tickborne rickettsial pathogens found in the United States can also be encountered abroad. For example, $R$. rickettsii infection can be acquired in Canada and Mexico, as well as in Central America and South America, where cases are reported from Costa Rica, Panama, Brazil, Colombia, and Argentina (253-260). R. parkeri infections have been described in Uruguay, Brazil, and Argentina $(38,253,261,262)$. Human anaplasmosis has been reported from several countries throughout Europe (263), as well as from several Asian countries, including China, Korea, Russia, and Japan (264-267).

\section{Confirmatory Diagnostic Tests}

Several categories of laboratory methods are used to diagnose tickborne rickettsial diseases; these vary in availability, time to obtain results, performance characteristics, and the type of information each provides. Rapid confirmatory assays are rarely available to guide treatment decisions for acutely ill patients; therefore, it is imperative that therapeutic interventions are based on clinical suspicion. Because of the rapidly progressive nature of certain rickettsial diseases, antibacterial treatment should never be delayed while awaiting laboratory confirmation of a rickettsial illness (268), nor should treatment be discontinued solely on the basis of a negative test result on an acute phase specimen. Nonetheless, these laboratory assays provide vital information that validates the accuracy of the clinical diagnosis (268-270) and are crucial for defining the changing epidemiology and public health impact of tickborne rickettsial diseases (3-5).

Determining the most appropriate diagnostic assays to request for suspected tickborne rickettsial illness requires consideration of several factors (Box 8). These include the suspected pathogen, the timing relative to symptom onset, and the type of specimens available for testing (Appendix B) (Table 4). Diagnostic assays should always be ordered and interpreted in the context of a compatible illness 
and appropriate epidemiologic setting to obtain optimal positive and negative predictive values (271). Misuse of specialized assays for patients with a low pretest probability of a rickettsial disease can result in confusion. For example, antirickettsial antibodies can remain detectable for months to years after infection $(222,223,272,273)$; however, in the absence of a clinically compatible acute illness, detectable antibodies are not an indication for treatment for tickborne rickettsial disease.

\section{Serologic Assays}

Indirect immunofluorescence antibody (IFA) assays using paired acute and convalescent sera are the reference standard for serologic confirmation of rickettsial infection $(269,270)$. The IFA assay consists of rickettsial antigens fixed on a slide that are detected by specific antibodies in patient serum, which can then be identified by a fluorescein-labeled conjugate. IFA assays for immunoglobulin $\mathrm{G}(\mathrm{IgG})$ antibodies reactive against many types of tickborne rickettsial pathogens are commercially available and are the recommended serologic method for confirming tickborne rickettsial disease in the United States $(274,275)$. However, IFA assays are insensitive during the first week of rickettsial infection, which is the period during which most patients seek medical attention and when the majority of specimens are collected for evaluation (268). As the illness progresses past 7 days, the sensitivity of most IFA assays increases in tandem with pathogen-specific antibody production (268). IFA assays are highly sensitive at detecting antibody 2-3 weeks after illness onset, and assay results are best interpreted if serum samples collected in the acute and convalescent phases of illness are tested in tandem (222,276). Clinical observations have suggested that very early therapy with a tetracycline-class drug can sometimes diminish or delay the development of antibodies in RMSF $(277,278)$; however, this should not dissuade appropriate serologic testing.

For serologic confirmation of SFG rickettsioses, ehrlichioses, or anaplasmosis, IgG IFA testing of at least two serum samples collected, ideally, 2-4 weeks apart, during acute and convalescent phases of illness, is recommended $(271,274,275,279)$. A diagnosis of tickborne rickettsial disease is confirmed with a fourfold or greater increase in antibody titer in samples collected at appropriately timed intervals in patients with a clinically compatible acute illness $(274,275)$. A diagnosis of tickborne rickettsial disease is supported but not confirmed by one or more samples with an $\operatorname{IgG}$ antibody reciprocal titer $\geq 64$ in patients with a clinically compatible acute illness $(274,275)$. A single elevated antibody titer is never sufficient to confirm acute infection with a rickettsial pathogen.

Although the majority of persons have increased IgG titers by the second week of the illness, persons infected with certain Rickettsia species might have delayed development of significant antibody titers. For example, patients infected with $R$. africae might not show seroconversion until 4 weeks after illness onset (280). Antigen-specific assays are not available commercially in the United States for $R$. africae; however, commercially available tests that use $R$. conorii or $R$. rickettsii antigens can often be useful diagnostically because of the frequent cross-reactions among the spotted fever group rickettsiae (271). Alternatively, pathogen-specific testing may be submitted to CDC through the state public health laboratories.

The duration that antibodies persist after recovery from the infection varies and depends on the pathogen and host factors. The serologic diagnosis of rickettsioses is often confounded by the occurrence of preexisting antibodies that are reactive with a particular pathogen although unrelated entirely to the disease under investigation (272). In certain persons high titers of antibodies against $A$. phagocytophilum have

TABLE 4. Recommended diagnostic tests for tickborne rickettsial diseases

\begin{tabular}{|c|c|c|c|c|c|}
\hline \multirow[b]{2}{*}{ Disease } & \multicolumn{3}{|c|}{ PCR } & \multirow[b]{2}{*}{$\begin{array}{l}\text { Microscopy for } \\
\text { morulae detection }\end{array}$} & \multirow{2}{*}{$\begin{array}{l}\text { IFA assay for } \\
\text { IgG antibodies } \\
\text { (acute and } \\
\text { convalescent)* }\end{array}$} \\
\hline & $\begin{array}{l}\text { Whole } \\
\text { blood }\end{array}$ & $\begin{array}{l}\text { Eschar biopsy } \\
\text { or swab }\end{array}$ & $\begin{array}{l}\text { Rash } \\
\text { biopsy }\end{array}$ & & \\
\hline Rocky Mountain spotted fever & Yes $^{\dagger}$ & - & Yes & - & Yes \\
\hline Rickettsia parkeri rickettsiosis & - & Yes & Yes & - & Yes \\
\hline Rickettsia species 364D rickettsiosis & - & Yes & - & - & Yes \\
\hline $\begin{array}{l}\text { Ehrlichia chaffeensis ehrlichiosis (human monocytic } \\
\text { ehrlichiosis) }\end{array}$ & Yes & - & - & Yes & Yes \\
\hline Ehrlichia ewingii ehrlichiosis & Yes & - & - & Yes & Yes \\
\hline Ehrlichia muris-like agent ehrlichiosis & Yes & - & - & - & Yes \\
\hline Human anaplasmosis (human granulocytic anaplasmosis) & Yes & - & - & Yes & Yes \\
\hline
\end{tabular}

Abbreviations: IFA = indirect immunofluorescence antibody; IgG = immunoglobulin G; PCR = polymerase chain reaction.

* IFA assay is insensitive during the first week of illness for most tickborne rickettsial diseases; a sample should be collected during this interval (acute specimen), and a second sample should be collected 2-4 weeks later (convalescent specimen) for comparison. Elevated titers alone are not sufficient to diagnose infection with tickborne rickettsial diseases; serial titers are needed for confirmation. Demonstration of at least a fourfold rise in antibody titer is considered confirmatory evidence of acute infection.

${ }^{\dagger}$ PCR of whole blood samples for Rickettsia rickettsii has low sensitivity; sensitivity increases in patients with severe disease. 
been observed for over 4 years after the acute illness (223). For $R$. rickettsii, detectable IgG titers can persist for $>1$ year after primary infection in some patients (222). In the United States, IgG antibodies reactive with antigens of $R$. rickettsii at reciprocal titers $\geq 64$ can be found in $5 \%-10 \%$ of the population $(273,281-283)$ and might be higher in certain regions. Misinterpretation of serologic data based on single or inappropriately timed samples is problematic and should be avoided, particularly when no other diagnostic techniques are included in patient assessments $(279,284)$.

The majority of commercial reference laboratories that conduct testing for rickettsial pathogens test for IgG antibodies. Some commercial laboratories also perform IFA assays and other serologic testing for IgM antibodies. However, IgM antibodies reactive with $R$. rickettsii are frequently detected in patients for whom no other supportive evidence of a recent rickettsiosis exists (285). IgM antibodies against ehrlichiae and A. phagocytophilum also might have lower specificity than IgG antibodies $(286,287)$. In this context, IgM antibody titers should be interpreted carefully and should not be used as a stand-alone method for diagnosis and public health reporting of tickborne rickettsial diseases.

Cross-reactive immune responses to rickettsial antigens result in antibodies that are typically group-specific, although perhaps not species-specific, for tickborne rickettsial pathogens (269). For example, antibodies reactive with $R$. rickettsii detected by a serologic test could result from infection with other SFG rickettsiae (288). Similarly, antibodies reactive with E. chaffeensis or A. phagocytophilum can react with the other species, which can impede epidemiologic distinction between the infections (286,289). Patients with E. ewingii or EML agent infections might develop antibodies that react with $E$. chaffeensis and, less commonly, A. phagocytophilum antigens $(49,145)$.

Some rickettsial serologic testing is available in the enzymelinked immunosorbent assay (ELISA) format. Commercial laboratories might offer ELISA because of the ease in reading and higher throughput. Unfortunately, the currently marketed ELISA kits offer only qualitative results (i.e., antibody presence or absence relative to a threshold value) and do not provide a quantitative method of demonstrating increases or decreases in antibody levels. Confirmation of an acute infection by documenting the rise in antibody titer between the acute and convalescent serum samples is the most useful serologic strategy for evaluating etiology of an acute illness.

\section{Nucleic Acid Detection}

Amplification of species-specific DNA by conventional and real-time PCR assays provides a useful method for detecting tickborne rickettsial infections and identifying the infecting agent $(269,270)$. PCR amplification of DNA extracted from whole blood specimens collected during the acute stage of illness is particularly useful for confirming E. chaffeensis, A. phagocytophilum, E. ewingii, and EML agent infections because of the tropism of these pathogens for circulating cells. PCR detection of $R$. rickettsii in whole blood is possible but less sensitive because low numbers of rickettsiae typically circulate in the blood in the absence of advanced disease $(16,269,290)$. Tissue specimens are a more useful source of SFG rickettsial DNA than acute blood samples (8). No optimal time frame for blood collection during the acute phase of infection has been established to ensure the highest sensitivity for diagnosing ehrlichioses, anaplasmosis, or RMSF using PCR, and this likely varies among the diseases. Doxycycline treatment decreases the sensitivity of PCR $(51,167)$; therefore, obtaining blood for molecular testing before antibacterial agents are administered is recommended to minimize the likelihood of a false-negative result. PCR tests for tickborne rickettsial diseases are available at $\mathrm{CDC}$, certain state health laboratories, and certain research and commercial laboratories. These tests are laboratory developed, target differing genes, and vary in sensitivity and specificity.

Diagnostic molecular methods for tickborne rickettsial diseases have incorporated new technologies such as real-time PCR assays that offer the advantages of speed, reproducibility, quantitative capability, and reduced risk for contamination compared with conventional PCR assays (291). The acquisition and evaluation of clinical samples previously believed suboptimal for a particular molecular method are now more frequently being considered as important sources of diagnostic information. For example, improved nucleic acid extraction technology has facilitated recovery of rickettsial DNA from some types of formalin-fixed, paraffin-embedded skin biopsies or autopsy tissues to allow species-specific PCR and sequence analysis $(292,293)$. Testing of CSF by PCR assays has successfully identified E. chaffeensis $(135,159,294)$. For eschar-producing tickborne rickettsial diseases, including $R$. parkeri, Rickettsia species 364D, and $R$. africae, an eschar biopsy, a swab of eschar exudate, or scab material from the eschar surface can provide suitable specimens for molecular confirmation of SFG rickettsial DNA $(41,44,292,295)$.

\section{Immunostaining of Biopsy or Autopsy Tissue}

Another approach to diagnosing tickborne rickettsial diseases is immunostaining, including immunohistochemistry and immunofluorescence of antigens in formalin-fixed, paraffinembedded biopsy or autopsy tissues (Figure 29). For patients with a rash or eschar, immunohistochemical staining of a skin punch biopsy is a useful diagnostic technique for SFG 
rickettsioses (296-298). Immunostaining of skin biopsy specimens is $100 \%$ specific and $70 \%$ sensitive in diagnosing RMSF $(290,299)$. Sensitivities might be higher for tests using eschars than for those using rash lesions (269) because of the higher concentration of organisms in eschars compared with rash lesions. In cases of ehrlichiosis or anaplasmosis in which bone marrow biopsies are performed as part of the investigation of cytopenias, immunostaining of bone marrow biopsy specimens can reveal the diagnosis $(156,160)$. Immunostaining can be particularly useful for diagnosing fatal tickborne rickettsial diseases in tissue specimens from patients who had not developed diagnostic levels of antibodies before death $(16,141,293,300)$. Immunostaining methods are most likely to reveal organisms in patients before or within the first 48 hours after initiating appropriate antibacterial therapy. Immunostaining for SFG rickettsiae, E. chaffeensis, and $A$. phagocytophilum is offered by $\mathrm{CDC}$ and certain academic hospitals in the United States.

\section{Blood-Smear Microscopy}

Careful microscopic examination of blood smears or buffycoat preparations stained with eosin-azure-type dyes (e.g., Wright-Giemsa stains) during the first week of illness might reveal morulae in the cytoplasm of infected circulating leukocytes of patients with $E$. chaffeensis ehrlichiosis (157) or anaplasmosis (166). Observation of morulae is highly suggestive of infection by ehrlichiae or anaplasmae (Figure 28). However, blood-smear examination is a relatively insensitive and inconsistent technique and should be performed by experienced microscopists who must distinguish morulae from other intraleukocytic structures

FIGURE 29. Immunohistochemical stain demonstrating Anaplasma phagocytophilum morulae (red) in the spleen of a patient with splenic rupture associated with anaplasmosis

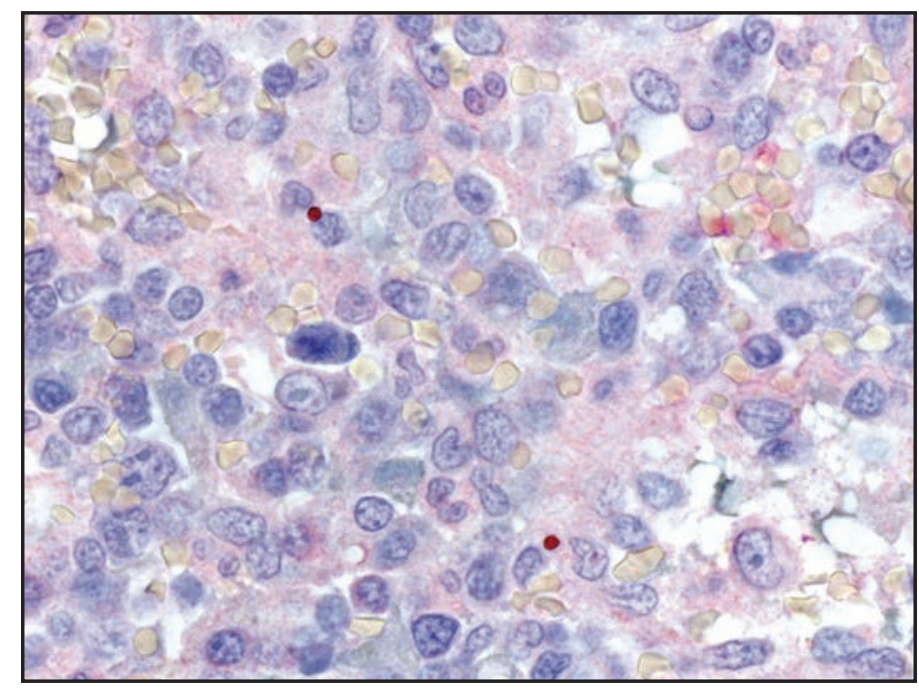

Photo/CDC including overlying platelets, Döhle bodies, phagocytosed bacteria, toxic granulations, and other cytoplasmic inclusions. A concentrated buffy-coat smear might improve the yield of morulae evaluation compared with a standard blood smear (270,301). Blood-smear examination is not useful for diagnosis of RMSF, other SFG rickettsioses, or EML agent infection.

\section{Culture}

Culture represents the reference standard for microbiological diagnosis (302) (Figure 30); however, the agents that cause tickborne rickettsial diseases are obligate intracellular pathogens and must be isolated from patient samples using cell culture techniques that are not widely available. Depending on the agent and the expertise of the diagnostic laboratory, the sensitivity of detection by culture can be lower than molecular or serologic techniques $(303,304)$. Clinical specimens used to inoculate cell cultures should be collected before the start of appropriate antibacterial therapy and preferably not frozen. Theoretically, any laboratory capable of performing routine viral isolations has the expertise to isolate these pathogens; however, $R$. rickettsii is classified as a biosafety level 3 (BSL-3) agent, and attempts to isolate this agent should be made only in laboratories equipped for and with laboratorians trained to work with BSL-3 pathogens (305).

FIGURE 30. Acridine orange stain of Rickettsia africae isolated in Vero E6 cells from an eschar biopsy specimen from a patient with African tick bite fever

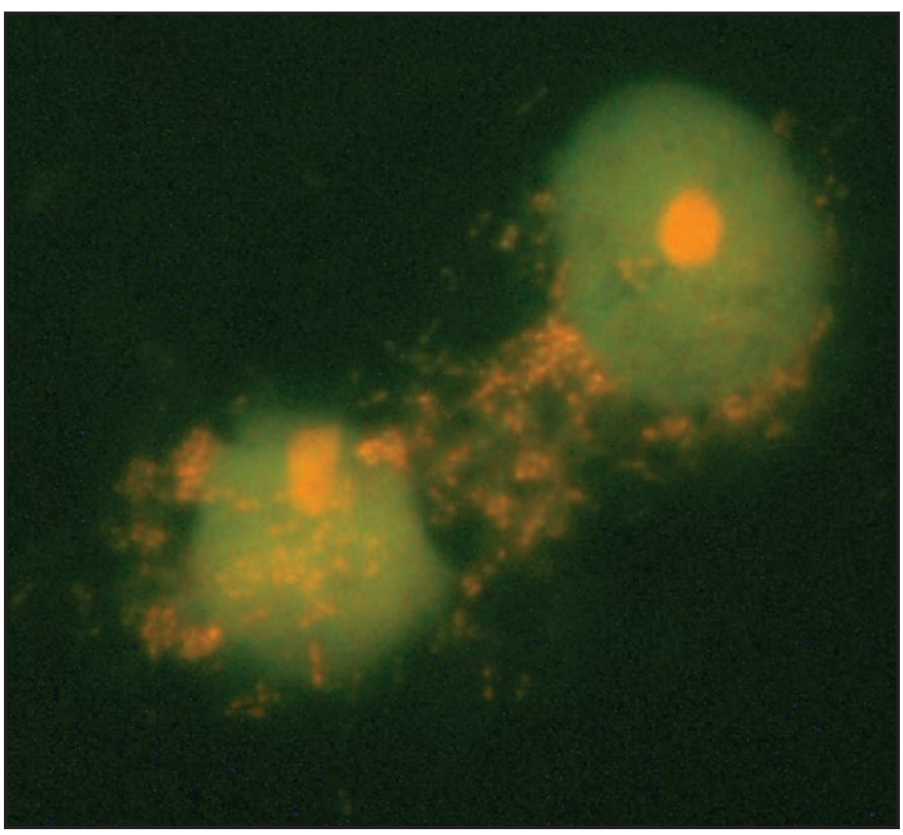

Photo/CDC 
BOX 8. Summary of confirmatory diagnostic tests

- Antibacterial treatment should never be delayed while awaiting laboratory confirmation of rickettsial illness, nor should treatment be discontinued solely on the basis of a negative test result with an acute phase specimen.

- The reference standard for diagnosis of tickborne rickettsial diseases is the IFA assay using paired serum samples obtained soon after illness onset and 2-4 weeks later. Demonstration of at least a fourfold rise in antibody titer is considered confirmatory evidence of acute infection.

- Patients usually do not have diagnostic serum antibody titers during the first week of illness, and a negative result by IFA assay or ELISA during this period does not exclude the diagnosis of tickborne rickettsial diseases.

- For ehrlichioses and anaplasmosis, diagnosis during the acute stage can be made using PCR amplification of DNA extracted from whole blood.

- PCR assay of whole blood is less sensitive for diagnosis of RMSF than it is for ehrlichiosis or anaplasmosis; however, sensitivity increases in patients with severe disease.

- For SFG rickettsioses, immunostaining of skin rash or eschar biopsy specimens or a PCR assay using DNA extracted from these specimens can help provide a pathogen-specific diagnosis.

- Immunostaining of autopsy specimens can be particularly useful for diagnosing fatal tickborne rickettsial infections.

- Blood-smear or buffy-coat preparation microscopy might reveal the presence of morulae in infected leukocytes, which is highly suggestive of anaplasmosis or ehrlichiosis. Blood-smear microscopy is not useful for RMSF, other SFG rickettsioses, or EML agent ehrlichiosis.

- Rickettsiae cannot be isolated with standard blood culture techniques because they are obligate intracellular pathogens; specialized cell culture methods are required. Because of limitations in availability and facilities, culture is not often used as a routine confirmatory diagnostic method for tickborne rickettsial diseases.

Abbreviations: ELISA = enzyme-linked immunosorbent assay; IFA = indirect immunofluorescence antibody; $\mathrm{PCR}=$ polymerase chain reaction; RMSF = Rocky Mountain spotted fever; SFG = spotted fever group.

\section{Prevention of Tickborne Rickettsial Diseases}

No vaccine is licensed for the prevention of tickborne rickettsial diseases in the United States. Avoiding tick bites and promptly removing attached ticks remain the best disease prevention strategies. General tick bite prevention strategies include various personal protective measures and behavior change components (Box 9).

\section{Regular Tick Checks on Humans and Pets}

After spending time with tick-infested animals or in tickinfested habitats, persons should inspect themselves, their children, and their pets for ticks. Sites where ticks commonly attach to humans include, but are not limited to, the scalp, abdomen, axillae, and groin, as well as under socks and along the belt line (306). Using a mirror, or having someone assist for hard-to-see areas, might be helpful. Bathing soon after spending recreational time or working in tick-infested habitats also can be an effective method of locating attached or crawling ticks and has been shown to be an important personal protective measure for other tickborne diseases (307). Several hours might elapse before ticks attach and transmit pathogens; therefore, timely tick checks increase the likelihood of finding and removing ticks before they can transmit an infectious agent. Dogs and other pets should be checked routinely for ticks because they can carry ticks back to their home, which increases the risk for human exposure. Ticks on dogs are commonly found around and inside the ears, between the toes, and in the axillae and groin.

The duration of tick attachment necessary to transmit rickettsial organisms varies and has been reported to range from 2 to 20 hours for $R$. rickettsii $(308,309)$. Limited data exist regarding the interval of transmission after tick attachment for A. phagocytophilum; however, animal studies indicate that $24-48$ hours might elapse before pathogen transmission occurs $(310,311)$. No comparable data exist for $E$. chaffeensis. Removing a tick as soon as possible is critical because longer periods of attachment considerably increase the probability of transmission of tickborne pathogens.

\section{Use of Repellents and Protective Clothing}

Repellents can reduce the risk for tick bites from numerous tick species (312-320). Various repellent products registered with the Environmental Protection Agency (EPA) are available and can be applied to exposed skin and clothing to repel ticks and prevent tick bites. Repellents labeled for use against mosquitoes, fleas, or other arthropods might not be effective tick repellents, and repellency varies by tick species. All commercial products should be used according to the label instructions, and persons should pay particular attention to frequency of application. 
$N, N$-diethyl-m-toluamide (DEET) effectively repels ticks and can be applied directly to the skin. Products with 20\%-30\% DEET are considered optimal for protection against most tick species (321), and concentrations $>50 \%$ do not confer additional protection (320). IR3535 (3-[N-Butyl-N-acetyl]-aminopropionic acid, ethyl ester) and picaridin (1-piperidinecaboxylic acid, 2-[2-hydroxyethyl], 1-methlypropyl ester) at concentrations $>15 \%$ can repel as well as DEET when applied to skin (315,322-325) and are considered effective DEET alternatives. Products containing permethrin should be applied to outer clothing (e.g., shirts and pants) and not directly to skin (314). Permethrin-impregnated clothing can reduce tick bites by $>80 \%$ among outdoor workers (326,327). Repellents, including plant-derived repellents, have a wide range of efficacy, periods of use, and safety $(328,329)$; check listed EPA-registered products for efficacy against ticks (http:// cfpub.epa.gov/oppref/insect).To help prevent ticks from reaching the skin and attaching, protective clothing should be worn when outdoors, including long-sleeved shirts, pants, socks, and closedtoe shoes (330). Tucking pants into socks and shirt into pants could prevent ticks from crawling inside clothing.

\section{Protecting Pets from Tick Bites}

Various domestic animals are susceptible to tickborne rickettsial diseases and can increase the likelihood of human exposure $(1,82,331,332)$. For example, dogs serve as the primary host for $R h$. sanguineus, which is known to transmit $R$. rickettsii both to humans and dogs in certain geographic areas. Regular use of pet ectoparasite control products (e.g., monthly topical acaricide products, acaricidal tick collars, oral acaricidal products, and acaricidal shampoos) can help reduce the risk for human exposure to ticks on pets.

\section{Limiting Exposure to Tick-Infested Habitats}

The habitats of humans, pets, and ticks overlap. Understanding the habitats where ticks might be encountered is important for preventing tickborne disease in persons and pets. The preferred habitats of ticks can vary widely on the basis of the biology of the tick and that of their hosts. Ticks have varying abilities to withstand desiccation. Ixodes spp. ticks require damper environments, whereas Rhipicephalus sanguineus ticks can survive high heat and low humidity. Dermacentor variabilis is found along wooded meadows, whereas Amblyomma americanum can be in dry woodlands. $R h$. sanguineus ticks are well adapted for domestic infestation and are commonly found in and around homes $(24,26)$. Certain ticks seek their hosts from grass or other leafy vegetation, whereas others are found in leaf litter or pine needles. Some ticks actively move toward their hosts, and others lie in wait for their host to pass nearby. The wide diversity of habitats makes avoiding tick-suitable habitats difficult; however, knowing this allows preventive measures to be taken before and after time spent outdoors. Walking on cleared trails, sidestepping vegetation, and creating tick-safe zones in yards can all help reduce the risk for tick bites (333).

\section{Tick Removal}

Attached ticks should be removed immediately. The preferred method of removal is to grasp the tick close to the skin with tweezers or fine-tipped forceps and gently pull back and upward with constant pressure (334). The application of gasoline, kerosene, petroleum jelly, fingernail polish, or lit matches should never be used to remove ticks (334). A wide array of devices has been marketed to help assist in the removal of attached ticks; however, their efficacy has not been proven to exceed that of regular forceps or tweezers. If possible, removing ticks with bare fingers should be avoided because fluids from the tick's body might contain infectious organisms; however, prompt removal of the tick is the primary consideration. Removed ticks should not be crushed with fingers. After removing a tick, the bite area should be cleaned thoroughly with soap and water, alcohol, or an iodine scrub (321). The hands of persons who might have touched the tick also should be thoroughly washed, especially before touching their face or eyes.

\section{BOX 9. Summary of prevention of tickborne rickettsial diseases}

- Perform regular tick checks on persons and pets and remove ticks immediately. Use tweezers or forceps, rather than bare fingers, to remove attached ticks when possible.

- Use tick repellents containing DEET, IR3535, picaridin (1-piperidinecaboxylic acid, 2-[2-hydroxyethyl], 1-methlypropyl ester), or other EPA-registered products when outdoors. Follow package label instructions for application.

- Wear protective clothing, including long-sleeved shirts, pants, socks, and closed-toe shoes.

- Permethrin-treated or impregnated clothing can significantly reduce the number of tick bites when working outdoors.

- Protect pets from tick bites by regularly applying veterinarian-approved ectoparasite control products, such as monthly topical acaricide products, acaricidal tick collars, oral acaricidal products, and acaricidal shampoos.

- Limit exposure to tick-infested habitats and tickinfested animals when possible.

Abbreviations: $\mathrm{DEET}=\mathrm{N}, \mathrm{N}$-diethyl-m-toluamide; $\mathrm{EPA}=$ Environmental Protection Agency; IR3535 = 3-[N-Butyl-N-acetyl]-aminopropionic acid, ethyl ester. 


\section{Surveillance and Reporting}

SFG rickettsioses (including RMSF), ehrlichioses, and anaplasmosis are nationally notifiable diseases in the United States (Box 10). RMSF has been nationally notifiable since 1920 (335) and anaplasmosis and ehrlichiosis since 1999 (336). In 2010, the reporting category of RMSF was changed to spotted fever rickettsiosis to reflect the limitations of serology specificity, which does not readily distinguish RMSF from other SFG rickettsioses (274).

When health care providers identify a potential case of tickborne rickettsial disease, they should notify the state or local health department according to the respective public health jurisdiction's disease reporting requirements. The health department can assist the health care provider in obtaining appropriate laboratory testing to confirm the diagnosis of a tickborne rickettsial disease. Although many state laboratories have systems that automatically report specific diseases on the basis of positive confirmatory diagnostic tests, these vary by state. As part of the standard case identification of tickborne rickettsial diseases, health department staff might contact health care providers and the patient to collect demographic, clinical, laboratory, and exposure information to determine the surveillance case classification. The national surveillance case definitions of notifiable tickborne rickettsial diseases are maintained collaboratively by the Council of

BOX 10. Summary of surveillance and reporting for tickborne rickettsial diseases, with surveillance websites

- Spotted fever group rickettsiosis, ehrlichiosis, and anaplasmosis are nationally notifiable diseases in the United States.

- Health care providers who identify a potential case of tickborne rickettsial disease should notify their state or local health department, which can assist with obtaining diagnostic testing to confirm the diagnosis.

- Surveillance and reporting of tickborne rickettsial diseases inform public health practice and guide disease prevention efforts.

CSTE case definition for spotted fever rickettsiosis: http:// wwwn.cdc.gov/nndss/conditions/spotted-fever-rickettsiosis CSTE case definition for ehrlichiosis and anaplasmosis: http://wwwn.cdc.gov/nndss/conditions/ ehrlichiosis-and-anaplasmosis

CSTE suggested timelines for reporting: http://wwwn. cdc.gov/nndss/document/NNC_2014_Notification_ Requirements_By_Category.pdf

Tickborne rickettsial disease case report form: http:// www.cdc.gov/ticks/forms/2010_tbrd_crf.pdf

$\overline{\text { Abbreviation: CSTE }}=$ Council of State and Territorial Epidemiologists.
State and Territorial Epidemiologists and the CDC National Notifiable Disease Surveillance System (NNDSS) (Box 10). Surveillance case definitions are used for standardization of national reporting and as a public health surveillance tool but are not intended to supplant clinical diagnoses on which treatment decisions are based.

Surveillance systems are critical for studying the changing epidemiology of tickborne rickettsial diseases and for developing effective prevention strategies and public health outreach activities. CDC collects and analyzes surveillance data on tickborne rickettsial diseases by using two complementary systems. As part of NNDSS, states submit standardized reports electronically, which include diagnosis, date of onset, basic demographics, and geographic data related to the case (Box 10). Data from NNDSS are published by CDC. A supplementary case report form system was designed to capture additional epidemiologic variables, including diagnostic tests used, clinical presentation, and illness outcome. Data in the case report form system is collected by CDC from local and state health departments most often using a standardized supplemental case report form. Data collected on the case report form are useful for guiding public health interventions and for identifying risk factors for hospitalization and death, changing trends in diagnostic test use, and emerging trends.

\section{Acknowledgments}

Marc Fischer, Paul Mead, Matthew Kuehnert, National Center for Emerging and Zoonotic Infectious Diseases; Barbara Herwaldt, Center for Global Health; Joy Hsu, National Center for Environmental Health; James Gathany, Office of the Associate Director for Communication, CDC.

\section{References}

1. Dantas-Torres F, Chomel BB, Otranto D. Ticks and tick-borne diseases: a One Health perspective. Trends Parasitol 2012;28:437-46. http:// dx.doi.org/10.1016/j.pt.2012.07.003

2. Dumler JS, Barbet AF, Bekker CP, et al. Reorganization of genera in the families Rickettsiaceae and Anaplasmataceae in the order Rickettsiales: unification of some species of Ehrlichia with Anaplasma, Cowdria with Ehrlichia and Ehrlichia with Neorickettsia, descriptions of six new species combinations and designation of Ehrlichia equi and 'HGE agent' as subjective synonyms of Ehrlichia phagocytophila. Int J Syst Evol Microbiol 2001;51:2145-65. http://dx.doi.org/10.1099/00207713-51-6-2145

3. Dahlgren FS, Heitman KN, Drexler NA, Massung RF, Behravesh CB. Human granulocytic anaplasmosis in the United States from 2008 to 2012: a summary of national surveillance data. Am J Trop Med Hyg 2015;93:66-72. http://dx.doi.org/10.4269/ajtmh.15-0122

4. Drexler NA, Dahlgren FS, Heitman KN, Massung RF, Paddock CD, Behravesh CB. National surveillance of spotted fever group rickettsioses in the United States, 2008-2012. Am J Trop Med Hyg 2016;23-34.

5. Nichols KH, Dahlgren FS, Drexler NA, Massung RF, Behravesh CB. Increasing incidence of ehrlichiosis in the United States: a summary of national surveillance of Ehrlichia chaffeensis and Ehrlichia ewingii infections in the United States, 2008-2012. Am J Trop Med Hyg 2016;94:52-60. http://dx.doi.org/10.4269/ajtmh.15-0540 
6. Helmick CG, Bernard KW, D’Angelo LJ. Rocky Mountain spotted fever: clinical, laboratory, and epidemiological features of 262 cases. J Infect Dis 1984;150:480-8. http://dx.doi.org/10.1093/infdis/150.4.480

7. Buckingham SC, Marshall GS, Schutze GE, et al; Tick-borne Infections in Children Study Group. Clinical and laboratory features, hospital course, and outcome of Rocky Mountain spotted fever in children. J Pediatr 2007;150:180-4, 184.e1. http://dx.doi.org/10.1016/j. jpeds.2006.11.023

8. Chapman AS, Bakken JS, Folk SM, et al. Diagnosis and management of tickborne rickettsial diseases: Rocky Mountain spotted fever, ehrlichioses, and anaplasmosis-United States: a practical guide for physicians and other health-care and public health professionals. MMWR Recomm Rep 2006;55(No. RR-4).

9. Dalton MJ, Clarke MJ, Holman RC, et al. National surveillance for Rocky Mountain spotted fever, 1981-1992: epidemiologic summary and evaluation of risk factors for fatal outcome. Am J Trop Med Hyg 1995;52:405-13.

10. Fishbein DB, Dawson JE, Robinson LE. Human ehrlichiosis in the United States, 1985 to 1990. Ann Intern Med 1994;120:736-43. http:// dx.doi.org/10.7326/0003-4819-120-9-199405010-00003

11. Gardner SL, Holman RC, Krebs JW, Berkelman R, Childs JE. National surveillance for the human ehrlichioses in the United States, 1997-2001, and proposed methods for evaluation of data quality. Ann N Y Acad Sci 2003;990:80-9. http://dx.doi.org/10.1111/j.1749-6632.2003. tb07341.x

12. Treadwell TA, Holman RC, Clarke MJ, Krebs JW, Paddock CD, Childs JE. Rocky Mountain spotted fever in the United States, 1993-1996. Am J Trop Med Hyg 2000;63:21-6.

13. Dahlgren FS, Mandel EJ, Krebs JW, Massung RF, McQuiston $\mathrm{JH}$. Increasing incidence of Ehrlichia chaffeensis and Anaplasma phagocytophilum in the United States, 2000-2007. Am J Trop Med Hyg 2011;85:124-31. http://dx.doi.org/10.4269/ajtmh.2011.10-0613

14. Openshaw JJ, Swerdlow DL, Krebs JW, et al. Rocky Mountain spotted fever in the United States, 2000-2007: interpreting contemporary increases in incidence. Am J Trop Med Hyg 2010;83:174-82. http:// dx.doi.org/10.4269/ajtmh.2010.09-0752

15. AZDHS.gov. [Internet]. Number of reported cases of notifiable diseases by year for Arizona, 2003-2013. Phoenix, AZ: Arizona Department of Health Services, Bureau of Epidemiology and Disease Control Services, Office of Infectious Disease Services; 2015. http://azdhs.gov/ preparedness/epidemiology-disease-control/index.php\#data-home

16. Demma LJ, Traeger MS, Nicholson WL, et al. Rocky Mountain spotted fever from an unexpected tick vector in Arizona. N Engl J Med 2005;353:587-94. http://dx.doi.org/10.1056/NEJMoa050043

17. Drexler N, Miller M, Gerding J, et al. Community-based control of the brown dog tick in a region with high rates of Rocky Mountain spotted fever, 2012-2013. PLoS One 2014;9:e112368. http://dx.doi. org/10.1371/journal.pone.0112368

18. Regan JJ, Traeger MS, Humpherys D, et al. Risk factors for fatal outcome from Rocky Mountain spotted fever in a highly endemic area-Arizona, 2002-2011. Clin Infect Dis 2015;60:1659-66. http:// dx.doi.org/10.1093/cid/civ116

19. Szabó MP, Pinter A, Labruna MB. Ecology, biology, and distribution of spotted-fever tick vectors in Brazil. Front Cell Infect Microbiol 2013;3:27. http://dx.doi.org/10.3389/fcimb.2013.00027

20. Guedes E, Leite RC, Pacheco RC, Silveira I, Labruna MB. Rickettsia species infecting Amblyomma ticks from an area endemic for Brazilian spotted fever in Brazil. Rev Bras Parasitol Vet 2011;20:308-11. http:// dx.doi.org/10.1590/S1984-29612011000400009

21. Labruna MB. Ecology of rickettsia in South America. Ann N Y Acad Sci 2009;1166:156-66. http://dx.doi.org/10.1111/j.1749-6632.2009.04516.x

22. Oliveira KA, Pinter A, Medina-Sanchez A, et al. Amblyomma imitator ticks as vectors of Rickettsia rickettsii, Mexico. Emerg Infect Dis 2010;16:1282-4. http://dx.doi.org/10.3201/eid1608.100231
23. Bustamante ME, Varela G. Una nueva rickettsiosis en Mexico: existencia de la fiebre manchada americana en los estadoes de Sinaloa y Sonora [Spanish]. Rev Inst Salubr Enferm Trop 1943;4:189-210.

24. Nicholson WL, Paddock CD, Demma L, et al. Rocky Mountain spotted fever in Arizona: documentation of heavy environmental infestations of Rhipicephalus sanguineus at an endemic site. Ann N Y Acad Sci 2006;1078:338-41. http://dx.doi.org/10.1196/annals.1374.065

25. Traeger MS, Regan JJ, Humpherys D, et al. Rocky Mountain spotted fever characterization and comparison to similar illnesses in a highly endemic area-Arizona, 2002-2011. Clin Infect Dis 2015;60:1650-8. http://dx.doi.org/10.1093/cid/civ115

26. Dantas-Torres F. The brown dog tick, Rhipicephalus sanguineus (Latreille, 1806) (Acari: Ixodidae): from taxonomy to control. Vet Parasitol 2008;152:173-85. http://dx.doi.org/10.1016/j.vetpar.2007.12.030

27. Alvarez-Hernandez G, Murillo-Benitez C, del Carmen Candia-Plata M, Moro M. Clinical profile and predictors of fatal Rocky Mountain spotted fever in children from Sonora, Mexico. Pediatr Infect Dis J 2015;34:125-30. http://dx.doi.org/10.1097/INF.0000000000000496

28. Alvarez Hernández G, Contreras Soto JJ. Mortality from Rickettsia rickettsii spotted fever in patients at a pediatric hospital in the state of Sonora, 2004-2012 [Spanish]. Salud Publica Mex 2013;55:151-2.

29. Eremeeva ME, Zambrano ML, Anaya L, et al. Rickettsia rickettsii in Rhipicephalus ticks, Mexicali, Mexico. J Med Entomol 2011;48:418-21. http://dx.doi.org/10.1603/ME10181

30. Sanchez R, Alpuche C, Lopez-Gatell H, et al. Rhipicephalus sanguineusassociated Rocky Mountain spotted fever in Mexicali, Mexico: observations from an outbreak in 2008-2009. Presented at the 23rd American Society for Rickettsiology meeting, Hilton Head, SC; August 15-18, 2009.

31. Moraes-Filho J, Pinter A, Pacheco RC, et al. New epidemiological data on Brazilian spotted fever in an endemic area of the state of São Paulo, Brazil. Vector Borne Zoonotic Dis 2009;9:73-8. http://dx.doi. org/10.1089/vbz.2007.0227

32. Pacheco RC, Moraes-Filho J, Guedes E, et al. Rickettsial infections of dogs, horses, and ticks in Juiz de Fora, southeastern Brazil, and isolation of Rickettsia rickettsii from Rhipicephalus sanguineus ticks. Med Vet Entomol 2011;25:148-55. http://dx.doi.org/10.1111/j.1365-2915.2010.00915.x

33. Wikswo ME, Hu R, Metzger ME, Eremeeva ME. Detection of Rickettsia rickettsii and Bartonella henselae in Rhipicephalus sanguineus ticks from California. J Med Entomol 2007;44:158-62. http://dx.doi.org/10.1093/ jmedent/41.5.158

34. Garrison LE, Kelly R, Nicholson WL, et al. Tick surveillance notes: Rickettsia rickettsii in Rhipicephalus sanguineus ticks from Gordon County. Ga Epidemiol Rep 2007;23:3.

35. Paddock CD, Sumner JW, Comer JA, et al. Rickettsia parkeri: a newly recognized cause of spotted fever rickettsiosis in the United States. Clin Infect Dis 2004;38:805-11. http://dx.doi.org/10.1086/381894

36. Cragun WC, Bartlett BL, Ellis MW, et al. The expanding spectrum of eschar-associated rickettsioses in the United States. Arch Dermatol 2010;146:641-8. http://dx.doi.org/10.1001/archdermatol.2010.48

37. Ekenna O, Paddock CD, Goddard J. Gulf Coast tick rash illness in Mississippi caused by Rickettsia parkeri. J Miss State Med Assoc 2014;55:216-9.

38. Paddock CD, Goddard J. The evolving medical and veterinary importance of the Gulf Coast tick (Acari: Ixodidae). J Med Entomol 2015;52:230-52. http://dx.doi.org/10.1093/jme/tju022

39. Paddock CD, Finley RW, Wright CS, et al. Rickettsia parkeri rickettsiosis and its clinical distinction from Rocky Mountain spotted fever. Clin Infect Dis 2008;47:1188-96. http://dx.doi.org/10.1086/592254

40. Kaskas NM, Ledet JJ, Wong A, Muzny CA, Elopre L, Hughey L. Rickettsia parkeri: eschar diagnosis. J Am Acad Dermatol 2014;71:e87-9. http://dx.doi.org/10.1016/j.jaad.2014.03.024

41. Myers T, Lalani T, Dent M, et al. Detecting Rickettsia parkeri infection from eschar swab specimens. Emerg Infect Dis 2013;19:778-80. http:// dx.doi.org/10.3201/eid1905.120622 
42. Teel PD, Ketchum HR, Mock DE, Wright RE, Strey OF. The Gulf Coast tick: a review of the life history, ecology, distribution, and emergence as an arthropod of medical and veterinary importance. J Med Entomol 2010;47:707-22. http://dx.doi.org/10.1093/jmedent/47.5.707

43. Shapiro MR, Fritz CL, Tait K, et al. Rickettsia 364D: a newly recognized cause of eschar-associated illness in California. Clin Infect Dis 2010;50:541-8. http://dx.doi.org/10.1086/649926

44. Johnston SH, Glaser CA, Padgett K, et al. Rickettsia spp. 364D causing a cluster of eschar-associated illness, California. Pediatr Infect Dis J 2013;32:1036-9. http://dx.doi.org/10.1097/INF.0b013e318296b24b

45. Eremeeva ME. Molecular epidemiology of rickettsial diseases in North America. Ticks Tick Borne Dis 2012;3:332-7. http://dx.doi. org/10.1016/j.ttbdis.2012.10.022

46. Wikswo ME, Hu R, Dasch GA, et al. Detection and identification of spotted fever group rickettsiae in Dermacentor species from southern California. J Med Entomol 2008;45:509-16. http://dx.doi.org/10.1093/ jmedent/45.3.509

47. Maeda K, Markowitz N, Hawley RC, Ristic M, Cox D, McDade JE. Human infection with Ehrlichia canis, a leukocytic rickettsia. N Engl J Med 1987;316:853-6. http://dx.doi.org/10.1056/NEJM198704023161406

48. Buller RS, Arens M, Hmiel SP, et al. Ehrlichia ewingii, a newly recognized agent of human ehrlichiosis. N Engl J Med 1999;341:148-55. http:// dx.doi.org/10.1056/NEJM199907153410303

49. Pritt BS, Sloan LM, Johnson DK, et al. Emergence of a new pathogenic Ehrlichia species, Wisconsin and Minnesota, 2009. N Engl J Med 2011;365:422-9. http://dx.doi.org/10.1056/NEJMoa1010493

50. Demma LJ, Holman RC, McQuiston JH, Krebs JW, Swerdlow DL. Human monocytic ehrlichiosis and human granulocytic anaplasmosis in the United States, 2001-2002. Ann N Y Acad Sci 2006;1078:118-9. http://dx.doi.org/10.1196/annals.1374.017

51. Olano JP, Masters E, Hogrefe W, Walker DH. Human monocytotropic ehrlichiosis, Missouri. Emerg Infect Dis 2003;9:1579-86. http://dx.doi. org/10.3201/eid0912.020733

52. Carpenter CF, Gandhi TK, Kong LK, et al. The incidence of ehrlichial and rickettsial infection in patients with unexplained fever and recent history of tick bite in central North Carolina. J Infect Dis 1999;180:9003. http://dx.doi.org/10.1086/314954

53. Fishbein DB, Kemp A, Dawson JE, Greene NR, Redus MA, Fields DH. Human ehrlichiosis: prospective active surveillance in febrile hospitalized patients. J Infect Dis 1989;160:803-9. http://dx.doi.org/10.1093/ infdis/160.5.803

54. Paddock CD, Yabsley MJ. Ecological havoc, the rise of white-tailed deer, and the emergence of Amblyomma americanum-associated zoonoses in the United States. Curr Top Microbiol Immunol 2007;315:289-324. http://dx.doi.org/10.1007/978-3-540-70962-6_12

55. Felz MW, Durden LA, Oliver JH Jr. Ticks parasitizing humans in Georgia and South Carolina. J Parasitol 1996;82:505-8. http://dx.doi. org/10.2307/3284095

56. Merten HA, Durden LA. A state-by-state survey of ticks recorded from humans in the United States. J Vector Ecol 2000;25:102-13.

57. Childs JE, Paddock CD. The ascendancy of Amblyomma americanum as a vector of pathogens affecting humans in the United States. Annu Rev Entomol 2003;48:307-37. http://dx.doi.org/10.1146/annurev. ento.48.091801.112728

58. Loftis AD, Levin ML, Spurlock JP. Two USA Ehrlichia spp. cause febrile illness in goats. Vet Microbiol 2008;130:398-402. http://dx.doi. org/10.1016/j.vetmic.2008.01.010

59. Breitschwerdt EB, Hegarty BC, Hancock SI. Sequential evaluation of dogs naturally infected with Ehrlichia canis, Ehrlichia chaffeensis, Ehrlichia equi, Ehrlichia ewingii, or Bartonella vinsonii. J Clin Microbiol 1998;36:2645-51.

60. Beall MJ, Alleman AR, Breitschwerdt EB, et al. Seroprevalence of Ehrlichia canis, Ehrlichia chaffeensis, and Ehrlichia ewingii in dogs in North America. Parasit Vectors 2012;5:29. http://dx.doi. org/10.1186/1756-3305-5-29
61. Johnson DKH, Schiffman EK, Davis JP, et al. Human infection with Ehrlichia muris-like pathogen, United States, 2007-2013. Emerg Infect Dis 2015;21:1794-9. http://dx.doi.org/10.3201/eid2110.150143

62. Saito TB, Walker DH. A tick vector transmission model of monocytotropic ehrlichiosis. J Infect Dis 2015;212:968-77. http:// dx.doi.org/10.1093/infdis/jiv134

63. Karpathy SE, Allerdice MEJ, Sheth M, Dasch GA, Levin ML. Co-feeding transmission of the Ehrlichia muris-like agent (EMLA) to mice (Mus musculus). Vector Borne Zoonotic Dis 2016;16:145-50. http://dx.doi. org/10.1089/vbz.2015.1878

64. Pritt BS, McFadden JD, Stromdah E, et al. Emergence of a novel Ehrlichia sp. agent pathogenic for humans in the Midwestern United States [Poster]. Presented at the 6th International Meeting on Rickettsiae and Rickettsial Diseases, Heraklion, Greece; June 5-7, 2011.

65. Stromdahl E, Hamer S, Jenkins S, et al. Comparison of phenology and pathogen prevalence, including infection with the Ehrlichia murislike (EML) agent, of Ixodes scapularis removed from soldiers in the Midwestern and the northeastern United States over a 15 year period (1997-2012). Parasit Vectors 2014;7:553. http://dx.doi.org/10.1186/ s13071-014-0553-z

66. Robinson SJ, Neitzel DF, Moen RA, et al. Disease risk in a dynamic environment: the spread of tick-borne pathogens in Minnesota, USA. EcoHealth 2015;12:152-63. http://dx.doi.org/10.1007/ s10393-014-0979-y

67. Belongia EA, Reed KD, Mitchell PD, et al. Tickborne infections as a cause of nonspecific febrile illness in Wisconsin. Clin Infect Dis 2001;32:1434-9. http://dx.doi.org/10.1086/320160

68. Eisen RJ, Eisen L, Beard CB. County-scale distribution of Ixodes scapularis and Ixodes pacificus (Acari: Ixodidae) in the continental United States. J Med Entomol 2016;pii:tjv237.

69. Horowitz HW, Aguero-Rosenfeld ME, Holmgren D, et al. Lyme disease and human granulocytic anaplasmosis coinfection: impact of case definition on coinfection rates and illness severity. Clin Infect Dis 2013;56:93-9. http://dx.doi.org/10.1093/cid/cis852

70. Krause PJ, McKay K, Thompson CA, et al; Deer-Associated Infection Study Group. Disease-specific diagnosis of coinfecting tickborne zoonoses: babesiosis, human granulocytic ehrlichiosis, and Lyme disease. Clin Infect Dis 2002;34:1184-91. http://dx.doi.org/10.1086/339813

71. Nadelman RB, Horowitz HW, Hsieh TC, et al. Simultaneous human granulocytic ehrlichiosis and Lyme borreliosis. N Engl J Med 1997;337:27-30. http://dx.doi.org/10.1056/NEJM199707033370105

72. Moss WJ, Dumler JS. Simultaneous infection with Borrelia burgdorferi and human granulocytic ehrlichiosis. Pediatr Infect Dis J 2003;22:91-2. http://dx.doi.org/10.1097/00006454-200301000-00023

73. De Martino SJ, Carlyon JA, Fikrig E. Coinfection with Borrelia burgdorferi and the agent of human granulocytic ehrlichiosis. N Engl J Med 2001;345:150-1. http://dx.doi.org/10.1056/NEJM200107123450218

74. Kirkland KB, Wilkinson WE, Sexton DJ. Therapeutic delay and mortality in cases of Rocky Mountain spotted fever. Clin Infect Dis 1995;20:1118-21. http://dx.doi.org/10.1093/clinids/20.5.1118

75. Holman RC, Paddock CD, Curns AT, Krebs JW, McQuiston JH, Childs JE. Analysis of risk factors for fatal Rocky Mountain spotted fever: evidence for superiority of tetracyclines for therapy. J Infect Dis 2001;184:1437-44. http://dx.doi.org/10.1086/324372

76. Falco RC, Fish D. Prevalence of Ixodes dammini near the homes of Lyme disease patients in Westchester County, New York. Am J Epidemiol 1988;127:826-30.

77. Walker DH. Rocky Mountain spotted fever: a seasonal alert. Clin Infect Dis 1995;20:1111-7. http://dx.doi.org/10.1093/clinids/20.5.1111

78. Blanton LS, Walker DH, Bouyer DH. Rickettsiae and ehrlichiae within a city park: is the urban dweller at risk? Vector Borne Zoonotic Dis 2014;14:168-70. http://dx.doi.org/10.1089/vbz.2013.1473

79. Falco RC, Fish D. Potential for exposure to tick bites in recreational parks in a Lyme disease endemic area. Am J Public Health 1989;79:12-5. http://dx.doi.org/10.2105/AJPH.79.1.12 
80. Standaert SM, Dawson JE, Schaffner W, et al. Ehrlichiosis in a golforiented retirement community. N Engl J Med 1995;333:420-5. http:// dx.doi.org/10.1056/NEJM199508173330704

81. Lange JV, Walker DH, Wester TB. Documented Rocky Mountain spotted fever in wintertime. JAMA 1982;247:2403-4. http://dx.doi. org/10.1001/jama.1982.03320420053034

82. Nicholson WL, Allen KE, McQuiston JH, Breitschwerdt EB, Little SE. The increasing recognition of rickettsial pathogens in dogs and people. Trends Parasitol 2010;26:205-12. http://dx.doi.org/10.1016/j. pt.2010.01.007

83. Elchos BN, Goddard J. Implications of presumptive fatal Rocky Mountain spotted fever in two dogs and their owner. J Am Vet Med Assoc 2003;223:1450-2. http://dx.doi.org/10.2460/javma.2003.223.1450

84. Uspensky I, Ioffe-Uspensky I. The dog factor in brown dog tick Rhipicephalus sanguineus (Acari: Ixodidae) infestations in and near human dwellings. Int J Med Microbiol 2002;291(Suppl 33):S156-63. http:// dx.doi.org/10.1016/S1438-4221(02)80030-3

85. Yevich SJ, Sánchez JL, DeFraites RF, et al. Seroepidemiology of infections due to spotted fever group rickettsiae and Ehrlichia species in military personnel exposed in areas of the United States where such infections are endemic. J Infect Dis 1995;171:1266-73. http://dx.doi.org/10.1093/ infdis/171.5.1266

86. McCall CL, Curns AT, Rotz LD, et al. Fort Chaffee revisited: the epidemiology of tick-borne rickettsial and ehrlichial diseases at a natural focus. Vector Borne Zoonotic Dis 2001;1:119-27. http://dx.doi. org/10.1089/153036601316977723

87. Jones TF, Craig AS, Paddock CD, et al. Family cluster of Rocky Mountain spotted fever. Clin Infect Dis 1999;28:853-9. http://dx.doi. org/10.1086/515213

88. CDC. Fatal cases of Rocky Mountain spotted fever in family clustersthree states, 2003. MMWR Morb Mortal Wkly Rep 2004;53:407-10.

89. Tribaldos M, Zaldivar Y, Bermudez S, et al. Rocky Mountain spotted fever in Panama: a cluster description. J Infect Dev Ctries 2011;5:737-41.

90. Paddock CD, Brenner O, Vaid C, et al. Short report: concurrent Rocky Mountain spotted fever in a dog and its owner. Am J Trop Med Hyg 2002;66:197-9.

91. Breitschwerdt EB, Meuten DJ, Walker DH, et al. Canine Rocky Mountain spotted fever: a kennel epizootic. Am J Vet Res 1985;46:2124-8.

92. Piranda EM, Faccini JL, Pinter A, et al. Experimental infection of dogs with a Brazilian strain of Rickettsia rickettsii: clinical and laboratory findings. Mem Inst Oswaldo Cruz 2008;103:696-701. http://dx.doi. org/10.1590/S0074-02762008000700012

93. Levin ML, Killmaster LF, Zemtsova GE, Ritter JM, Langham G. Clinical presentation, convalescence, and relapse of Rocky Mountain spotted fever in dogs experimentally infected via tick bite. PLoS One 2014;9:e115105. http://dx.doi.org/10.1371/journal.pone.0115105

94. Valbuena G, Walker DH. Infection of the endothelium by members of the order Rickettsiales. Thromb Haemost 2009;102:1071-9.

95. Kaplowitz LG, Robertson GL. Hyponatremia in Rocky Mountain spotted fever: role of antidiuretic hormone. Ann Intern Med 1983;98:334-5. http://dx.doi.org/10.7326/0003-4819-98-3-334

96. Wolbach SB. Studies on Rocky Mountain spotted fever. J Med Res 1919;41:1-198.41.

97. Harrell GT. Rocky Mountain spotted fever. Medicine (Baltimore) 1949;28:333-70. http://dx.doi.org/10.1097/00005792-194912000-00001

98. Hattwick MA, Retailliau H, O'Brien RJ, Slutzker M, Fontaine RE, Hanson B. Fatal Rocky Mountain spotted fever. JAMA 1978;240:1499_ 503. http://dx.doi.org/10.1001/jama.1978.03290140041019

99. Sexton DJ, Corey GR. Rocky Mountain "spotless" and "almost spotless" fever: a wolf in sheep's clothing. Clin Infect Dis 1992;15:439-48. http:// dx.doi.org/10.1093/clind/15.3.439
100. Walker DH, Gay RM, Valdes-Dapena M. The occurrence of eschars in Rocky Mountain spotted fever. J Am Acad Dermatol 1981;4:571-6. http://dx.doi.org/10.1016/S0190-9622(81)70059-8

101. Argüello AP, Hun L, Rivera P, Taylor L. A fatal urban case of Rocky Mountain spotted fever presenting an eschar in San Jose, Costa Rica. Am J Trop Med Hyg 2012;87:345-8. http://dx.doi.org/10.4269/ ajtmh.2012.12-0153

102. Walker DH, Henderson FW, Hutchins GM. Rocky Mountain spotted fever: mimicry of appendicitis or acute surgical abdomen? Am J Dis Child 1986;140:742-4.

103. WalkerDH, LesesneHR, VarmaVA,ThackerWC. RockyMountain spotted fever mimicking acute cholecystitis. Arch Intern Med 1985;145:2194-6. http://dx.doi.org/10.1001/archinte.1985.00360120062010

104. Walker DH, Blanton LS. Rickettsia rickettsii and other spotted fever group rickettsiae (Rocky Mountain spotted fever and other spotted fevers) [Chapter 188]. In: Bennett JE, Dolin R, Blaser MJ, eds. Mandell, Douglas, and Bennett's Principles and practice of infectious diseases. Philadelphia, PA: Elsevier Saunders; 2015:2198-205.

105. Kirkland KB, Marcom PK, Sexton DJ, Dumler JS, Walker DH. Rocky Mountain spotted fever complicated by gangrene: report of six cases and review. Clin Infect Dis 1993;16:629-34. http://dx.doi.org/10.1093/ clind/16.5.629

106. Booth KK, Terrell DR, Vesely SK, George JN. Systemic infections mimicking thrombotic thrombocytopenic purpura. Am J Hematol 2011;86:743-51. http://dx.doi.org/10.1002/ajh.22091

107. Turner RC, Chaplinski TJ, Adams HG. Rocky Mountain spotted fever presenting as thrombotic thrombocytopenic purpura. Am J Med 1986;81:153-7. http://dx.doi.org/10.1016/0002-9343(86)90201-9

108. George JN, Vesely SK, Terrell DR. The Oklahoma Thrombotic Thrombocytopenic Purpura-Hemolytic Uremic Syndrome (TTPHUS) Registry: a community perspective of patients with clinically diagnosed TTP-HUS. Semin Hematol 2004;41:60-7. http://dx.doi. org/10.1053/j.seminhematol.2003.10.001

109. Horney LF, Walker DH. Meningoencephalitis as a major manifestation of Rocky Mountain spotted fever. South Med J 1988;81:915-8. http:// dx.doi.org/10.1097/00007611-198807000-00028

110. Archibald LK, Sexton DJ. Long-term sequelae of Rocky Mountain spotted fever. Clin Infect Dis 1995;20:1122-5. http://dx.doi. org/10.1093/clinids/20.5.1122

111. Massey EW, Thames T, Coffey CE, Gallis HA. Neurologic complications of Rocky Mountain spotted fever. South Med J 1985;78:1288-90, 1303. http://dx.doi.org/10.1097/00007611-198511000-00004

112. Bleck TP. Central nervous system involvement in rickettsial diseases. Neurol Clin 1999;17:801-12. http://dx.doi.org/10.1016/ S0733-8619(05)70167-5

113. Childs JE, Paddock CD. Passive surveillance as an instrument to identify risk factors for fatal Rocky Mountain spotted fever: is there more to learn? Am J Trop Med Hyg 2002;66:450-7.

114. Smadel JE. Status of the rickettsioses in the United States. Ann Intern Med 1959;51:421-35. http://dx.doi.org/10.7326/0003-4819-51-3-421

115. Topping NH. Rocky Mountain spotted fever: a note on some aspects of its epidemiology. Public Health Rep 1941;56:1699-703. http:// dx.doi.org/10.2307/4583839

116. Dahlgren FS, Holman RC, Paddock CD, Callinan LS, McQuiston JH. Fatal Rocky Mountain spotted fever in the United States, 1999-2007. Am J Trop Med Hyg 2012;86:713-9. http://dx.doi.org/10.4269/ ajtmh.2012.11-0453 
117. Walker DH. The role of host factors in the severity of spotted fever and typhus rickettsioses. Ann N Y Acad Sci 1990;590:10-9. http:// dx.doi.org/10.1111/j.1749-6632.1990.tb42201.x

118. Walker DH, Hawkins HK, Hudson P. Fulminant Rocky Mountain spotted fever. Its pathologic characteristics associated with glucose6-phosphate dehydrogenase deficiency. Arch Pathol Lab Med 1983;107:121-5.

119. Topping NH. Experimental Rocky Mountain spotted fever and endemic typhus treated with prontosil or sulfapyridine. Public Health Rep 1939;54:1143-7. http://dx.doi.org/10.2307/4582935

120. Harrell GT. Rocky Mountain spotted fever. Medicine (Baltimore) 1949;28:333-70. http://dx.doi.org/10.1097/00005792-194912000-00001

121. Bergeron JW, Braddom RL, Kaelin DL. Persisting impairment following Rocky Mountain spotted fever: a case report. Arch Phys Med Rehabil 1997;78:1277-80. http://dx.doi.org/10.1016/ S0003-9993(97)90345-2

122. Kirk JL, Fine DP, Sexton DJ, Muchmore HG. Rocky Mountain spotted fever. A clinical review based on 48 confirmed cases, 1943-1986. Medicine (Baltimore) 1990;69:35-45. http://dx.doi. org/10.1097/00005792-199001000-00003

123. Wright L. Intellectual sequelae of Rocky Mountain spotted fever. J Abnorm Psychol 1972;80:315-6. http://dx.doi.org/10.1037/h0033742

124. Gorman RJ, Saxon S, Snead OC 3rd. Neurologic sequelae of Rocky Mountain spotted fever. Pediatrics 1981;67:354-7.

125. Walker DH. Rickettsiae and rickettsial infections: the current state of knowledge. Clin Infect Dis 2007;45(Suppl 1):S39-44. http://dx.doi. org/10.1086/518145

126. Elghetany MT, Walker DH. Hemostatic changes in Rocky Mountain spotted fever and Mediterranean spotted fever. Am J Clin Pathol 1999;112:159-68. http://dx.doi.org/10.1093/ajcp/112.2.159

127. Kaplowitz LG, Fischer JJ, Sparling PF. Rocky Mountain spotted fever: a clinical dilemma. In: Remington JS, Swartz MN, eds. Current clinical topics in infectious diseases. Vol 2. New York, NY: McGraw-Hill; 1981:89-109.

128. Paddock CD, Childs JE. Ehrlichia chaffeensis: a prototypical emerging pathogen. Clin Microbiol Rev 2003;16:37-64. http://dx.doi. org/10.1128/CMR.16.1.37-64.2003

129. Dumler JS, Walker DH. Ehrlichia chaffeensis (human monocytotropic ehrlichiosis), Anaplasma phagocytophilum (human granulocytotropic anaplasmosis), and other anaplasmataceae [Chapter 194]. In: Bennett JE, Dolin R, Blaser MJ, eds. Mandell, Douglas, and Bennett's Principles and practice of infectious diseases. 8th ed. Philadelphia, PA: Elsevier Saunders; 2015:2227-33.

130. Zaidi SA, Singer C. Gastrointestinal and hepatic manifestations of tickborne diseases in the United States. Clin Infect Dis 2002;34:1206-12. http://dx.doi.org/10.1086/339871

131. Devereaux CE. Human monocytic ehrlichiosis presenting as febrile diarrhea. J Clin Gastroenterol 1997;25:544-5. http://dx.doi. org/10.1097/00004836-199710000-00014

132. Schutze GE, Buckingham SC, Marshall GS, et al; Tick-borne Infections in Children Study (TICS) Group. Human monocytic ehrlichiosis in children. Pediatr Infect Dis J 2007;26:475-9. http://dx.doi. org/10.1097/INF.0b013e318042b66c

133. Fichtenbaum CJ, Peterson LR, Weil GJ. Ehrlichiosis presenting as a lifethreatening illness with features of the toxic shock syndrome. Am J Med 1993;95:351-7. http://dx.doi.org/10.1016/0002-9343(93)90302-6

134. Harkess JR. Ehrlichiosis. Infect Dis Clin North Am 1991;5:37-51.
135. Ratnasamy N, Everett ED, Roland WE, McDonald G, Caldwell CW. Central nervous system manifestations of human ehrlichiosis. Clin Infect Dis 1996;23:314-9. http://dx.doi.org/10.1093/clinids/23.2.314

136. Abbott KC, Vukelja SJ, Smith CE, et al. Hemophagocytic syndrome: a cause of pancytopenia in human ehrlichiosis. Am J Hematol 1991;38:230-4. http://dx.doi.org/10.1002/ajh.2830380315

137. Burns S, Saylors R, Mian A. Hemophagocytic lymphohistiocytosis secondary to Ehrlichia chaffeensis infection: a case report. J Pediatr Hematol Oncol 2010;32:e142-3. http://dx.doi.org/10.1097/ MPH.0b013e3181c80ab9

138. Vijayan V, Thambundit A, Sukumaran S. Hemophagocytic lymphohistiocytosis secondary to ehrlichiosis in a child. Clin Pediatr (Phila) 2015;54:84-6. http://dx.doi.org/10.1177/0009922814529183

139. Hanson D, Walter AW, Powell J. Ehrlichia-induced hemophagocytic lymphohistiocytosis in two children. Pediatr Blood Cancer 2011;56:661-3. http://dx.doi.org/10.1002/pbc.22814

140. Pandey R, Kochar R, Kemp S, Rotaru D, Shah SV. Ehrlichiosis presenting with toxic shock-like syndrome and secondary hemophagocytic lymphohistiocytosis. J Ark Med Soc 2013;109:280-2.

141. Marty AM, Dumler JS, Imes G, Brusman HP, Smrkovski LL, Frisman DM. Ehrlichiosis mimicking thrombotic thrombocytopenic purpura. Case report and pathological correlation. Hum Pathol 1995;26:920-5. http://dx.doi.org/10.1016/0046-8177(95)90017-9

142. Smith Sehdev AE, Sehdev PS, Jacobs R, Dumler JS. Human monocytic ehrlichiosis presenting as acute appendicitis during pregnancy. Clin Infect Dis 2002;35:e99-102. http://dx.doi.org/10.1086/342887

143. Smith Sehdev AE, Dumler JS. Hepatic pathology in human monocytic ehrlichiosis. Ehrlichia chaffeensis infection. Am J Clin Pathol 2003;119:859-65. http://dx.doi.org/10.1309/F7EAB5P7321716LJ

144. McMullan LK, Folk SM, Kelly AJ, et al. A new phlebovirus associated with severe febrile illness in Missouri. N Engl J Med 2012;367:834-41. http://dx.doi.org/10.1056/NEJMoa1203378

145. Paddock CD, Folk SM, Shore GM, et al. Infections with Ehrlichia chaffeensis and Ehrlichia ewingii in persons coinfected with human immunodeficiency virus. Clin Infect Dis 2001;33:1586-94. http:// dx.doi.org/10.1086/323981

146. Talbot TR, Comer JA, Bloch KC. Ehrlichia chaffeensis infections among HIV-infected patients in a human monocytic ehrlichiosis-endemic area. Emerg Infect Dis 2003;9:1123-7. http://dx.doi.org/10.3201/ eid0909.020560

147. Lawrence KL, Morrell MR, Storch GA, Hachem RR, Trulock EP. Clinical outcomes of solid organ transplant recipients with ehrlichiosis. Transpl Infect Dis 2009;11:203-10. http://dx.doi.org/10.1111/j.1399-3062.2009.00373.x

148. Esbenshade A, Esbenshade J, Domm J, Williams J, Frangoul H. Severe Ehrlichia infection in pediatric oncology and stem cell transplant patients. Pediatr Blood Cancer 2010;54:776-8.

149. Thomas LD, Hongo I, Bloch KC, Tang YW, Dummer S. Human ehrlichiosis in transplant recipients. Am J Transplant 2007;7:1641-7. http://dx.doi.org/10.1111/j.1600-6143.2007.01821.x

150. Peters TR, Edwards KM, Standaert SM. Severe ehrlichiosis in an adolescent taking trimethoprim-sulfamethoxazole. Pediatr Infect Dis J 2000;19:170-2. http://dx.doi.org/10.1097/00006454-200002000-00021

151. Brantley RK. Trimethoprim-sulfamethoxazole and fulminant ehrlichiosis. Pediatr Infect Dis J 2001;20:231. http://dx.doi. org/10.1097/00006454-200102000-00028

152. Nayak SU, Simon GL. Myocarditis after trimethoprim/sulfamethoxazole treatment for ehrlichiosis. Emerg Infect Dis 2013;19:1975-7. http:// dx.doi.org/10.3201/eid1912.121459 
153. Patel RG, Byrd MA. Near fatal acute respiratory distress syndrome in a patient with human ehrlichiosis. South Med J 1999;92:333-5. http:// dx.doi.org/10.1097/00007611-199903000-00017

154. Liddell AM, Sumner JW, Paddock CD, et al. Reinfection with Ehrlichia chaffeensis in a liver transplant recipient. Clin Infect Dis 2002;34:1644-7. http://dx.doi.org/10.1086/340523

155. Caldwell CW, Everett ED, McDonald G, Yesus YW, Roland WE. Lymphocytosis of gamma/delta T cells in human ehrlichiosis. Am J Clin Pathol 1995;103:761-6. http://dx.doi.org/10.1093/ajcp/103.6.761

156. Dumler JS, Dawson JE, Walker DH. Human ehrlichiosis: hematopathology and immunohistologic detection of Ehrlichia chaffeensis. Hum Pathol 1993;24:391-6. http://dx.doi. org/10.1016/0046-8177(93)90087-W

157. Hamilton KS, Standaert SM, Kinney MC. Characteristic peripheral blood findings in human ehrlichiosis. Mod Pathol 2004;17:512-7. http://dx.doi.org/10.1038/modpathol.3800075

158. Berry DS, Miller RS, Hooke JA, Massung RF, Bennett J, Ottolini MG. Ehrlichial meningitis with cerebrospinal fluid morulae. Pediatr Infect Dis J 1999;18:552-5. http://dx.doi. org/10.1097/00006454-199906000-00016

159. Dunn BE, Monson TP, Dumler JS, et al. Identification of Ehrlichia chaffeensis morulae in cerebrospinal fluid mononuclear cells. J Clin Microbiol 1992;30:2207-10.

160. Allen MB, Pritt BS, Sloan LM, et al. First reported case of Ehrlichia ewingii involving human bone marrow. J Clin Microbiol 2014;52:4102-4. http://dx.doi.org/10.1128/JCM.01670-14

161. Dumler JS, Choi KS, Garcia-Garcia JC, et al. Human granulocytic anaplasmosis and Anaplasma phagocytophilum. Emerg Infect Dis 2005;11:1828-34. http://dx.doi.org/10.3201/eid1112.050898

162. Dumler JS, Madigan JE, Pusterla N, Bakken JS. Ehrlichioses in humans: epidemiology, clinical presentation, diagnosis, and treatment. Clin Infect Dis 2007;45(Suppl 1):S45-51. http://dx.doi. org/10.1086/518146

163. Bakken JS, Krueth J, Wilson-Nordskog C, Tilden RL, Asanovich K, Dumler JS. Clinical and laboratory characteristics of human granulocytic ehrlichiosis. JAMA 1996;275:199-205. http://dx.doi.org/10.1001/ jama.1996.03530270039029

164. Bellone M, Chiang J, Ahmed T, Galanakis D, Senzel L. Thrombotic thrombocytopenic purpura and its look-alikes: a single institution experience. Transfus Apheresis Sci 2012;46:59-64. http://dx.doi. org/10.1016/j.transci.2011.11.003

165. Dumler JS. The biological basis of severe outcomes in Anaplasma phagocytophilum infection. FEMS Immunol Med Microbiol 2012;64:13-20. http://dx.doi.org/10.1111/j.1574-695X.2011.00909.x

166. Bakken JS, Dumler S. Human granulocytic anaplasmosis. Infect Dis Clin North Am 2008;22:433-48, viii. http://dx.doi.org/10.1016/j. idc.2008.03.011

167. Bakken JS, Dumler JS. Ehrlichiosis and anaplasmosis. Infect Med 2004;21:433-51.

168. Bakken JS, Dumler JS. Human granulocytic ehrlichiosis. Clin Infect Dis 2000;31:554-60. http://dx.doi.org/10.1086/313948

169. Bakken JS, Aguero-Rosenfeld ME, Tilden RL, et al. Serial measurements of hematologic counts during the active phase of human granulocytic ehrlichiosis. Clin Infect Dis 2001;32:862-70. http://dx.doi. org/10.1086/319350

170. Aguero-Rosenfeld ME, Horowitz HW, Wormser GP, et al. Human granulocytic ehrlichiosis: a case series from a medical center in New York State. Ann Intern Med 1996;125:904-8. http://dx.doi. org/10.7326/0003-4819-125-11-199612010-00006
171. Jereb M, Pecaver B, Tomazic J, et al. Severe human granulocytic anaplasmosis transmitted by blood transfusion. Emerg Infect Dis 2012;18:1354-7. http://dx.doi.org/10.3201/eid1808.120180

172. Belongia EA, Reed KD, Mitchell PD, et al. Clinical and epidemiological features of early Lyme disease and human granulocytic ehrlichiosis in Wisconsin. Clin Infect Dis 1999;29:1472-7. http://dx.doi. org/10.1086/313532

173. Wormser GP, Dattwyler RJ, Shapiro ED, et al. The clinical assessment, treatment, and prevention of Lyme disease, human granulocytic anaplasmosis, and babesiosis: clinical practice guidelines by the Infectious Diseases Society of America. Clin Infect Dis 2006;43:1089134. http://dx.doi.org/10.1086/508667

174. Swanson SJ, Neitzel D, Reed KD, Belongia EA. Coinfections acquired from Ixodes ticks. Clin Microbiol Rev 2006;19:708-27. http://dx.doi. org/10.1128/CMR.00011-06

175. Chowdri HR, Gugliotta JL, Berardi VP, et al. Borrelia miyamotoi infection presenting as human granulocytic anaplasmosis: a case report. Ann Intern Med 2013;159:21-7. http://dx.doi. org/10.7326/0003-4819-159-1-201307020-00005

176. Weber DJ, Cohen MS, Morrell DS, Rutala WA. The acutely ill patient with fever and rash [Chapter 52]. In: Mandell GL, Bennett JE, Dolin $\mathrm{R}$, eds. Mandell, Douglas, and Bennett's Principles and practices of infectious diseases. 7th ed. Philadelphia, PA: Churchill Livingstone; 2010:791-808.

177. Weber DJ, Cohen MS, Rutala WA. The acutely ill patient with fever and rash [Chapter 57]. In: Bennett JE, Dolin R, Blaser MJ, eds. Mandell, Douglas, and Bennett's Principles and practice of infectious diseases. 8th ed. Philadelphia, PA: Elsevier Saunders; 2015:732-46.

178. American Academy of Pediatrics, Committee on Infectious Diseases. Rickettsial diseases. In: Kimberlin DW, Long SS, Brady MT, Jackson M, eds. Red book: 2015 report of the Committee on Infectious Diseases. 30th ed. Elk Grove Village, IL: American Academy of Pediatrics; 2015:677-80.

179. Donovan BJ, Weber DJ, Rublein JC, Raasch RH. Treatment of tickborne diseases. Ann Pharmacother 2002;36:1590-7. http://dx.doi. org/10.1345/aph.1C089

180. American Academy of Pediatrics, Committee on Infectious Diseases. Rocky Mountain spotted fever. In: Kimberlin DW, Long SS, Brady MT, Jackson M, eds. Red book: 2015 report of the Committee on Infectious Diseases. 30th ed. Elk Grove Village, IL: American Academy of Pediatrics; 2015:682-84.

181. CDC. Consequences of delayed diagnosis of Rocky Mountain spotted fever in children-West Virginia, Michigan, Tennessee, and Oklahoma, May-July 2000. MMWR Morb Mortal Wkly Rep 2000;49:885-8.

182. Peterson JC. Rickettsial infections. Pediatr Clin North Am 1960;7:1003-14.

183. American Academy of Pediatrics, Committee on Infectious Diseases. Ehrlichia, Anaplasma, and related infections (human ehrlichiosis, anaplasmosis, and related infections). In: Kimberlin DW, Brady MT, Jackson M, et al., eds. Red book: 2015 report of the Committee on Infectious Diseases. 30th ed. Elk Grove Village, IL: American Academy of Pediatrics; 2015:329-33.

184. Weber DJ, Walker DH. Rocky Mountain spotted fever. Infect Dis Clin North Am 1991;5:19-35.

185. Schach von Wittenau M. Some pharmacokinetic aspects of doxycycline metabolism in man. Chemotherapy 1968;13(Suppl 1):S41-50. http:// dx.doi.org/10.1159/000220581 
186. Todd SR, Dahlgren FS, Traeger MS, et al. No visible dental staining in children treated with doxycycline for suspected Rocky Mountain spotted fever. J Pediatr 2015;166:1246-51. http://dx.doi. org/10.1016/j.jpeds.2015.02.015

187. Volovitz B, Shkap R, Amir J, Calderon S, Varsano I, Nussinovitch M. Absence of tooth staining with doxycycline treatment in young children. Clin Pediatr (Phila) 2007;46:121-6. http://dx.doi. org/10.1177/0009922806290026

188. Lochary ME, Lockhart PB, Williams WT Jr. Doxycycline and staining of permanent teeth. Pediatr Infect Dis J 1998;17:429-31. http://dx.doi. org/10.1097/00006454-199805000-00019

189. Zientek J, Dahlgren FS, McQuiston JH, Regan J. Self-reported treatment practices by healthcare providers could lead to death from Rocky Mountain spotted fever. J Pediatr 2014;164:416-8. http:// dx.doi.org/10.1016/j.jpeds.2013.10.008

190. Mosites E, Carpenter LR, McElroy K, et al. Knowledge, attitudes, and practices regarding Rocky Mountain spotted fever among healthcare providers, Tennessee, 2009. Am J Trop Med Hyg 2013;88:162-6. http://dx.doi.org/10.4269/ajtmh.2012.12-0126

191. O’Reilly M, Paddock C, Elchos B, Goddard J, Childs J, Currie M. Physician knowledge of the diagnosis and management of Rocky Mountain spotted fever: Mississippi, 2002. Ann N Y Acad Sci 2003;990:295-301. http://dx.doi.org/10.1111/j.1749-6632.2003. tb07379.x

192. Feder HM Jr, Osier C, Maderazo EG. Chloramphenicol: a review of its use in clinical practice. Rev Infect Dis 1981;3:479-91. http://dx.doi. org/10.1093/clinids/3.3.479

193. Frensenius-kabi.us. [Internet]. Chloramphenicol sodium succinate. Lake Zurich, IL: APP, A Frensius Kabi Company; 2008. http://editor. fresenius-kabi.us/PIs/Chloramphenicol_for_Inj_45841E_Jan_08.pdf

194. Brouqui P, Raoult D. In vitro antibiotic susceptibility of the newly recognized agent of ehrlichiosis in humans, Ehrlichia chaffeensis. Antimicrob Agents Chemother 1992;36:2799-803. http://dx.doi. org/10.1128/AAC.36.12.2799

195. Klein MB, Nelson CM, Goodman JL. Antibiotic susceptibility of the newly cultivated agent of human granulocytic ehrlichiosis: promising activity of quinolones and rifamycins. Antimicrob Agents Chemother 1997;41:76-9.

196. Buitrago MI, IJdo JW, Rinaudo P, et al. Human granulocytic ehrlichiosis during pregnancy treated successfully with rifampin. Clin Infect Dis 1998;27:213-5. http://dx.doi.org/10.1086/517678

197. Dhand A, Nadelman RB, Aguero-Rosenfeld M, Haddad FA, Stokes DP, Horowitz HW. Human granulocytic anaplasmosis during pregnancy: case series and literature review. Clin Infect Dis 2007;45:589-93. http:// dx.doi.org/10.1086/520659

198. Shields K, Cumming M, Rios J, et al. Transfusion-associated Anaplasma phagocytophilum infection in a pregnant patient with thalassemia trait: a case report. Transfusion 2015;55:719-25. http://dx.doi.org/10.1111/ trf.12908

199. Krause PJ, Corrow CL, Bakken JS. Successful treatment of human granulocytic ehrlichiosis in children using rifampin. Pediatrics 2003;112:e252-3. http://dx.doi.org/10.1542/peds.112.3.e252

200. Rolain JM, Maurin M, Vestris G, Raoult D. In vitro susceptibilities of 27 rickettsiae to 13 antimicrobials. Antimicrob Agents Chemother 1998;42:1537-41.

201. Botelho-Nevers E, Rovery C, Richet H, Raoult D. Analysis of risk factors for malignant Mediterranean spotted fever indicates that fluoroquinolone treatment has a deleterious effect. J Antimicrob Chemother 2011;66:1821-30. http://dx.doi.org/10.1093/jac/dkr218
202. Gudiol F, Pallares R, Carratala J, et al. Randomized double-blind evaluation of ciprofloxacin and doxycycline for Mediterranean spotted fever. Antimicrob Agents Chemother 1989;33:987-8. http://dx.doi. org/10.1128/AAC.33.6.987

203. Maurin M, Bakken JS, Dumler JS. Antibiotic susceptibilities of Anaplasma (Ehrlichia) phagocytophilum strains from various geographic areas in the United States. Antimicrob Agents Chemother 2003;47:413-5. http://dx.doi.org/10.1128/AAC.47.1.413-415.2003

204. Wormser GP, Filozov A, Telford SR 3rd, et al. Dissociation between inhibition and killing by levofloxacin in human granulocytic anaplasmosis. Vector Borne Zoonotic Dis 2006;6:388-94. http:// dx.doi.org/10.1089/vbz.2006.6.388

205. Walker DH, Sexton DJ. Rickettsia rickettsii. In: Yu VL, Merigan TC, Barriere SL, eds. Antimicrobial therapy and vaccines. Baltimore, MD: Williams \& Wilkins; 1999:562-8.

206. Fernando SL, Hudson BJ. Rapid desensitization to doxycycline. Ann Allergy Asthma Immunol 2013;111:73-4. http://dx.doi.org/10.1016/j. anai.2013.05.005

207. Fellner MJ, Baer RL. Anaphylactic reaction to tetracycline in a penicillinallergic patient: immunologic studies. JAMA 1965;192:997-8. http:// dx.doi.org/10.1001/jama.1965.03080240067023

208. Stollings JL, Chadha SN, Paul AM, Shaver CM, Hagaman D. Doxycycline desensitization for a suspected case of ehrlichiosis. J Allergy Clin Immunol Pract 2014;2:103-4. http://dx.doi.org/10.1016/j. jaip.2013.08.002

209. Kutscher AH, Zegarelli EV, Tovell HM, Hochberg B, Hauptman J. Discoloration of deciduous teeth induced by administration of tetracycline antepartum. Am J Obstet Gynecol 1966;96:291-2. http://dx.doi. org/10.1016/0002-9378(66)90328-0

210. Wenk RE, Gebhardt FC, Bhagavan BS, Lustgarten JA, McCarthy EF. Tetracycline-associated fatty liver of pregnancy, including possible pregnancy risk after chronic dermatologic use of tetracycline. J Reprod Med 1981;26:135-41.

211. Allen WM. The use of progestational agents in pregnancy. Rocky Mt Med J 1965;62:31-5.

212. Genot MT, Golan HP, Porter PJ, Kass EH. Effect of administration of tetracycline in pregnancy on the primary dentition of the offspring. J Oral Med 1970;25:75-9.

213. Porter PJ, Sweeney EA, Golan H, Kass EH. Controlled study of the effect of prenatal tetracycline on primary dentition. Antimicrob Agents Chemother (Bethesda) 1965;5:668-71.

214. Friedman JM, Polifka JE. Teratogenic effects of drugs: a resource for clinicians (TERIS). 2nd ed. Baltimore, MD: The Johns Hopkins University Press; 2000.

215. FDA.gov. [Internet]. Doxycycline (vibramycin, monodox, doryx, doxy, atridox, periodox, vibra-tabs) use by pregnant and lactating women. Silver Spring, MD: US Food and Drug Administration; 2015. http://www.fda.gov/Drugs/EmergencyPreparedness/ BioterrorismandDrugPreparedness/ucm131011.htm

216. Cross R, Ling C, Day NP, McGready R, Paris DH. Revisiting doxycycline in pregnancy and early childhood-time to rebuild its reputation? Expert Opin Drug Saf 2015. Epub Dec 17, 2015. http:// dx.doi.org/10.1517/14740338.2016.1133584

217. Meaney-Delman D, Rasmussen SA, Beigi RH, et al. Prophylaxis and treatment of anthrax in pregnant women. Obstet Gynecol 2013;122:885-900. http://dx.doi.org/10.1097/AOG.0b013e3182a5fdfd 
218. Schultz JC, Adamson JS Jr, Workman WW, Norman TD. Fatal liver disease after intravenous administration of tetracycline in high dosage. N Engl J Med 1963;269:999-1004. http://dx.doi.org/10.1056/ NEJM196311072691903

219. Nahum GG, Uhl K, Kennedy DL. Antibiotic use in pregnancy and lactation: what is and is not known about teratogenic and toxic risks. Obstet Gynecol 2006;107:1120-38. http://dx.doi.org/10.1097/01. AOG.0000216197.26783.b5

220. American Academy of Pediatrics Committee on Drugs. Transfer of drugs and other chemicals into human milk. Pediatrics 2001;108:776-89. http://dx.doi.org/10.1542/peds.108.3.776

221. Kenyon RH, Williams RG, Oster CN, Pedersen CE Jr. Prophylactic treatment of Rocky Mountain spotted fever. J Clin Microbiol 1978;8:102-4.

222. Clements ML, Dumler JS, Fiset P, Wisseman CL Jr, Snyder MJ, Levine MM. Serodiagnosis of Rocky Mountain spotted fever: comparison of IgM and IgG enzyme-linked immunosorbent assays and indirect fluorescent antibody test. J Infect Dis 1983;148:876-80. http://dx.doi.org/10.1093/infdis/148.5.876

223. Bakken JS, Haller I, Riddell D, Walls JJ, Dumler JS. The serological response of patients infected with the agent of human granulocytic ehrlichiosis. Clin Infect Dis 2002;34:22-7. http://dx.doi. org/10.1086/323811

224. Dawson JE, Fishbein DB, Eng TR, Redus MA, Greene NR. Diagnosis of human ehrlichiosis with the indirect fluorescent antibody test: kinetics and specificity. J Infect Dis 1990;162:91-5. http://dx.doi. org/10.1093/infdis/162.1.91

225. McQuiston JH, Childs JE, Chamberland ME, Tabor E. Transmission of tick-borne agents of disease by blood transfusion: a review of known and potential risks in the United States. Transfusion 2000;40:274-84. http://dx.doi.org/10.1046/j.1537-2995.2000.40030274.x

226. Wells GM, Woodward TE, Fiset P, Hornick RB. Rocky Mountain spotted fever caused by blood transfusion. JAMA 1978;239:2763-5. http://dx.doi.org/10.1001/jama.239.26.2763

227. Alhumaidan H, Westley B, Esteva C, Berardi V, Young C, Sweeney J. Transfusion-transmitted anaplasmosis from leukoreduced red blood cells. Transfusion 2013;53:181-6. http://dx.doi. org/10.1111/j.1537-2995.2012.03685.x

228. Annen K, Friedman K, Eshoa C, Horowitz M, Gottschall J, Straus T. Two cases of transfusion-transmitted Anaplasma phagocytophilum. Am J Clin Pathol 2012;137:562-5. http://dx.doi.org/10.1309/ AJCP4E4VQQQOZIAQ

229. CDC. Anaplasma phagocytophilum transmitted through blood transfusion-Minnesota, 2007. MMWR Morb Mortal Wkly Rep 2008;57:1145-8.

230. EastlundT, Persing D, Mathiesen D, et al. Human granulocytic ehrlichiosis after red cell transfusion. Transfusion 1999;39(10 Suppl 1):S117.

231. Fine AB, Sweeney JD, Nixon CP, Knoll BM. Transfusion-transmitted anaplasmosis from a leukoreduced platelet pool. Transfusion 2015. Epub Dec 9, 2015. http://dx.doi.org/10.1111/trf.13392

232. Townsend RL, Moritz ED, Fialkow LB, Berardi V, Stramer SL. Probable transfusion-transmission of Anaplasma phagocytophilum by leukoreduced platelets. Transfusion 2014;54:2828-32. http://dx.doi. org/10.1111/trf.12675

233. Regan J, Matthias J, Green-Murphy A, et al. A confirmed Ehrlichia ewingii infection likely acquired through platelet transfusion. Clin Infect Dis 2013;56:e105-7. http://dx.doi.org/10.1093/cid/cit177
234. Mettille FC, Salata KF, Belanger KJ, Casleton BG, Kelly DJ. Reducing the risk of transfusion-transmitted rickettsial disease by WBC filtration, using Orientia tsutsugamushi in a model system. Transfusion 2000;40:290-6. http://dx.doi.org/10.1046/j.1537-2995.2000.40030290.x

235. Proctor MC, Leiby DA. Do leukoreduction filters passively reduce the transmission risk of human granulocytic anaplasmosis? Transfusion 2015;55:1242-8. http://dx.doi.org/10.1111/trf.12976

236. McKechnie DB, Slater KS, Childs JE, Massung RF, Paddock CD. Survival of Ehrlichia chaffeensis in refrigerated, ADSOL-treated RBCs. Transfusion 2000;40:1041-7. http://dx.doi. org/10.1046/j.1537-2995.2000.40091041.x

237. Kalantarpour F, Chowdhury I, Wormser GP, Aguero-Rosenfeld ME. Survival of the human granulocytic ehrlichiosis agent under refrigeration conditions. J Clin Microbiol 2000;38:2398-9.

238. Sachdev SH, Joshi V, Cox ER, Amoroso A, Palekar S. Severe lifethreatening Ehrlichia chaffeensis infections transmitted through solid organ transplantation. Transpl Infect Dis 2014;16:119-24. http:// dx.doi.org/10.1111/tid.12172

239. Jensenius M, Davis X, von Sonnenburg F, et al; GeoSentinel Surveillance Network. Multicenter GeoSentinel analysis of rickettsial diseases in international travelers, 1996-2008. Emerg Infect Dis 2009;15:1791-8. http://dx.doi.org/10.3201/eid1511.090677

240. Jensenius M, Fournier PE, Raoult D. Tick-borne rickettsioses in international travellers. Int J Infect Dis 2004;8:139-46. http://dx.doi. org/10.1016/j.ijid.2003.06.004

241. RaoultD, Fournier PE, FenollarF, etal. Rickettsia africae, a tick-bornepathogen in travelers to sub-Saharan Africa. N Engl J Med 2001;344:1504-10. http://dx.doi.org/10.1056/NEJM200105173442003

242. McQuiston JH, Paddock CD, Singleton J Jr, Wheeling JT, Zaki SR, Childs JE. Imported spotted fever rickettsioses in United States travelers returning from Africa: a summary of cases confirmed by laboratory testing at the Centers for Disease Control and Prevention, 1999-2002. Am J Trop Med Hyg 2004;70:98-101.

243. Jensenius M, Fournier PE, Vene S, et al; Norwegian African Tick Bite Fever Study Group. African tick bite fever in travelers to rural subEquatorial Africa. Clin Infect Dis 2003;36:1411-7. http://dx.doi. org/10.1086/375083

244. Jensenius M, Fournier PE, Kelly P, Myrvang B, Raoult D. African tick bite fever. Lancet Infect Dis 2003;3:557-64. http://dx.doi. org/10.1016/S1473-3099(03)00739-4

245. Smoak BL, McClain JB, Brundage JF, et al. An outbreak of spotted fever rickettsiosis in U.S. Army troops deployed to Botswana. Emerg Infect Dis 1996;2:217-21. http://dx.doi.org/10.3201/eid0203.960309

246. CDC. African tick-bite fever among international travelers-Oregon, 1998. MMWR Morb Mortal Wkly Rep 1998;47:950-2.

247. Freedman DO, Weld LH, Kozarsky PE, et al; GeoSentinel Surveillance Network. Spectrum of disease and relation to place of exposure among ill returned travelers. N Engl J Med 2006;354:119-30. http://dx.doi. org/10.1056/NEJMoa051331

248. Leder K, Torresi J, Libman MD; GeoSentinel Surveillance Network. GeoSentinel surveillance of illness in returned travelers, 2007-2011. Ann Intern Med 2013;158:456-68. http://dx.doi. org/10.7326/0003-4819-158-6-201303190-00005

249. Sousa R, França A, Dória Nòbrega S, et al. Host- and microbe-related risk factors for and pathophysiology of fatal Rickettsia conorii infection in Portuguese patients. J Infect Dis 2008;198:576-85. http://dx.doi. org/10.1086/590211

250. Rovery C, Raoult D. Mediterranean spotted fever. Infect Dis Clin North Am 2008;22:515-30, ix. http://dx.doi.org/10.1016/j.idc.2008.03.003 
251. Levin ML, Killmaster LF, Zemtsova GE. Domestic dogs (Canis familiaris) as reservoir hosts for Rickettsia conorii. Vector Borne Zoonotic Dis 2012;12:28-33. http://dx.doi.org/10.1089/vbz.2011.0684

252. Rovery C, Brouqui P, Raoult D. Questions on Mediterranean spotted fever a century after its discovery. Emerg Infect Dis 2008;14:1360-7. http://dx.doi.org/10.3201/eid1409.071133

253. Parola P, Paddock CD, Socolovschi C, et al. Update on tick-borne rickettsioses around the world: a geographic approach. Clin Microbiol Rev 2013;26:657-702. http://dx.doi.org/10.1128/CMR.00032-13

254. Angerami RN, Câmara M, Pacola MR, et al. Features of Brazilian spotted fever in two different endemic areas in Brazil. Ticks Tick Borne Dis 2012;3:346-8. http://dx.doi.org/10.1016/j.ttbdis.2012.10.010

255. Paddock CD, Fernandez S, Echenique GA, et al. Rocky Mountain spotted fever in Argentina. Am J Trop Med Hyg 2008;78:687-92.

256. Hidalgo M, Orejuela L, Fuya P, et al. Rocky Mountain spotted fever, Colombia. Emerg Infect Dis 2007;13:1058-60. http://dx.doi. org/10.3201/eid1307.060537

257. Ripoll CM, Remondegui CE, Ordonez G, et al. Evidence of rickettsial spotted fever and ehrlichial infections in a subtropical territory of Jujuy, Argentina. Am J Trop Med Hyg 1999;61:350-4.

258. Hun L, Cortés X, Taylor L. Molecular characterization of Rickettsia rickettsii isolated from human clinical samples and from the rabbit tick Haemaphysalis leporispalustris collected at different geographic zones in Costa Rica. Am J Trop Med Hyg 2008;79:899-902.

259. Eremeeva ME, Berganza E, Suarez G, et al. Investigation of an outbreak of rickettsial febrile illness in Guatemala, 2007. Int J Infect Dis 2013;17:e304-11. http://dx.doi.org/10.1016/j.ijid.2012.11.011

260. Estripeaut D, Aramburú MG, Sáez-Llorens X, et al. Rocky Mountain spotted fever, Panama. Emerg Infect Dis 2007;13:1763-5. http:// dx.doi.org/10.3201/eid1311.070931

261. Romer Y, Seijo AC, Crudo F, et al. Rickettsia parkeri rickettsiosis, Argentina. Emerg Infect Dis 2011;17:1169-73. http://dx.doi. org/10.3201/eid1707.101857

262. Conti-Díaz IA, Moraes-Filho J, Pacheco RC, Labruna MB. Serological evidence of Rickettsia parkeri as the etiological agent of rickettsiosis in Uruguay. Rev Inst Med Trop Sao Paulo 2009;51:337-9. http://dx.doi. org/10.1590/S0036-46652009000600005

263. Blanco JR, Oteo JA. Human granulocytic ehrlichiosis in Europe. Clin Microbiol Infect 2002;8:763-72. http://dx.doi. org/10.1046/j.1469-0691.2002.00557.x

264. Ohashi N, Gaowa, Wuritu, et al. Human granulocytic anaplasmosis, Japan. Emerg Infect Dis 2013;19:289-92. http://dx.doi.org/10.3201/ eid1902.120855

265. Zhang L, Wang G, Liu Q, et al. Molecular analysis of Anaplasma phagocytophilum isolated from patients with febrile diseases of unknown etiology in China. PLoS One 2013;8:e57155. http://dx.doi. org/10.1371/journal.pone.0057155

266. Heo EJ, Park JH, Koo JR, et al. Serologic and molecular detection of Ehrlichia chaffeensis and Anaplasma phagocytophila (human granulocytic ehrlichiosis agent) in Korean patients. J Clin Microbiol 2002;40:3082-5. http://dx.doi.org/10.1128/JCM.40.8.3082-3085.2002

267. Sidel'nikov IuN, Mediannikov O, Ivanov LI, et al. The first case of granulocytic ehrlichiosis in the Far East of the Russian Federation [Russian]. Klin Med (Mosk) 2003;81:67-8.

268. Walker DH, Dumler JS. Rickettsiae: spotted fever and typhus group [Chapter 40]. In: Lennette EH, Lennette DA, Lennette ET, eds. Diagnostic procedures for viral, rickettsial, and chlamydial infections. 7th ed. Washington, DC: American Public Health Association; 1995:575-81.
269. Walker DH, Bouyer DH. Rickettsia and Orientia [Chapter 64]. In: Jorgensen JH, Pfaller MA, Carroll KC, et al., eds. Manual of clinical microbiology. 11th ed. Washington, DC: American Society of Microbiology Press; 2015:1122-34.

270. Reller ME, Dumler JS. Ehrlichia, Anaplasma, and related intracellular bacteria [Chapter 65]. In: Jorgensen JH, Pfaller MA, Carroll KC, et al., eds. Manual of clinical microbiology. 11th ed. Washington, DC: American Society of Microbiology Press; 2015:1135-49.

271. Dumler JS. Indirect fluorescent-antibody test [Chapter 11.7.2 ]. In: Isenberg HD, ed. Clinical microbiology procedures handbook. 2nd ed. Washington, DC: American Society for Microbiology Press; 2004.

272. Bakken JS, Goellner P, Van Etten M, et al. Seroprevalence of human granulocytic ehrlichiosis among permanent residents of northwestern Wisconsin. Clin Infect Dis 1998;27:1491-6. http://dx.doi. org/10.1086/515048

273. Wilfert CM, MacCormack JN, Kleeman K, et al. The prevalence of antibodies to Rickettsia rickettsii in an area endemic for Rocky Mountain spotted fever. J Infect Dis 1985;151:823-31. http://dx.doi. org/10.1093/infdis/151.5.823

274. CSTE.org. [Internet]. Smithee L, Hull HF, Lynch C, Parrish RG. Position statement 09-ID-16, Public health reporting and national notification for spotted fever rickettsiosis (including Rocky Mountain spotted fever). Atlanta, GA: Council of State and Territorial Epidemiologists; 2009. http://c.ymcdn.com/sites/www.cste.org/ resource/resmgr/PS/09-ID-16.pdf

275. CSTE.org. [Internet]. Engel J, Bradley K, Swerdlow D, et al. Position statement 07-ID-03, Revision of the national surveillance case definition for ehrlichiosis (ehrlichiosis/anaplasmosis). Atlanta, GA: Council of State and Territorial Epidemiologists; 2007. http://c.ymcdn. com/sites/www.cste.org/resource/resmgr/PS/07-ID-03.pdf

276. Newhouse VF, Shepard CC, Redus MD, Tzianabos T, McDade JE. A comparison of the complement fixation, indirect fluorescent antibody, and microagglutination tests for the serological diagnosis of rickettsial diseases. Am J Trop Med Hyg 1979;28:387-95.

277. Davis JP, Wilfert CM, Sexton DJ, Burgdorfer W, Casper EA. Philip RN. Serologic comparison of $R$. rickettsii isolated from patients in North Carolina to $R$. rickettsii isolated from patients in Montana. In: Burgdorfer W, Anacker RL, eds. Rickettsiae and rickettsial diseases. New York, NY: Academic Press, Inc.; 1981:139-47.

278. Philip RN, Casper EA, MacCormack JN, et al. A comparison of serologic methods for diagnosis of Rocky Mountain spotted fever. Am J Epidemiol 1977;105:56-67.

279. Crump JA, Corder JR, Henshaw NG, Reller LB. Development, implementation, and impact of acceptability criteria for serologic tests for infectious diseases. J Clin Microbiol 2004;42:881-3. http://dx.doi. org/10.1128/JCM.42.2.881-883.2004

280. Fournier PE, Jensenius M, Laferl H, Vene S, Raoult D. Kinetics of antibody responses in Rickettsia africae and Rickettsia conorii infections. Clin Diagn Lab Immunol 2002;9:324-8.

281. Taylor JP, Tanner WB, Rawlings JA, et al. Serological evidence of subclinical Rocky Mountain spotted fever infections in Texas. J Infect Dis 1985;151:367-9. http://dx.doi.org/10.1093/infdis/151.2.367

282. Hilton E, DeVoti J, Benach JL, et al. Seroprevalence and seroconversion for tick-borne diseases in a high-risk population in the northeast United States. Am J Med 1999;106:404-9. http://dx.doi.org/10.1016/ S0002-9343(99)00046-7 
283. Marshall GS, Stout GG, Jacobs RF; Tick-Borne Infections in Children Study Group. Antibodies reactive to Rickettsia rickettsii among children living in the southeast and south central regions of the United States. Arch Pediatr Adolesc Med 2003;157:443-8. http://dx.doi. org/10.1001/archpedi.157.5.443

284. Paddock CD. Perspectives on the laboratory diagnosis of rickettsial diseases in the 21st century. Acta Med Costarric 2013;55(Suppl 1):S13-24.

285. McQuiston JH, Wiedeman C, Singleton J, et al. Inadequacy of IgM antibody tests for diagnosis of Rocky Mountain spotted fever. Am J Trop Med Hyg 2014;91:767-70. http://dx.doi.org/10.4269/ajtmh.14-0123

286. Walls JJ, Aguero-Rosenfeld M, Bakken JS, et al. Inter- and intralaboratory comparison of Ehrlichia equi and human granulocytic ehrlichiosis (HGE) agent strains for serodiagnosis of HGE by the immunofluorescent-antibody test. J Clin Microbiol 1999;37:2968-73.

287. Brouqui P, Salvo E, Dumler JS, Raoult D. Diagnosis of granulocytic ehrlichiosis in humans by immunofluorescence assay. Clin Diagn Lab Immunol 2001;8:199-202.

288. Vaughn MF, Delisle J, Johnson J, et al. Seroepidemiologic study of human infections with spotted fever group rickettsiae in North Carolina. J Clin Microbiol 2014;52:3960-6. http://dx.doi. org/10.1128/JCM.01733-14

289. Comer JA, Nicholson WL, Olson JG, Childs JE. Serologic testing for human granulocytic ehrlichiosis at a national referral center. J Clin Microbiol 1999;37:558-64.

290. Kaplowitz LG, Lange JV, Fischer JJ, Walker DH. Correlation of rickettsial titers, circulating endotoxin, and clinical features in Rocky Mountain spotted fever. Arch Intern Med 1983;143:1149-51. http:// dx.doi.org/10.1001/archinte.1983.00350060073012

291. Kato CY, Chung IH, Robinson LK, Austin AL, Dasch GA, Massung RF. Assessment of real-time PCR assay for detection of Rickettsia spp. and Rickettsia rickettsii in banked clinical samples. J Clin Microbiol 2013;51:314-7. http://dx.doi.org/10.1128/JCM.01723-12

292. Denison AM, Amin BD, Nicholson WL, Paddock CD. Detection of Rickettsia rickettsii, Rickettsia parkeri, and Rickettsia akari in skin biopsy specimens using a multiplex real-time polymerase chain reaction assay. Clin Infect Dis 2014;59:635-42. http://dx.doi.org/10.1093/cid/ciu358

293. Paddock CD, Denison AM, Lash RR, et al. Phylogeography of Rickettsia rickettsii genotypes associated with fatal Rocky Mountain spotted fever. Am J Trop Med Hyg 2014;91:589-97. http://dx.doi.org/10.4269/ ajtmh.14-0146

294. Standaert SM, Yu T, Scott MA, et al. Primary isolation of Ehrlichia chaffeensis from patients with febrile illnesses: clinical and molecular characteristics. J Infect Dis 2000;181:1082-8. http://dx.doi. org/10.1086/315346

295. Bechah Y, Socolovschi C, Raoult D. Identification of rickettsial infections by using cutaneous swab specimens and PCR. Emerg Infect Dis 2011;17:83-6. http://dx.doi.org/10.3201/eid1701.100854

296. Walker DH, Cain BG, Olmstead PM. Laboratory diagnosis of Rocky Mountain spotted fever by immunofluorescent demonstration of Rickettsia in cutaneous lesions. Am J Clin Pathol 1978;69:619-23. http://dx.doi.org/10.1093/ajcp/69.6.619

297. Procop GW, Burchette JL Jr, Howell DN, Sexton DJ. Immunoperoxidase and immunofluorescent staining of Rickettsia rickettsii in skin biopsies. A comparative study. Arch Pathol Lab Med 1997;121:894-9.

298. Dumler JS, Gage WR, Pettis GL, Azad AF, Kuhadja FP. Rapid immunoperoxidase demonstration of Rickettsia rickettsii in fixed cutaneous specimens from patients with Rocky Mountain spotted fever. Am J Clin Pathol 1990;93:410-4. http://dx.doi.org/10.1093/ ajcp/93.3.410
299. Walker DH, Burday MS, Folds JD. Laboratory diagnosis of Rocky Mountain spotted fever. South Med J 1980;73:1443-6, 1449. http:// dx.doi.org/10.1097/00007611-198011000-00007

300. Dawson JE, Paddock CD, Warner CK, et al. Tissue diagnosis of Ehrlichia chaffeensis in patients with fatal ehrlichiosis by use of immunohistochemistry, in situ hybridization, and polymerase chain reaction. Am J Trop Med Hyg 2001;65:603-9.

301. Aguero-Rosenfeld ME. Laboratory aspects of tick-borne diseases: Lyme, human granulocytic ehrlichiosis, and babesiosis. Mt Sinai J Med 2003;70:197-206.

302. Lagier JC, Edouard S, Pagnier I, Mediannikov O, Drancourt M, Raoult D. Current and past strategies for bacterial culture in clinical microbiology. Clin Microbiol Rev 2015;28:208-36.

303. Horowitz HW, Aguero-Rosenfeld ME, McKenna DF, et al. Clinical and laboratory spectrum of culture-proven human granulocytic ehrlichiosis: comparison with culture-negative cases. Clin Infect Dis 1998;27:1314-7. http://dx.doi.org/10.1086/515000

304. Angelakis E, Richet H, Rolain JM, La Scola B, Raoult D. Comparison of real-time quantitative PCR and culture for the diagnosis of emerging Rickettsioses. PLoS Negl Trop Dis 2012;6:e1540. http://dx.doi. org/10.1371/journal.pntd.0001540

305. CDC. Chosewood LC, Wilson DE, eds. Biosafety in microbiological and biomedical laboratories (BMBL). 5th ed. Washington, DC: US Department of Health and Human Services, CDC; National Institutes of Health; 2009. http://www.cdc.gov/biosafety/publications/bmbl5/ BMBL.pdf

306. Felz MW, Durden LA. Attachment sites of four tick species (Acari: Ixodidae) parasitizing humans in Georgia and South Carolina. J Med Entomol 1999;36:361-4. http://dx.doi.org/10.1093/jmedent/36.3.361

307. Connally NP, Durante AJ, Yousey-Hindes KM, Meek JI, Nelson RS, Heimer R. Peridomestic Lyme disease prevention: results of a populationbased case-control study. Am J Prev Med 2009;37:201-6. http://dx.doi. org/10.1016/j.amepre.2009.04.026

308. Moore JJ. Time relationship of the wood-tick in the transmission of Rocky Mountain spotted fever. J Infect Dis 1911;8:339-47. http:// dx.doi.org/10.1093/infdis/8.3.339

309. Spencer RR, Parker RR. Rocky Mountain spotted fever: infectivity of fasting and recently fed ticks. Public Health Rep 1923;38:333-9. http://dx.doi.org/10.2307/4576667

310. Katavolos P, Armstrong PM, Dawson JE, Telford SR 3rd. Duration of tick attachment required for transmission of granulocytic ehrlichiosis. J Infect Dis 1998;177:1422-5. http://dx.doi.org/10.1086/517829

311. des Vignes F, Piesman J, Heffernan R, Schulze TL, Stafford KC 3rd, Fish D. Effect of tick removal on transmission of Borrelia burgdorferi and Ehrlichia phagocytophila by Ixodes scapularis nymphs. J Infect Dis 2001;183:773-8. http://dx.doi.org/10.1086/318818

312. Carroll JF, Klun JA, Debboun M. Repellency of DEET and SS220 applied to skin involves olfactory sensing by two species of ticks. Med Vet Entomol 2005;19:101-6. http://dx.doi. org/10.1111/j.0269-283X.2005.00559.x

313. Kumar S, Prakash S, Kaushik MP, Rao KM. Comparative activity of three repellents against the ticks Rhipicephalus sanguineus and Argas persicus. Med Vet Entomol 1992;6:47-50. http://dx.doi. org/10.1111/j.1365-2915.1992.tb00034.x

314. Lane RS. Treatment of clothing with a permethrin spray for personal protection against the western black-legged tick, Ixodes pacificus (Acari: Ixodidae). Exp Appl Acarol 1989;6:343-52. http://dx.doi.org/10.1007/ BF01193304 
315. Pretorius AM, Jensenius M, Clarke F, Ringertz SH. Repellent efficacy of DEET and KBR 3023 against Amblyomma hebraeum (Acari: Ixodidae). J Med Entomol 2003;40:245-8. http://dx.doi. org/10.1603/0022-2585-40.2.245

316. Schreck CE, Snoddy EL, Spielman A. Pressurized sprays of permethrin or DEET on military clothing for personal protection against Ixodes dammini (Acari: Ixodidae). J Med Entomol 1986;23:396-9. http:// dx.doi.org/10.1093/jmedent/23.4.396

317. Solberg VB, Klein TA, McPherson KR, Bradford BA, Burge JR, Wirtz RA. Field evaluation of DEET and a piperidine repellent (AI3-37220) against Amblyomma americanum (Acari: Ixodidae). J Med Entomol 1995;32:870-5. http://dx.doi.org/10.1093/ jmedent/32.6.870

318. Jensenius M, Pretorius AM, Clarke F, Myrvang B. Repellent efficacy of four commercial DEET lotions against Amblyomma hebraeum (Acari: Ixodidae), the principal vector of Rickettsia africae in southern Africa. Trans R Soc Trop Med Hyg 2005;99:708-11. http://dx.doi. org/10.1016/j.trstmh.2005.01.006

319. Jordan RA, Schulze TL, Dolan MC. Efficacy of plant-derived and synthetic compounds on clothing as repellents against Ixodes scapularis and Amblyomma americanum (Acari: Ixodidae). J Med Entomol 2012;49:101-6. http://dx.doi.org/10.1603/ME10241

320. Pages F, Dautel H, Duvallet G, Kahl O, de Gentile L, Boulanger N. Tick repellents for human use: prevention of tick bites and tick-borne diseases. Vector Borne Zoonotic Dis 2014;14:85-93. http://dx.doi. org/10.1089/vbz.2013.1410

321. CDC, National Center for Emerging and Zoonotic Infectious Diseases. Ticks. Atlanta, GA: US Department of Health and Human Services, CDC, National Center for Emerging and Zoonotic Infectious Diseases; 2015. http://www.cdc.gov/ticks/index.html

322. Bissinger BW, Zhu J, Apperson CS, Sonenshine DE, Watson DW, Roe RM. Comparative efficacy of BioUD to other commercially available arthropod repellents against the ticks Amblyomma americanum and Dermacentor variabilis on cotton cloth. Am J Trop Med Hyg 2009;81:685-90. http://dx.doi.org/10.4269/ajtmh.2009.09-0114

323. Carroll JF, Benante JP, Klun JA, et al. Twelve-hour duration testing of cream formulations of three repellents against Amblyomma americanum. Med Vet Entomol 2008;22:144-51. http://dx.doi. org/10.1111/j.1365-2915.2008.00721.x

324. Carroll JF, Benante JP, Kramer M, Lohmeyer KH, Lawrence K. Formulations of DEET, picaridin, and IR3535 applied to skin repel nymphs of the lone star tick (Acari: Ixodidae) for 12 hours. J Med Entomol 2010;47:699-704. http://dx.doi.org/10.1093/ jmedent/47.4.699
325. Staub D, Debrunner M, Amsler L, Steffen R. Effectiveness of a repellent containing DEET and EBAAP for preventing tick bites. Wilderness Environ Med 2002;13:12-20. http://dx.doi. org/10.1580/1080-6032(2002)013[0012:EOARCD]2.0.CO;2

326. Vaughn MF, Funkhouser SW, Lin FC, et al. Long-lasting permethrin impregnated uniforms: a randomized-controlled trial for tick bite prevention. Am J Prev Med 2014;46:473-80. http://dx.doi. org/10.1016/j.amepre.2014.01.008

327. Miller NJ, Rainone EE, Dyer MC, González ML, Mather TN. Tick bite protection with permethrin-treated summer-weight clothing. J Med Entomol 2011;48:327-33. http://dx.doi.org/10.1603/ME10158

328. Semmler M, Abdel-Ghaffar F, Al-Rasheid KA, Mehlhorn H. Comparison of the tick repellent efficacy of chemical and biological products originating from Europe and the USA. Parasitol Res 2011;108:899-904. http://dx.doi.org/10.1007/s00436-010-2131-4

329. Katz TM, Miller JH, Hebert AA. Insect repellents: historical perspectives and new developments. J Am Acad Dermatol 2008;58:865-71. http:// dx.doi.org/10.1016/j.jaad.2007.10.005

330. Piesman J, Eisen L. Prevention of tick-borne diseases. Annu Rev Entomol 2008;53:323-43. http://dx.doi.org/10.1146/annurev. ento.53.103106.093429

331. Colwell DD, Dantas-Torres F, Otranto D. Vector-borne parasitic zoonoses: emerging scenarios and new perspectives. Vet Parasitol 2011;182:14-21. http://dx.doi.org/10.1016/j.vetpar.2011.07.012

332. Day MJ. One health: the importance of companion animal vector-borne diseases. Parasit Vectors 2011;4:49. http://dx.doi. org/10.1186/1756-3305-4-49

333. Stafford KC III; Connecticut Agricultural Experiment Station. Tick management handbook. An integrated guide for homeowners, pest control operators, and public health officials for the prevention of tick-associated disease. New Haven, CT: Connecticut Agricultural Experiment Station, Connecticut General Assembly; 2007. http:// www.ct.gov/caes/lib/caes/documents/publications/bulletins/b1010.pdf

334. Needham GR. Evaluation of five popular methods for tick removal. Pediatrics 1985;75:997-1002.

335. CDC, National Office of Vital Statistics. Reported incidence of selected notifiable diseases: United States, each division and state, 1920-1950. Washington, DC: US Department of Health, Education, and Welfare, CDC; 1953:240-2.

336. CSTE.org. [Internet]. Position statement 98-ID-06, Adding ehrlichiosis as a condition reportable to the national public health surveillance system (NPHSS). Atlanta, GA: Council of State and Territorial Epidemiologists; 1998. http://c.ymcdn.com/sites/www.cste.org/ resource/resmgr/PS/1998-ID-6.pdf 


\section{Appendix A}

\section{Selected Tickborne Rickettsioses Outside of the United States}

Tickborne rickettsial diseases are found worldwide. This appendix highlights some of the more common tickborne rickettsial pathogens typically transmitted outside the United States and known to cause disease in humans.

\begin{tabular}{|c|c|c|c|}
\hline Disease & $\begin{array}{l}\text { Geographic distribution } \\
\text { of human cases }\end{array}$ & Pathogen & Signs and symptoms \\
\hline African tick bite fever & $\begin{array}{l}\text { Sub-Saharan Africa, } \\
\text { Caribbean (French West } \\
\text { Indies), and Oceania }\end{array}$ & Rickettsia africae & $\begin{array}{l}\text { Fever, headache, myalgia, eschar (sometimes multiple), regional } \\
\text { lymphadenopathy, rash (maculopapular or vesicular); typically mild } \\
\text { illness with benign course }\end{array}$ \\
\hline $\begin{array}{l}\text { Mediterranean spotted fever } \\
\text { (also known as } \\
\text { boutonneuse fever) }\end{array}$ & $\begin{array}{l}\text { Europe (Mediterranean } \\
\text { basin), Middle East, Indian } \\
\text { subcontinent, and Africa }\end{array}$ & Rickettsia conorii & $\begin{array}{l}\text { Fever, headache, myalgia, eschar (usually singular), and rash } \\
\text { (maculopapular or petechial, sometimes involving palms and soles); } \\
\text { typically moderately severe illness, can be severe or fatal }\end{array}$ \\
\hline Queensland tick typhus & $\begin{array}{l}\text { Eastern Australia, including } \\
\text { Tasmania }\end{array}$ & Rickettsia australis & $\begin{array}{l}\text { Fever, headache, myalgia, eschar, regional lymphadenopathy, and rash } \\
\text { (maculopapular or vesicular); typically mild illness, can be severe } \\
\text { or fatal }\end{array}$ \\
\hline Flinders Island spotted fever & Australia and southeast Asia & Rickettsia honei & $\begin{array}{l}\text { Fever, headache, myalgia, eschar (in a minority of patients), and rash; } \\
\text { typically mild illness }\end{array}$ \\
\hline Japanese spotted fever & Japan and South Korea & Rickettsia japonica & Fever, headache, eschar, and rash; can be severe or fatal \\
\hline $\begin{array}{l}\text { Siberian tick typhus (also } \\
\text { known as North Asian } \\
\text { tick typhus) }\end{array}$ & North Asia & Rickettsia sibirica & $\begin{array}{l}\text { Fever, eschar, regional lymphadenopathy, and rash (maculopapular); } \\
\text { typically mild illness }\end{array}$ \\
\hline $\begin{array}{l}\text { Lymphangitis associated } \\
\text { rickettsiosis* }\end{array}$ & Southern Europe and Africa & $\begin{array}{l}\text { Rickettsia sibirica } \\
\text { mongolitimonae }\end{array}$ & $\begin{array}{l}\text { Fever, eschar (single or multiple), regional lymphadenitis, } \\
\text { lymphangitis, and rash (maculopapular); typically mild illness, can } \\
\text { have severe complications }\end{array}$ \\
\hline $\begin{array}{l}\text { Tickborne lymphadenopathy } \\
\text { (also known as Dermacentor- } \\
\text { borne necrosis and } \\
\text { lymphadenopathy or scalp } \\
\text { eschar and neck } \\
\text { lymphadenopathy after } \\
\text { tick bite) }\end{array}$ & Europe & $\begin{array}{l}\text { Rickettsia slovaca and } \\
\text { Rickettsia raoultii }\end{array}$ & $\begin{array}{l}\text { Eschar (typically on the scalp), painful regional lymphadenopathy, } \\
\text { alopecia surrounding eschar, low fever }(<50 \%) \text {, rash (rare), and } \\
\text { asthenia; typically mild illness with benign course }\end{array}$ \\
\hline $\begin{array}{l}\text { Rickettsia massiliae spotted } \\
\text { fever* }\end{array}$ & Europe and South America & Rickettsia massiliae & Fever, eschar, and rash; typically mild to moderately severe illness \\
\hline
\end{tabular}

* Few human cases are described in the peer-reviewed literature, and the clinical picture and geographic distribution might be incomplete. 


\section{Appendix B}

\section{Diagnostic Assays for Tickborne Rickettsial Diseases}

\begin{tabular}{|c|c|c|c|c|c|}
\hline $\begin{array}{l}\text { Stage } \\
\text { of illness }\end{array}$ & Specimen & $\begin{array}{l}\text { Optimal specimen } \\
\text { characteristics }\end{array}$ & Pathogen & Assay & Test advantages and limitations \\
\hline \multirow{13}{*}{$\begin{array}{l}\text { Acute } \\
\text { (active } \\
\text { signs and } \\
\text { symptoms } \\
\text { of disease) }\end{array}$} & \multirow[t]{3}{*}{$\begin{array}{l}\text { Whole } \\
\text { blood }\end{array}$} & \multirow[t]{3}{*}{$\begin{array}{l}\text { - EDTA-anticoagulated blood } \\
\text { - Preferred volume of } 3-5 \mathrm{~mL}\end{array}$} & $\begin{array}{l}\text { - Anaplasma and } \\
\text { Ehrlichia spp. } \\
\text {-SFG rickettsiae }\end{array}$ & PCR & $\begin{array}{l}\text { - Test is most sensitive during the first week of illness and before or } \\
\text { within } 48 \text { hours of beginning therapy with doxycycline. } \\
\text { - Sensitivity diminishes within } 1 \text { week after the collection date. }\end{array}$ \\
\hline & & & $\begin{array}{l}\text { Anaplasma and } \\
\text { Ehrlichia spp. }\end{array}$ & $\begin{array}{l}\text { Blood } \\
\text { smear }\end{array}$ & $\begin{array}{l}\text { - A blood smear can provide a rapid presumptive diagnosis. } \\
\text { - Sensitivity is low. } \\
\text { - An experienced microscopist is required. }\end{array}$ \\
\hline & & & $\begin{array}{l}\text { - Anaplasma and } \\
\text { Ehrlichia spp. } \\
\text {-SFG rickettsiae }\end{array}$ & Culture & $\begin{array}{l}\text { - Culture is the microbiological reference standard. } \\
\text { - Confirmation of diagnosis might require } \geq 10 \text { days, and } \\
\text { propagation requires BSL-3 facilities. } \\
\text { - Test is most sensitive during the first week of illness and before } \\
\text { beginning therapy with doxycycline. } \\
\text { - Availability is restricted to reference centers or research } \\
\text { laboratories. }\end{array}$ \\
\hline & \multirow[t]{2}{*}{ Serum } & \multirow[t]{2}{*}{ Preferred volume of $3-5 \mathrm{~mL}$} & \multirow[t]{2}{*}{$\begin{array}{l}\text { - Anaplasma and } \\
\text { Ehrlichia spp. } \\
\text {-SFG rickettsiae }\end{array}$} & PCR & $\begin{array}{l}\text { - Molecular assessment of serum is generally less sensitive than } \\
\text { evaluation of whole blood. } \\
\text { - Serum can be used if whole blood is not available. }\end{array}$ \\
\hline & & & & IFA & $\begin{array}{l}\text { - Antibodies are often absent during the first week of illness. } \\
\text { - Antibodies are usually specific to the genus rather than the species } \\
\text { of pathogen. } \\
\text { - Confirmation requires a fourfold or greater increase in titer } \\
\text { between acute and convalescent serum specimens (see below for } \\
\text { convalescent serum). }\end{array}$ \\
\hline & Eschar & Swab of unroofed eschar & SFG rickettsiae & PCR & $\begin{array}{l}\text { - Swab is less invasive than skin biopsy. } \\
\text { - Assessment of swab might be less sensitive than evaluation of } \\
\text { eschar biopsy and does not allow for culture or IHC. }\end{array}$ \\
\hline & \multirow[t]{5}{*}{$\begin{array}{l}\text { Fresh } \\
\text { tissue }\end{array}$} & \multirow[t]{2}{*}{$\begin{array}{l}\text { Punch biopsy specimens } \\
(\geq 4 \mathrm{~mm}) \text { of eschar or rash }\end{array}$} & \multirow[t]{2}{*}{ SFG rickettsiae } & PCR & $\begin{array}{l}\text { - Eschars contain abundant numbers of SFG rickettsiae relative to } \\
\text { blood; when present, they represent the best clinical sample for a } \\
\text { specific diagnosis. } \\
\text { - Test is most sensitive during the first week of illness and before or } \\
\text { within } 48 \text { hours of beginning therapy with doxycycline. }\end{array}$ \\
\hline & & & & Culture & $\begin{array}{l}\text { - Isolation is more effective from tissue than from blood for } \\
\text { SFG rickettsiae. } \\
\text { - Collect specimen before beginning therapy with doxycycline. } \\
\text { - Availability is restricted to reference centers or research } \\
\text { laboratories. }\end{array}$ \\
\hline & & \multirow{3}{*}{$\begin{array}{l}\text { Autopsy specimens might } \\
\text { include representative } \\
\text { samples of all major organs }\end{array}$} & \multirow{3}{*}{$\begin{array}{l}\text { - Anaplasma and } \\
\text { Ehrlichia spp. } \\
\text {-SFG rickettsiae }\end{array}$} & PCR & $\begin{array}{l}\text { Test is most sensitive during the first week of illness and before or } \\
\text { within } 48 \text { hours of beginning therapy with doxycycline. }\end{array}$ \\
\hline & & & & Culture & $\begin{array}{l}\text { - Isolation is more effective from tissue than from blood for } \\
\text { SFG rickettsiae. } \\
\text { - Isolation is most effective from spleen, lymph node, liver, or bone } \\
\text { marrow for Anaplasma and Ehrlichia spp. } \\
\text { - Collect specimen before beginning therapy with doxycycline. } \\
\text { - Availability is restricted to reference centers or research } \\
\text { laboratories. }\end{array}$ \\
\hline & & & & IHC & Availability is restricted to reference centers or research laboratories. \\
\hline & \multirow{2}{*}{$\begin{array}{l}\text { Formalin- } \\
\text { fixed } \\
\text { tissue }\end{array}$} & \multirow{2}{*}{$\begin{array}{l}\text { - Biopsy specimens might } \\
\text { include skin, bone marrow, or } \\
\text { lymph node } \\
\text { - Autopsy specimens might } \\
\text { include representative samples } \\
\text { of all major organs }\end{array}$} & \multirow{2}{*}{$\begin{array}{l}\text { - Anaplasma and } \\
\text { Ehrlichia spp. } \\
\text {-SFG rickettsiae }\end{array}$} & PCR & $\begin{array}{l}\text { Formalin fixation results in cross-linking and fragmentation of DNA, } \\
\text { which might limit sensitivity of nucleic acid detection methods. }\end{array}$ \\
\hline & & & & IHC & Availability is restricted to reference centers or research laboratories. \\
\hline $\begin{array}{l}\text { Convalescent } \\
(2-4 \text { weeks } \\
\text { after } \\
\text { resolution } \\
\text { of illness) }\end{array}$ & Serum & Preferred volume of $3-5 \mathrm{~mL}$ & $\begin{array}{l}\text { - Anaplasma and } \\
\text { Ehrlichia spp. } \\
\text {-SFG rickettsiae }\end{array}$ & IFA & $\begin{array}{l}\text { - Antibodies are usually specific to the genus rather than the species } \\
\text { of pathogen. } \\
\text { - Confirmation of acute infection requires a fourfold or greater } \\
\text { increase in titer between acute and convalescent serum } \\
\text { specimens. }\end{array}$ \\
\hline
\end{tabular}

Abbreviations: BSL-3 = biosafety level 3; DNA = deoxyribonucleic acid; EDTA = ethylenediaminetetraacetic acid; IFA = indirect immunofluorescence antibody; $\mathrm{IHC}=$ immunohistochemical stain; $\mathrm{PCR}=$ polymerase chain reaction; $\mathrm{SFG}=$ spotted fever group . 

The Morbidity and Mortality Weekly Report (MMWR) Series is prepared by the Centers for Disease Control and Prevention (CDC) and is available free of charge in electronic format. To receive an electronic copy each week, visit MMWR's free subscription page at http://www.cdc.gov/mmwr/mmwrsubscribe.html. Paper copy subscriptions are available through the Superintendent of Documents, U.S. Government Printing Office, Washington, DC 20402; telephone 202-512-1800.

Readers who have difficulty accessing this PDF file may access the HTML file at http://www.cdc.gov/mmwr/volumes/65/rr/rr6502a1.htm?s_cid=rr6502a1_w. htm. Address all inquiries about the $M M W R$ Series, including material to be considered for publication, to Executive Editor, $M M W R$ Series, Mailstop E-90, CDC, 1600 Clifton Rd., N.E., Atlanta, GA 30329-4027 or to mmwrq@cdc.gov.

All material in the MMWR Series is in the public domain and may be used and reprinted without permission; citation as to source, however, is appreciated. Use of trade names and commercial sources is for identification only and does not imply endorsement by the U.S. Department of Health and Human Services.

References to non-CDC sites on the Internet are provided as a service to $M M W R$ readers and do not constitute or imply endorsement of these organizations or their programs by CDC or the U.S. Department of Health and Human Services. CDC is not responsible for the content of these sites. URL addresses listed in $M M W R$ were current as of the date of publication.

ISSN: $1057-5987$ (Print) 